\title{
MÉTODO DE AMOSTRAGEM DE ÁREA AGRÍCOLA COM SENSORES EMBARCADOS: UMA ABORDAGEM QUE LEVA EM CONTA A VARIABILIDADE DO CAMPO
}

Tese de doutorado apresentada à Escola de Engenharia de São Carlos da Universidade de São Paulo, como parte dos requisitos para obtenção do título de Doutora em Ciências em Engenharia Mecânica.

Área de concentração: Manufatura

Orientador: Dr. Ricardo Yassushi Inamasu

São Carlos 2014

$$
\begin{gathered}
\text { ESTE EXEMPLAR TRATA-SE DA } \\
\text { VERSÃO CORRIGIDA. } \\
\text { A VERSÃO ORIGINAL } \\
\text { ENCONTRA-SE DISPONÍVEL } \\
\text { JUNTO AO DEPARTAMENTO DE } \\
\text { ENGENHARIA MECÂNICA DA } \\
\text { EESC-USP }
\end{gathered}
$$


AUTORIZO A REPRODUCÃO TOTAL OU PARCIAL RESTE TRABALHO POR QUALQUER MEIO CONVENCIONAL OU ELETROONICO, PARA FINS DE ESTUDO E PESQUISA, DESDE QUE CITADA A FONTE.

Tangerino, Giovana Tripoloni

VfTODO DE AMOSTRAGEM DE ÁREA AGRICOLA COM SEMSORES EMPARCADOS: TIM ABORDAGEM QUE LEVA EM CONTA A

VARIABILIDADE DO CAMPO / Giovana Tripoloni Tangerino; orientador Ricardo Yassushi Inamasu. SLo Carlos, 2014.

Tese (Doutorado) - Programa de Pos-Graduação em Engenharia Mecanica e Área de Concentraç̃o em Manufatura -- Escola de Engenharia de SAo Carlos da Universidade de SHo Paulo, 2014.

1. Amostragen inteligente. 2. planejamento de trajetoria. 3. variabilidade. 4. Agricultura de Precislo. I. Tf́tulo. 


\section{FOLHA DE JULGAMENTO}

Candidata: Engorheira GIOVANA IRIPOLONO TANGERINO.

Títu'o da teso: "Método de arrosiragerr de Gieo agricola com sensores embarcados: uma abordagem que leva em conta a variatilidade do campo".

Data da defesa: $29 / 12 / 2014$

\section{Comissc̃o Julgadora:}

PIol. Dr. Ricardo Yassushr Inamsu (Orientador)

iEmpresa Brasilera do Posquira Agropecuária/EMBRAPA)

Prot. Ttular Arthur José Vieira Porto

iEscola de Engenharia de Säs Carlosf́ESC;

Prol. Associado José Paulo Molin

(Escola S.Jperior de Agricultura "Luiz de Queiroz"/ESALQ-JSF)

Prof. Dr, Rafoel Vieira de Sousa

[Faculdade de Zootecnia o [ngenharic de Alimentos/FZEA-LSP]

Dr. Ronaldo Pereira de Oliveīra

ímpresa Bras leirc de Pesquisa Agropecuária/EMGRA,A.

Coordenador do Programa de Pós-Groduoção em Engenheira Mecánica: Pro: Associado Marcelo Areles Trindede

Prosicente da Comissão de Pós-Graduaçăo:

Prol. Associado Paulo César LIma Segantine

\section{Resultado:}

Aprovada

QPOD VADA 

Dedicado aos meus pais Edson e Teresa. 



\section{Agradecimentos}

Agradeço a todos que direta ou indiretamente me ajudaram neste trabalho.

À USP, ao Departamento de Engenharia Mecânica da EESC e à Embrapa pelo apoio no desenvolvimento do doutorado.

Ao CNPq pelo apoio financeiro.

Ao Prof. Dr. Ricardo Yassushi Inamasu por sua orientação.

Ao Prof. Dr. Rafael Vieira de Sousa por seu apoio constante.

Ao Prof. Dr. Arthur José Viera Porto pelas oportunidades oferecidas por meio do Núcleo de Ensino e Pesquisa em Automação e Simulação (NEPAS) do Departamento de Engenharia Mecânica da EESC/USP.

À Dra. Maria Garcia-Alegre, ao Dr. David Martín, ao Dr. Domingo Guínea e ao Consejo Superior de Investigación Científica (CSIC) pela colaboração e oportunidade de intercâmbio internacional.

Aos amigos do NEPAS, aos amigos da USP e aos amigos de São Carlos pela amizade, apoio e colaboração.

Aos amigos do CSIC por me receberam com tanto carinho na Espanha no período do doutorado sanduíche.

À toda minha família pelo carinho, pelo apoio incondicional e pela paciência por meus momentos ausentes dedicados à elaboração deste trabalho. 



\section{Resumo}

TANGERINO, G. T. (2014). Método de amostragem de área agrícola com sensores embarcados: uma abordagem que leva em conta a variabilidade do campo. São Carlos, 131 p. Tese (Doutorado) - Escola de Engenharia de São Carlos, Universidade de São Paulo, São Carlos, 2014.

O trabalho apresentado destaca a importância do uso de práticas agrícolas que estimulem a manutenção da agricultura em níveis de alta produtividade, mas que, ao mesmo tempo, viabilizem uma minimização dos efeitos negativos da agricultura sobre o meio ambiente. $\mathrm{O}$ trabalho situa-se no contexto da aquisição de informação sobre a plantação considerando sua variabilidade para uso em Agricultura de Precisão. Foi proposto o desenvolvimento de um método inteligente de amostragem, que faz uso de sensores embarcados em veículos autônomos com capacidade de processamento em conjunto com técnicas geoestatísticas de amostragem. $\mathrm{O}$ processo de amostragem proposto leva em consideração a dependência espacial do campo, obtendo apenas a quantidade de informação necessária para reproduzir confiavelmente a variável em estudo para análises posteriores, amostrando mais densamente áreas de maior variabilidade e menos densamente áreas de menor variabilidade. O método desenvolvido estabelece a exploração em duas fases. $\mathrm{Na}$ fase de levantamento exploratório é utilizado um esquema de amostragem aninhado adaptado para as características do sistema de coleta de dados, nesta fase é realizada uma primeira avaliação sobre a escala espacial de variabilidade do campo. Na fase do levantamento principal são realizados ciclos de amostragens em grade, quantas vezes seja necessário até que critérios de decisão sejam atingidos. Nestes ciclos, ou etapas, são tomadas decisões com base na qualidade e na densidade de variabilidade das amostras. Tais decisões estabelecem se a área deve ser mais amostrada ou dividida em subáreas. A mínima precisão que se deseja alcançar é determinada pelo usuário e também limitada pelas capacidades estruturais da máquina que realizará aplicações a taxa variada. Em comparação com métodos tradicionais de obtenção de dados com sensores embarcados, as análises dos resultados mostram reduções que chegam a $98 \%$ na quantidade de pontos amostrados e redução de mais de $49 \%$ na distância final percorrida pelo veículo. Assim, a utilização do método proposto viabiliza a redução em custos computacionais de armazenagem e processamento, de gastos com combustíveis e de tempo de mão de obra. Os resultados evidenciam que é viável a amostragem baseada na densidade de variabilidade, racionalizando a quantidade, a qualidade e 
a disposição da informação obtida e armazenada. Em conclusão, o método de amostragem proposto apresenta potencial capacidade para sua utilização como uma ferramenta de apoio às novas práticas agrícolas, oferecendo uma alternativa mais eficiente e inteligente aos métodos tradicionais de coleta de dados.

Palavras chave: Amostragem inteligente, planejamento de trajetória, variabilidade, Agricultura de Precisão. 


\section{Abstract}

TANGERINO, G.T. (2014). Sampling method for agricultural area with embedded sensors: an approach that takes the variability of the field into account. São Carlos, $131 \mathrm{p}$. Dissertation (Master of Science) - School of Engineering of São Carlos, University of São Paulo, São Carlos, 2014.

The present work highlights the importance of using farming practices that encourage the maintenance of agriculture in high levels of productivity and, at the same time, enable reduction of the negative effects of agriculture on the environment. The work is in the context of acquisition of crop information considering its variability for use in Precision Agriculture. The development of a smart sampling method has been proposed, which uses of embedded sensors in autonomous vehicles with a processing capacity together with sampling geostatistics techniques. The sampling process takes into account the spatial dependence of the field, obtaining strictly the necessary amount of information to subsequent analyzes in a reliable way. It also aims to sample areas of higher variability more densily and areas of lower variability less densily. The developed method performs the exploration in two phases. In the exploratory phase, a nested sampling scheme adapted to the characteristics of the system is used. In this phase, the first assessment about the spatial scale of variability of the field is done. In the main survey phase, grid samplings are performed in stages, as many times as necessary until the decision criteria are reached. At the stages of the main survey, decisions are taken based on the quality and variability density of the samples, and this establishes whether the area should be better sampled or divided into subareas. The user determines the minimum precision to be reached. The structural capabilities of the machine, that will perform the variable rate applications, also restrict the system precision. The result analyses show that the number of samples reduced $98 \%$ and the final distance ran by the autonomous vehicle reduced $49 \%$, compared to traditional methods that use embedded sensors to collect data. Thus, the use of the proposed method represents reduced computational costs of data storage and processing, fuel costs and manpower. The results show that the sampling based on variability density is feasible, rationalizing the quantity, quality and layout of the information obtained and stored. In summary, the proposed sampling method shows potential capacity to be used as a tool to support new agricultural practices, offering a more efficient and smart alternative to traditional methods of data collection. 
Keywords: Smart sampling, path planning, variability, Precision Agriculture. 


\section{Lista de figuras}

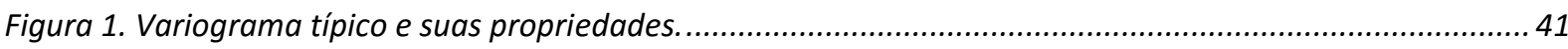

Figura 2. Representação de pixels como dados de sensores ......................................................................59

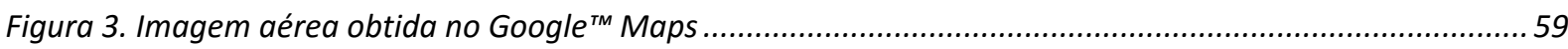

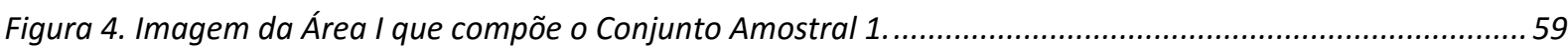

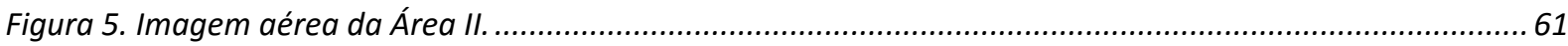

Figura 6. Conjunto Amostral II, dentro da Área II, localização dos pontos do conjunto composto por dados de sensor de refletância (a) e dados de sensor de condutividade (b) dentro da Área II

Figura 7. Resultado de interpolação sobre dados do sensor de condutividade para CE rasa (a) e para CE profunda (b).

Figura 8. Esquema representativo da estruturação do ambiente em linhas de referência da Área II. Sendo (a) contorno do campo, (b) linha de referência horizontal, (c) linha de referência vertical, (d) réplicas da linha de referência horizontal, (e) réplicas da linha de referência vertical, (f) matriz de cruzamento das linhas de referência horizontal e vertical e $(g)$ pontos de cruzamento entre as linhas de referência.

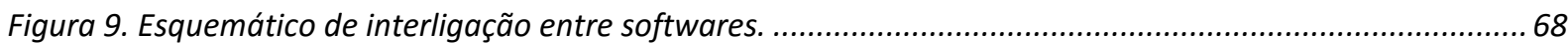

Figura 10. Esquema de navegação por densidade de variabilidade. ......................................................... 72

Figura 11. Esquemático dos critérios para decisão de amostragem ou divisão............................................. 75

Figura 12. Exemplo divisões de áreas, sendo (a) a área total, (b) subárea I-I, (c) subárea I-II, (d) subárea I-III, (e) subárea I-IV, (f) subárea I-Ia, (g) subárea I-Ib, (h) subárea I-Ic, (i) subárea I-Id .

Figura 13. Exemplo de esquemas de amostragem para o levantamento exploratório (a) e para as etapas do levantamento principal (b), (c) e (d).

Figura 14. (a) todas linhas a serem percorridas; (b) planejamento de trajetória para o levantamento exploratório (c) planejamento de trajetória para a etapa 1 do levantamento principal (c) planejamento de trajetória para a etapa 2 do levantamento principal.

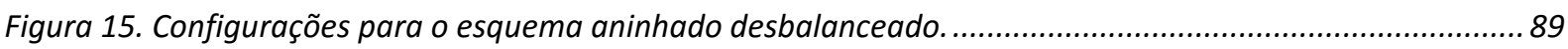

Figura 16. Esquema de determinação da grade inicial de amostragem no levantamento principal. ................... 90

Figura 17. Área I com grades com espaçamento de (a) 4,2 m, (b) $7 \mathrm{~m}$, (c) $14 \mathrm{~m}$, e (d) $21 \mathrm{~m}$.............................. 94

Figura 18. Esquema de amostragem final, do estudo de escalas de precisão e de exploração na Área I.............98

Figura 19.Esquema final de subáreas, do estudo de escalas de precisão e de exploração na Área l...................99

Figura 20. Resultados do estudo sobre qualidade em relação à quantidade mínima de dados. Esquemas de amostragem para limites iguais a (a) 4, (b) 8 , (c) 16 e (d) 20 dados. Esquemas de divisões para limites iguais a (e) 4, (f) 8, (g) 16 e (h) 20.

Figura 21. Área I e suas subáreas I-I, I-II, I-III e I-IV.. 
Figura 22. Resultados do estudo sobre critério de decisão de qualidade em relação à indicadores de krigagem, aplicado sobre o Conjunto Amostral I, em NC, para a Área I. Esquemas de amostragem para limites iguais a (a) $100 \%$, (b) 105\%, (c) 110\% e (d) 115\%. Esquemas de divisões para limites iguais a (e) 100\%, (f) 105\%, (g) 110\% e (h) $115 \%$. Imagens sobre krigagem para limites iguais a (i) 100\%, (j) 105\%, (k) $110 \%$ e (I) $115 \%$. 107 Figura 23. Área I e suas (a) subáreas I-I, I-II, I-III e I-IV e (b) subáreas I-Ia, I-Ib, I-Ic, I-Id, I-II, I-III, I-IVa, I-IVb, I-IVC e I-IVd. 109

Figura 24. Método de amostragem aplicado sobre o Conjunto Amostral I, sobre dados em NC, na Área I. 115 Figura 25. Método de amostragem aplicado sobre o Conjunto Amostral I, sobre dados em NC, na subárea I-I.

Figura 26. Método de amostragem aplicado sobre o Conjunto Amostral I, sobre dados em NC, na subárea I-IV.

Figura 27. Método de amostragem aplicado sobre o Conjunto Amostral I, sobre dados em NC, na subárea I-IV, com limite igual ao desvio padrão.

Figura 28. Resultados sobre CE rasa na Área II. (a) Dados originais krigados, (b) resultado de krigagem sobre amostra final, (c) linhas de referências percorridas, (d) esquema de amostragem final e (e) esquema de divisões final. 120

Figura 29. Resultados sobre CE profunda na Área II. (a) Dados originais krigados, (b) resultado de krigagem sobre amostra final, (c) linhas de referências percorridas, (d) esquema de amostragem final e (e) esquema de divisões final.

Figura 30. Resultados sobre NDVI na Área II. (a) resultado de krigagem sobre amostra final, (b) linhas de referências percorridas, (c) esquema de amostragem final e (d) esquema de divisões final. 


\section{Lista de tabelas}

Tabela 1. Resultados do estudo das escalas de precisão e de exploração na Área I.

Tabela 2. Resultados para amostragem realizada sobre o Conjunto Amostral I, sobre dados em NC, para amostragem em grade com espaçamentos de 3,5m, 7m e 21m, para a Área I e as subáreas I-I, I-II, I-III e I-IV.

Tabela 3. Análise sobre o Conjunto Amostral l, sobre dados em NC, na Área l, para escala de precisão de 3,5 m, escalas de exploração de 3,5 m, densidade de variabilidade de desvio padrão de $1 / 2$ do levantamento exploratório e qualidade de quantidade de 4 pontos 108

Tabela 4. Método aplicado sobre o Conjunto Amostral I, sobre dados em NC, para amostragem em grade com espaçamento de 3,5m para a Área I e suas subáreas (I-I, I-II, I-III e I-IV).

Tabela 5. Método de amostragem aplicado sobre o Conjunto Amostral I, sobre dados em NC, da Área I, para escala de precisão de 3,5 m, escalas de exploração de 3,5 m, qualidade de quantidade de 4 pontos e densidade de variabilidade de desvio padrão de $1 / 2$ do levantamento exploratório.

Tabela 6. Método aplicado sobre o Conjunto Amostral I, sobre dados em NC, na subárea I-I, para escala de precisão de 3,5 m, escalas de exploração de 3,5 m, qualidade de quantidade de 4 pontos e densidade de variabilidade de desvio padrão de $1 / 2$ do levantamento exploratório.

Tabela 7. Método de amostragem aplicado sobre o Conjunto Amostral I, sobre dados em NC, na subárea I-IV, para escala de precisão de 3,5 m, escalas de exploração de 3,5 m, qualidade de quantidade de 4 pontos e densidade de variabilidade de desvio padrão de $1 / 2$ do levantamento exploratório.

Tabela 8. Resultados de experimentos para amostragem e planejamento de trajetórias sobre o Conjunto Amostral I na Área I.

Tabela 9. Resultados do levantamento exploratório e da amostragem final para o método de amostragem aplicado sobre o Conjunto Amostral II (CE rasa, CE profunda e NDVI) da Área II.

Tabela 10. Resultados sobre quantidade de amostras e distância percorrida final para o método de amostragem aplicado sobre o Conjunto Amostral II (CE rasa, CE profunda e NDVI) da Área II. 



\section{Glossário}

ANOVA (Hierarchical Analysis of Variance)

AP - Agricultura de Precisão

CE - Condutividade Elétrica do Solo

CV - Coeficiente de Variabilidade

DGPS (Differential Global Positioning System) - Sistema de Posicionamento Global Diferencial

Escala de exploração - dimensões mínimas em que a área pode ser explorada, determinada com base em capacidades da máquina agrícola.

Escala de precisão - mínimo espaçamento de grade que se deseja atingir na exploração, determinada pelo usuário.

Escala espacial de variabilidade - correspondente ao alcance do variograma, é a distância a partir da qual os pontos amostrais podem ser considerados independentes.

FMIS (Farm Information Management System)

GIS (Geographic Information System) - Sistema de Informação Geográfica

GLONASS - sigla do acrônimo russo Globalnaya navigatsionnaya sputnikovaya sistema

GNSS (Global Navigation Satellite System)

GPS (Global Positioning System) - Sistema de Posicionamento Global

IBGE - Instituto Brasileiro de Geografia e Estatística

Krigagem (kriging) - Técnica de interpolação geoestatística que considera a correlação espacial entre dados.

ML (Maximum Likelihood) - Máxima Verossimilhança

MoM - Método dos Momentos

MSDR (Mean Squared Deviation Ratio) - Taxa de desvio quadrático médio

MSE (Mean Squared Error) - Erro quadrático médio

NC - Níveis de Cinza

NDRE (Normalized Differrence Red-Edge)

NDVI (Normalized Difference Vegetation Index) - Índice de Vegetação por Diferença Normalizada

PCV (Traveling salesman problem - TSP) - Problema do caixeiro Viajante

PIB - Produto Interno Bruto 
PRV (Vehicle routing problem - VRP) - Problema de roteamento de veículos

REML (Residual Maximum Likelihood ou Restricted Maximum Likelihood)

RMSE (Root mean squared error) - Raiz do erro quadrático médio

RTK-GPS (Real Time Kinematic GPS) - Receptores GPS de posicionamento relativo cinemático em tempo real

SIG - Sistema de informação Geográfica

SSA (Spatial Simulated Annealing)

VANT - Veículo aéreo não tripulado 


\section{Sumário}

1 Introdução

1.1 Justificativa 24

1.2 Objetivos 25

2 Revisão bibliográfica 27

2.1 Automação de máquinas na agricultura 28

2.1.1 Robótica agrícola 29

2.1.2 Planejamento de trajetórias em ambiente agrícola 32

2.2 Ferramentas para aquisição de dados em agricultura 34

2.3 Geoestatística 39

2.3.1 O variograma 40

2.3.2 Amostragem 43

2.3.3 Levantamento aninhado 49

2.3.4 Krigagem 52

3 Materiais 57

3.1 Conjuntos amostrais ___

3.1.1 Conjunto amostral I___ 58

3.1.2 Conjunto amostral II _ 60

3.2 Estruturação do ambiente ________________________ 63

3.2.1 Linhas de referência __ 64

3.3 Softwares _____________ 66

4 Metodologia__ 69

4.1 Esquema geral ____________________

4.2 Critérios de decisão e parâmetros de análise_____ 74

4.2.1 Qualidade da amostra ___ 76

4.2.2 Escala de precisão _ـ 77

4.2.3 Escalas de exploração ___ 77

4.2.4 Escala espacial de variabilidade _ 77 
4.3 Exploração em fases___ 79

4.4 Exploração em subáreas ___ _ _ _ 81

4.5 Ciclos de Amostragem ___ _ 82

4.6 Levantamento aninhado adaptado ___ 88

4.7 Levantamento principal ___ 90

5 Resultados__ 93

5.1 Escalas de precisão e exploração_____ 94

5.2 Qualidade ___ 100

5.3 Densidade de variabilidade ___ 109

5.4 Amostragem e planejamento de trajetórias____ 116

5.5 Metodologia completa aplicada sobre o Conjunto Amostral II ___ 118

5.6 Considerações finais__________________ 124

6 Conclusões__ 127

Referências Bibliográficas___ 129 


\section{Introdução}

Mesmo com a crise mundial iniciada em 2007, o agronegócio e as atividades agropecuárias brasileiras têm apresentado, até a data de defesa deste trabalho, bons desempenhos, contribuindo de forma relevante para a economia e apresentando recordes de produção e exportação (MAPA, 2013a). Até o primeiro trimestre de 2014, segundo o Instituto Brasileiro de Geografia e Estatística (IBGE), mesmo com a economia desacelerando (indústria e investimentos em queda), foi o agronegócio quem contribuiu para manter positivo o Produto Interno Bruto (PIB) e com a economia em crescimento (AMORIM et al., 2014).

Outra informação importante sobre o agronegócio é que, desde 2008, o Brasil ocupa o posto de maior consumidor de insumos químicos para agricultura do planeta. Este consumo excessivo está diretamente relacionado com o modelo de produção agrícola vigente no Brasil (MMA, 2014), baseado em grandes propriedades e com a alta produtividade vinculada ao uso de herbicidas, fertilizantes e inseticidas.

$\mathrm{O}$ aspecto econômico positivo em conjunto com o aspecto negativo sobre o consumo excessivo de agrotóxicos, revelam a importância da implementação de práticas agrícolas que viabilizem a manutenção da agricultura em níveis de alta produtividade, mas que, ao mesmo tempo, estimule uma maior preservação do meio ambiente com a redução do uso de agrotóxicos. Neste cenário de melhores práticas agrícolas, o uso de Agricultura de Precisão (AP) pode trazer um impacto socioeconômico positivo com possibilidade de aumento de $10 \%$ 
da produtividade, podendo aumentar o PIB e gerar mais de 450 mil empregos (COSTA; GUILHOTO, 2011).

O objetivo da AP é melhorar o gerenciamento da produção agrícola através de respostas às variações em escalas no sistema de solo-colheita dentro do campo (MARCHANT \& LARK, 2010). A principal proposta da AP é a gestão da variabilidade, através do uso racional de insumos e atividades agrícolas, se opondo ao método tradicional de aplicações uniformes em todo um campo (COMMITTEE, 1997). O uso de AP traz consigo possibilidades de aumento de retorno econômico, de sustentabilidade e de minimização dos efeitos negativos ao meio ambiente (MAPA, 2013b). A AP visa atuar localmente e como consequência utilizando adequadamente tempo e recursos (COMMITTEE, 1997) através de aplicações de técnicas e da utilização de ferramentas que permitam um maior controle sobre todas as atividades executadas (MAPA, 2013b).

A viabilidade do uso de AP depende de três questões básicas: se existe variabilidade no campo sendo investigado, se existe informação correta e suficiente sobre a variável sendo investigada e se existe tecnologia capacitada para aplicações de insumos a taxa variada.

O ponto de partida para a implementação da AP é a observação da existência de diferentes produtividades em diferentes áreas do mesmo campo, o que leva à premissa de que existe variabilidade na plantação. Com a existência da variabilidade, a atuação uniforme em todo o campo é não racional e ineficiente (WHELAN \& MACBRATNEY, 2000). Assim, a maior diversidade dos solos está diretamente relacionada com a efetividade do uso de AP (COSTA; GUILHOTO, 2011). A avaliação da oportunidade de aplicações de AP pode ser realizada com o uso de índices que indicam se a variabilidade existente no campo é suficiente para justificar aplicações de técnicas a taxa variada (OLIVEIRA, 2009; OLIVEIRA et al., 2011; OLIVEIRA \& BENITES, 2011).

Ou seja, ter disponível a informação correta sobre a variação dos atributos do solo e da plantação é decisivo para um gerenciamento preciso na agricultura. Tal afirmação leva a pensar na importância dos processos de obtenção da informação sobre o campo. Uma amostragem correta sustenta a qualidade e a acurácia das subsequentes análises e tomadas de decisões. Amostragens mais objetivas, com estruturas conceituais mais claras e consistentes são necessárias em AP (KERRY et al., 2010).

Dentre os métodos de amostragens mais utilizados está coleta de amostras pontuais que geralmente é guiada por esquemas em formato grade. Tal método, em geral, é caro e trabalhoso por exigir a excursão em campo e ocupar longos períodos de tempo para sua execução. Outro método de amostragem atualmente muito difundido é o sensoriamento remoto, que possibilita 
a coleta de grande quantidade informações e com menor esforço, mas que também pode apresentar altos custos dependendo da forma como é aplicado.

Para um gerenciamento preciso da plantação são exigidas informações do sistema de solocolheita em finas escalas de resolução, mas muitos tipos de amostragem fornecem pequena quantidade de informação. A predição geoestatística por interpolação é um dos modos que pode ser utilizado para se obter tais informações a partir de um conjunto menor de observações. Essas observações devem ser obtidas por esquemas apropriados de amostragem. E para garantir a relação custo-benefício em AP, a amostragem deve ser o mais eficiente possível, o que evidencia a necessidade de um modelo sofisticado de decisão. Modelo tal que permita uma gestão racional da amostragem e uma ampla exploração de poderosas abordagens geoestatísticas (MARCHANT \& LARK, 2010).

O uso de sistemas automatizados em amostragens, tais como veículos autônomos, traz a possibilidade da redução de custos em coletas, fornecendo a qualidade e a quantidade suficiente de dados que a geoestatística requer para uma análise confiável. Com os avanços em robótica, os robôs autônomos devem ser capazes de explorar campos, coletando e processando amostras automaticamente (SCHUELLER, 2010). Um planejamento automatizado e inteligente de trajetórias pode ajudar a encontrar o melhor caminho para cobertura completa do campo, fazendo com que custos de várias operações sejam minimizados, além de possibilitar a redução de emissão de poluentes atmosféricos (HAMEED, 2014).

Os avanços em engenharia estão fornecendo novas possibilidades em sensoriamento, em atuação, em tecnologias de informação e em comunicação que poderiam ser adotadas para promover mais eficácia nos sistemas biológicos complexos e simultaneamente cumprir as exigências cada vez maiores para a sustentabilidade. Para promover eficácia, é necessário que sejam ultrapassadas as barreiras ainda existentes entre dados adquiridos e geração de conhecimento (no nível da tomada de decisão humana) e entre sensoriamento e atuação (no nível da malha de controle de máquinas) (BOCHTIS; SORENSEN, 2014). 


\subsection{Justificativa}

O conceito a ser desenvolvido por este trabalho nasceu da necessidade da elaboração de inteligência no processo de sensoriamento de plantações realizado por um robô agrícola para suporte a trabalhos de pesquisas em AP. O robô em questão, chamado Agribot e descrito com mais detalhes no Capítulo 2.1.1, tem como uma das funções esperadas a capacidade de aquisição de dados em tempo real de plantações utilizando sensoriamento embarcado. Tendo em conta a necessidade de criação de métodos que possibilitem que o robô citado execute a função de sensoriamento de forma eficaz e inteligente, o trabalho apresentado a seguir busca desenvolver métodos que agreguem inteligência aos processos de deslocamento do robô na tarefa de sensoriamento de plantações, principalmente no que diz respeito ao processo de planejamento de trajetórias. A eficiência e a inteligência que se busca agregar ao sistema de sensoriamento robótico podem ser expandidas a sistemas que utilizem veículos autônomos com capacidade de sensoriamento e processamento de informações em tempo real.

Partindo do pressuposto que o veículo autônomo será utilizado em AP e que a eficiência ou necessidade da utilização de ferramentas em AP depende da existência de variabilidade na plantação, o desenvolvimento deste método se baseou principalmente em conceitos de variabilidade espacial e geoestatística. $\mathrm{O}$ estado da arte em pesquisas de amostragem mostra que a utilização de geoestatística torna os processos de coleta mais eficazes ao possibilitar acesso a informação mais precisa sobre variações dos atributos do campo.

Assim, o presente trabalho atua no âmbito global do desenvolvimento de ferramentas que fomentem melhores práticas na agricultura. Centrado na melhora de processos de obtenção de informação de plantações por sensoriamento, busca benefícios tais como reduzir a quantidade de informação coletada sobre uma área (reduzindo custos computacionais de armazenagem e processamento), além de tornar o processo de sensoriamento da plantação um processo mais ágil e econômico (reduzindo custos com combustível e tempo de mão de obra).

Além disso, o presente trabalho atua também com a intenção de fomentar $o$ desenvolvimento de sistemas robóticos para aplicações agrícolas. Embora exista uma quantidade crescente de trabalhos sobre robótica voltados para AP, ainda são poucos que conseguem abranger a complexidade que toda área agrícola impõe. Portanto, o trabalho apresentado visa contribuir também com o desenvolvimento de capacidades que possibilitem 
que sistemas robóticos alcancem um patamar de inteligência e segurança que permita que sejam efetivamente utilizados em campos agrícolas.

A revisão da literatura, apresentada no Capítulo 2, relata o estado da arte dos principais conceitos utilizados no desenvolvimento deste método, tais como planejamento de trajetórias em área agrícola, sensoriamento, variabilidade e amostragem geoestastísca. Os capítulos apresentados a seguir evoluem no sentido de explicar como o método proposto permite a obtenção da informação através do uso de um veículo autônomo, cuja missão é coletar apenas as amostras desejadas com o uso de sensores embarcáveis, detalhando os passos necessários para realizar essa união entre o uso de tecnologias robóticas e de sensoriamento com as técnicas de amostragem em favor de uma amostragem mais inteligente.

\subsection{Objetivos}

Este projeto tem como objetivo o desenvolvimento de um método inteligente de sensoriamento embarcado, tendo como objetivos específicos:

- Oferecer suporte ao processo de deslocamento e planejamento de trajetórias de veículos autônomos na tarefa de sensoriamento em ambientes agrícolas.

- Agregar eficiência a sistemas de amostragem de campos agrícolas, reduzindo custos e viabilizando a coleta de dados em quantidade reduzida, mas confiável, para uso em análises de decisão para AP.

- Capacitar a identificação de diferenças de variabilidade entre áreas dentro de uma mesma plantação, amostrando mais densamente áreas de maior variabilidade e menos densamente áreas de menor variabilidade. 

2 Revisão bibliográfica 


\subsection{Automação de máquinas na agricultura}

A utilização de novas tecnologias tem permitido que a escala de tratamento seja reduzida até planta e até mesmo a folha, e assim permite também o desenvolvimento e aplicação de novos conceitos e práticas de gerenciamento de plantação, que não eram possíveis antes (BLACKMORE, 2009).

O uso de veículos autônomos na agricultura torna-se mais viável conforme as tecnologias se tornam cada vez mais acessíveis e com custos mais baixos, tais como, computadores, sistemas de visão de máquina e sistemas de navegação (KEICHER \& SEUFERT, 2000). Em contrapartida, o uso de veículos autônomos implica em demandas mais complexas, tais como planejamento de trajetórias, automação de frenagem, aceleração e trocas de marchas e a implementação e o controle de sistemas de segurança para evitar colisões.

Sistemas autônomos são mais flexíveis que os sistemas convencionais e podem reduzir significativamente custos trabalhistas e restrições sobre o número de horas diárias de trabalho. E também tornam possível a substituição das rotinas triviais de trabalho por sistemas autônomos (PEDERSEN et al., 2006).

A automação de máquinas agrícolas traz benefícios ambientais, econômicos, trabalhistas e de produtividade (STENTZ et al., 2002; BLACKMORE et al., 2005). Um mau desempenho humano das atividades agrícolas com máquinas pode interferir negativamente no meio ambiente, com consumo excessivo de combustível e preparo inadequado do solo, levando a um potencial risco de erosão, ou ao excesso de aplicação de produtos químicos com aumento na poluição. Em contrapartida, um bom desempenho das atividades com máquina é compatível com os objetivos econômicos e ambientais em que o campo deve ser cultivado, semeado e colhido com mínimos custo e poluição (WILSON, 2000).

Um dos objetivos do planejamento de trajetórias automático e da guiagem automática de veículos agrícolas é aliviar o operador das contínuas manobras de direção ao mesmo tempo que executa aplicações com implementos, buscando assim, reduzir o estresse sobre o motorista e evitar que ambas as atividades sejam cumpridas de forma insatisfatória (WILSON, 2000).

Por exemplo, o piloto automático existente em máquinas agrícolas é um sistema de direcionamento baseado em sistemas GNSS. Direciona automaticamente o equipamento sobre uma linha planejada de aplicação através do acionamento automático do comando da direção. Opera em reta ou em curva e é extremamente preciso, pois não tem a interferência do operador. 
Os benefícios na utilização de veículos com certo nível de controle recai principalmente na questão de redução da compactação do solo, além de trazer outros benefícios, tais como aumentar a performance do equipamento, reduzir sobreposição ou falhas nas passadas sucessivas, aumentar a jornada de trabalho mesmo durante a noite, reduzir o consumo de combustível, entre outros.

\subsubsection{Robótica agrícola}

O uso de robôs como veículos agrícolas autônomos tem potencial de utilização como uma valiosa ferramenta tecnológica para a AP, trazendo a vantagem de poder fazer uso das diversas teorias em controle robótico, já fundamentadas e consolidadas para aplicações em diversas outras áreas (GRIFT et al.,2008). A recente tendência de desenvolvimento de robôs móveis e veículos autônomos para realização de tarefas agrícolas é norteada principalmente por melhorar a eficiência e originar ganhos de operação (reduzir compactação do solo, ausência de operador), se comparados com a utilização de grandes máquinas (BLACKMORE \& GRIEPENTROG, 2006).

Tecnologias computacionais e robóticas têm tido recentes avanços em áreas aplicáveis em robótica agrícola móvel: percepção, manipulação e veículos autônomos. Sendo que, veículos autônomos constituem a área que tem experimentado o maior aumento de interesse em robótica agrícola. A maturidade de tecnologias robóticas autônomas tem alimentado a possibilidade de rodagem de diversos veículos não-tripulados em modo coordenado e robusto para operar diversas atividades na produção da fazenda (PEDERSEN et al., 2005).

A robótica pode ser usada como uma ferramenta eficiente na otimização e redução de custos de processos. A robótica voltada para agricultura tem avançado, e mesmo que ainda não seja um elemento que faça parte do cenário de um campo agrícola, tem grande potencial de aplicação. Esse potencial existe pois, além de os processos agrícolas apresentarem muitas possibilidades de otimização, como o tratamento da variabilidade espacial do campo, as atividades agrícolas demandam um esforço físico considerável, muitos deles repetitivos. Dentre as atividades repetitivas, se encaixam a coleta e o processamento de dados georeferenciados. $\mathrm{O}$ uso de um robô móvel ou veículo autônomo em campo com sensores embarcados pode tornar o processo de coleta de amostras e de dados mais eficiente e menos custoso. Um dos pontos de 
diferenciação da robótica agrícola para a tradicional é o ambiente semiestruturado e rústico onde o robô se desloca, além disso, a presença de uma plantação estabelece a necessidade de regras específicas para o deslocamento de máquinas em campo.

Em geral, o desenvolvimento em robótica busca suprir incapacidades ou complementar capacidades humanas, buscando executar tarefas com mais precisão e agilidade (indústria) ou realizando aquelas em que ainda não estão capacitados (viagens espaciais, exploração marítima), ou ainda buscando uma vida mais cômoda (tarefas domésticas), ou mais segura (tráfego). Aplicação de robótica em ambiente agrícola aborda o aspecto da execução de tarefas com maior precisão e agilidade, e oferece a capacidade de explorar o campo minuciosamente através de sensoriamento embarcado.

Em uma avaliação comparativa entre o uso de sistemas autônomos no Brasil com o uso na Europa, Japão ou Estados Unidos, a grande diferença é que nesses países, ao contrário do Brasil, a mão de obra especializada não é um problema e, muitas vezes as operações são realizadas pelo proprietário ou membros da família. No Brasil, os sistemas autônomos vêm para suprir a carência de profissionais frente a demanda crescente (TABILE et al., 2011b)

Entre os grupos ao redor do mundo que trabalham com robótica voltada para agricultura destaca-se o comitê técnico IEEE em Robótica e Automação Agrícola (AgRA - Agricultural Robotics and Automation) que tem a missão de promover a pesquisa, desenvolvimento, inovação e padronização na área de robótica e automação para permitir a produção agrícola segura, eficiente e econômica. O AgRA é um fórum onde pesquisadores e engenheiros industriais e acadêmicos se reúnem para avançar no estado da arte em tecnologias de sensoriamento, mobilidade, manipulação e gestão aplicadas à produção de grãos, frutas, legumes, nozes, horticultura e viveiros (AGRA, 2014).

Trabalhos como os Sousa et al. (2006) e Garcia-Alegre e Guinea (1997) estabelecem arquiteturas para sistemas robóticos agrícolas. Inclusive, o grupo liderado pela pesquisadora Maria Garcia-Alegre, que teve início por volta da década de 90 e que opera na instituição CSIC, na Espanha, foi um dos primeiros a buscar algoritmos inteligentes em diferentes áreas da robótica e trazê-los para a agricultura, inclusive realizando passos de readaptação de algoritmos, readaptação dos tipos de sensores que são utilizados para a realidade do ambiente agrícola.

Entre os trabalhos relacionados com guiagem de veículos orientada a ambientes agrícolas, destacam-se os trabalhos desenvolvidos para seguimento de trajetórias (path tracking) (ZHU et al., 2007; LENAIN et al., 2006), planejamento de trajetórias (path planning) (OKSANEN, 2007; BOCHTIS et al., 2010; LINKER \& BLASS, 2008; VOUGIOUKAS et al., 2006; 
BARRIENTOS et al., 2011) e controle de esterçamento e velocidade (GARCIA-ALEGRE et al, 2001; TANGERINO et al., 2011b, GODOY et al., 2012).

Em planejamento de trajetórias, existem algumas abordagens que buscam otimizar o processo decompondo o campo em sub-regiões para melhorar o processo (JIN \& TANG, 2006; JIN \& TANG, 2010; OKSANEN \& VISALA, 2009) ou usando um time de robôs para atravessar o campo com um plano de múltiplos caminhos (VOUGIOUKAS, 2009). Outros estudos relatam a busca por um plano de trajetória que garanta minimização de tempo e custo na performance de tarefas agrícolas com veículos (BOCHTIS \& VOUGIOUKAS, 2008; CONESA et al, 2012, BOCHITS et al., 2013).

Estudos sobre o uso de Controle de Tráfego em Fazendas (Controled Traffid Farming CTF) apontam melhoras em questões ambientais, tais como redução de emissões de gases de efeito estufa, redução da compactação aleatória, redução em impactos indiretos associados com fertilizantes, pesticidas, sementes e combustíveis, maior rendimento operacional das máquinas agrícolas e melhora no escoamento de água (GASSO et al., 2013).

No Brasil, destaca-se o trabalho desenvolvido em parceria entre Escola de Engenharia de São Carlos da Universidade de São Paulo (EESC-USP), a Unidade de Instrumentação da Empresa Brasileira de Pesquisa Agropecuária (Embrapa Instrumentação) e a empresa Máquinas Agrícolas Jacto S.A., na construção de uma plataforma robótica modular e multifuncional para aquisição de dados em AP. O Agribot, como é chamado, é uma plataforma robótica desenvolvida especificamente para tarefas de exploração agrícola, capaz de se locomover em ambientes típicos da área agrícola com a finalidade de aquisição de dados e pesquisa de novas tecnologias para o sensoriamento remoto de áreas agrícola. Suas principais características são a robustez, mobilidade, elevada capacidade operacional e autonomia condizente com as necessidades agrícolas. Usualmente denominado em AP como "plataforma multisensor", a plataforma robótica apresenta característica multifuncional no sentido de permitir o acoplamento de módulos de aquisição de dados em campo para estudo da variabilidade espacial por meio de sensores e equipamentos considerados portáteis (SOUSA, 2007; GODOY et al., 2009; GODOY et al., 2010; GODOY et al., 2012; TABILE et al., 2010; TABILE et al., 2011a; TABILE et al., 2013 TANGERINO et al., 2011a, TANGERINO et al., 2011b; ARCHILA et al., 2013). 


\subsubsection{Planejamento de trajetórias em ambiente agrícola}

A maioria das trajetórias em operação agrícolas, podem ser descritas como uma combinação de linhas retas e segmentos de curva com o objetivo de seguir uma linha e trocar entre uma linha e outra, apresentando um padrão regular e repetitivo (THUILOT et al., 2002). É esperado do operador humano que ele consiga executar com segurança e precisão esse padrão de deslocamento, tendo em conta reações inteligentes a eventos inesperados, através de habilidades deliberativas e reflexivas, sem perturbar muito o plano de navegação. Um veículo agrícola auto-pilotado em uma operação agrícola deve completar um padrão geométrico sob restrições impostas por uma tarefa específica. Geralmente, a maioria dos atributos espaciais permanentes são conhecidos e injetados no sistema de controle para execução de uma missão de navegação. Os aspectos dinâmicos do sistema e do ambiente também devem ser considerados como garantia de segurança (GARCIA-PÉREZ et al., 2008).

Garcia-Pérez et al. (2008) e Garcia-Alegre e Recio (1998) propuseram uma arquitetura de comportamento de agentes híbridos para realizar navegação não-tripulada em operações agrícolas. Usando processos computacionais e de controle para alcançar ou manter a meta, com habilidades perceptivas, deliberativas e reativas sem restrições em sua complexidade. Implementaram um sistema multi-agentes para reproduzir a sequência de ações, tanto perceptivas quanto motoras, realizadas pelo motorista humano no manual de operações de pilotagem. $\mathrm{O}$ agente de navegação é o gerente que coordena outros agentes na condução do veículo ao longo da trajetória proposta. A rota é definida por um conjunto de posições intermediárias no mapa digital georeferenciado. Assim, o operador precisa marcar o ponto inicial e final de cada linha. O agente de seguir linha reta foi baseado no algoritmo de perseguição de trajetória proposto por Coulter (1992).

Segundo Garcia-Pérez et al. (2008), o rastreamento de linha reta é uma estratégia fundamental para a maioria das operações agrícolas. As estratégias de seguir uma linha reta podem ser classificadas como: i) abordagens locais que são guiadas pela informação extraída a partir de estruturas de campo (RIBEIRO et al., 2005); e ii) guiagem por coordenadas absolutas de GPS diferencial (DGPS, do inglês Differential Global Positioning System) (STENTZ et al., 2002). Abordagens de auto-guiagem são geralmente baseadas em informações globais que dependem de receptores GNSS com correção de posicionamento relativo cinemático em tempo real, o RTK (Real Time Kinematic). 
O problema de roteamento de veículos (PRV), do inglês vehicle routing problem (VRP), determina a rota de menor custo de um ponto de origem para um grupo de pontos geograficamente dispersos, visando o atendimento de um conjunto de consumidores por intermédio de uma frota de veículos. O PRV é uma generalização do Problema do Caixeiro Viajante (PCV - do inglês traveling salesman problem (TSP)), no qual as rotas são geradas de modo que cada ponto é visitado uma única vez e por exatamente um veículo com todas as rotas começando e terminando no ponto de origem.

Segundo Bochtis \& Sorensen (2009), em agricultura o PRV tem sido utilizado em transporte de pecuária ou de produtos agrícolas, bem como em aplicações logísticas de mercadorias e carnes e colheita das culturas em operações entre fazendas. E somente recentemente tem sido implementado para planejamento e execução de operações dentro do campo envolvendo máquinas agrícolas.

O modelo de PRV apresenta a problemática para mais de um veículo que em conjunto percorrem todos os caminhos, sendo que cada caminho é percorrido por um único veículo e uma única vez (BOCHTIS \& VOUGIOUKAS, 2008; BOCHTIS \& SORENSEN, 2009; BOCHTIS et al., 2010).

Para o planejamento de trajetórias de uma máquina em campo agrícola deve-se observar características do terreno, da plantação e da máquina. Bochtis e Sorensen (2009) detalham a notação utilizada para representação de planejamento de trajetórias em ambientes agrícolas. Por exemplo, sobre o terreno deve-se observar a geometria da plantação, espaço disponível para manobras nas cabeceiras, presença de curvas de nível e presença de obstáculos naturais, como lagos e árvores; sobre a plantação deve-se observar características como espaçamento entre linhas de plantio e altura das plantas; sobre a máquina, largura, comprimento, espaçamento entre rodas, e altura do vão entre rodas. Além disso, a plantação apresenta uma característica mutável, relacionada com a sua não perenidade. A cada nova safra ou plantio pode ocorrer uma realocação das linhas de plantio, além da presença de pragas ou falhas que também podem modificar o ambiente. 


\subsection{Ferramentas para aquisição de dados em agricultura}

A viabilidade do uso de AP depende de três questões básicas: se existe variabilidade no campo sendo investigado, se existe informação correta e suficiente sobre a variável sendo investigada e se existe tecnologia capacitada para aplicações de insumos a taxa variada.

No que diz respeito à informação sobre a variável sendo investigada, em AP tem-se tirado muito proveito do avanço tecnológico em sistemas de aquisição, tratamento e transmissão de dados agrícolas. Entretanto, historicamente, a aplicação da filosofia de AP não é determinada pelo uso de tecnologias, é, na verdade, vinculada ao conhecimento que se tem da plantação. Um pequeno agricultor já praticava AP em sua fazenda familiar há séculos, pois tinha o conhecimento sobre cada área de seu cultivo e agia localmente para melhorá-lo como lhe convinha.

Nos tempos atuais, os grandes benefícios no uso de novas tecnologias para aquisição de informação recaem principalmente sobre o tamanho das plantações, que inviabilizam que uma única pessoa tenha conhecimento de cada pedaço de sua plantação. Além do mais, o uso de tecnologias para monitorar e investigar plantações traz benefícios como a capacidade de observar fatores que não são perceptíveis ao olho nu, além de facilitarem o estudo e análise das inúmeras variáveis que interferem no processo produtivo de uma plantação.

Novas práticas agrícolas relacionadas com a AP têm demandado um número crescente de pesquisas em sensores embarcados e redes de comunicação para o estudo da variabilidade espacial e para a aplicação de insumos a taxa variada (AUERNHAMMER \& SPECKMAN, 2006). Novas tecnologias e dispositivos para aquisição de dados e atuação em tempo real estão sendo desenvolvidos para equipar máquinas agrícolas para dar suporte a essas práticas e tornálas automatizadas (STONE et al., 2008).

Um conceito já bastante difundido são as práticas por zonas de manejo em sítios específicos (Site-Specific-Management-Zone). Sua adoção em larga escala tem implicado em mudanças estruturais nos processos de geração e de tomada de decisão, principalmente no que diz respeito às tecnologias agrícolas, geoespaciais e de informações. Zonas de manejo são áreas do terreno de iguais produções, eficiência do uso de insumos e risco de impacto ambiental (LUCHIARI et al., 2010). 
Num âmbito mais abrangente, um novo conceito tem tido de crescente interesse por parte da comunidade que utiliza AP, o FMIS (Sistema de Gestão de Informação da Fazenda - Farm Information Management System) (SORENSEN et al., 2010; SORENSEN et al., 2011). Tais modelos propõem um sistema de gerenciamento da informação de toda a fazenda para coleta, processamento, armazenagem e disseminação de dados na forma de informação necessária para executar as operações da fazenda. Nesse modelo ficam claros todos os processos envolvidos na produção de uma fazenda. Fica claro também a demanda por tecnologias de suporte.

No Brasil, com o intuito de fomentar o desenvolvimento e a utilização da AP, a Empresa Brasileira de Pesquisa Agropecuária (Embrapa) organizou uma Rede de AP que, através de esforço conjuntos, realizou pesquisas relacionadas a práticas e tecnologias, com contribuições que podem ajudar os proprietários rurais a adotarem AP (BERNARDI et al., 2014; INAMASU et al., 2011).

As tecnologias para aplicações de AP abrangem desde sensores e equipamentos até sistemas de informação e de comunicação.

Dentre as ferramentas tecnológicas utilizadas em AP, o receptor GPS (Global Positioning System) é a mais conhecida, mas, na realidade, o termo GPS se refere a um sistema específico norte americano. O mais correto é se referir a essa ferramenta como Sistema de Satélites para Navegação Global (GNSS - Global Navigation Satellite System) que é o termo genérico para definir sistemas de localização geográfica baseados em informações de satélites, que permitem determinar coordenadas de localização de um receptor (latitude, longitude e altitude). Atualmente, os dois únicos sistemas GNSS completamente operacionais são o sistema americano, o GPS, e o sistema russo, o GLONASS (sigla do acrônimo russo Globalnaya navigatsionnaya sputnikovaya sistema, Sistema de Navegação Global por Satélite). O sistema europeu, o Galileo, e o sistema chinês, o Compass, ainda estão em fase de implantação. O aumento da informação e da capacitação do agricultor para uso de AP, tem ocasionado a ampliação da gama de ferramentas desenvolvidas ou aproveitadas para este fim, muito além do GNSS.

No quesito informação, ganha destaque o Sistema de Informação Geográfica (SIG, do inglês Geographic Information System - GIS) que é uma coleção de ferramentas computacionais que facilitam, por meio de georeferenciamento, a integração de dados espaciais, não espaciais, qualitativos e quantitativos em uma base de dados que pode ser gerenciada sob um ambiente de sistema, atuando na identificação, aquisição, gerenciamento, e processamento de dados e na tomada de decisão. O SIG visa o armazenamento e recuperação de todos os tipos de dados em uma determinada localização geográfica, dentre eles, geológicos, geofísicos, geoquímicos, 
sensoriamento remoto, topografia, uso da terra, solo, vegetação e todos os outros tipos possíveis de dados. Os dados são sobrepostos usando-se como referência uma grade geográfica comum (BONHAM-CARTER, 1994).

Dentre as formas de armazenamento de dados estão os mapas de produtividade de culturas, importantes tanto para implementação quanto para avaliação de estratégias de manejo de culturas. Um mapa de produtividade busca mostrar tendências com regiões de altas ou de baixas produtividades, se existirem (MOLIN, 2003), e sua resolução e precisão devem ser levadas em consideração em decisões de gestão e avaliações baseadas no mapa. Mapas, em geral, são construídos por métodos de interpolação.

No campo de interpolação de dados (ou predição), a técnica de krigagem geoestatística destaca-se como modelo que pondera os vizinhos do ponto a ser estimado fornecendo estimativas pontuais não viciadas e de variância mínima. O termo krigagem, muito utilizado neste trabalho, é uma tradução livre do termo em inglês "kriging” definido por G. Matheron em 1963 em homenagem a D. G. Krige, um engenheiro de minas Sul Africano, que desenvolveu uma técnica de médias móveis para determinar a concentração de ouro em jazidas minerais.

Desenvolvimentos recentes em tecnologias e técnicas de aquisição de dados e recursos computacionais têm proporcionado a aplicação de geoestatística com grandes quantidades de informação e de diferentes tipos, que podem ser armazenadas, gerenciadas e processadas rapidamente em um SIG (GOOVAERTS, 1999).

Em relação à aquisição de dados, é essencial para um gerenciamento preciso na agricultura que exista a disponibilidade de informações corretas sobre a variação dos atributos do solo e da planta. A informação sobre a área cultivada pode ser obtida sobre o solo cru, sobre o dossel ou sobre a colheita (produtividade). A informação pode ser disponibilizada através de imagens, mapas ou listas, podendo ser obtida através de sensoriamento ou amostragem. Para uso em análises agrícolas a informação deve ser georeferenciada.

O sensoriamento pode ser remoto ou local (in situ). O sensoriamento remoto é caracterizado por informação obtida sem contato com o alvo, tais como imagens aéreas. No sensoriamento local destacam-se as informações obtidas diretamente no campo (JENSEN, 2009). Medidas feitas com ajuda de tratores ou manualmente também são conhecidas como sensoriamento proximal, especialmente aquelas não envolvem medidas de radiação refletida. O sensoriamento on-the-go é um sensoriamento proximal no qual os sensores estão embarcados na máquina que está realizando uma operação agrícola.

Segundo Mulla (2013), o sensoriamento remoto é um método para coleta de informações sobre a plantação e o campo e se refere ás medidas de radiação refletida ou emitida sem contato 
direto com os campos agrícolas. As plataformas para aquisição de dados por este meio incluem satélites, aviões, tratores e sensores portáteis manualmente. As aplicações de sensoriamento remoto em AP são classificadas de acordo com o tipo de plataforma para o sensor, incluindo plataformas orbitais, aéreas ou terrestres. Estas plataformas e seus respectivos sistemas de imagem podem ser diferenciados com base na altitude da plataforma, na resolução espacial da imagem e na frequência mínima de retorno para imagens sequenciais. A resolução espacial afeta a área do menor pixel que pode ser identificado. Conforme a resolução espacial melhora, a área do menor pixel diminui, e a homogeneidade das características do solo ou da plantação aumenta dentro do pixel. Resoluções espaciais pobres implicam pixels maiores com aumento de heterogeneidade das características do solo ou da plantação. A disponibilidade de imagens de sensoriamento remoto de plataformas de satélite ou aéreas são severamente limitadas pela presença de nuvens, enquanto que sensoriamentos terrestres são menos afetados por essa limitação. Quanto maior a resolução da imagem, mais espaço de armazenamento e capacidade de processamento são necessários.

No sensoriamento remoto, imagens aéreas tem vasto campo de aplicação em AP, e por serem obtidas de forma não-destrutiva e rápida têm se tornado de fundamental importância na obtenção e tratamento de dados do campo (SHIRATSUCHI et al., 2014). Podem ser utilizadas para medidas de radiação refletida ou emitida pelo solo ou pela planta, permitindo assim análises sobre o campo agrícola (MULLA, 2013). Outra aplicação é na determinação de esquemas ótimos de amostragem através de análises geoestatísticas com variogramas auxiliares (OLIVER, 2010a).

Imagens aéreas podem ser obtidas por meio de satélites, aeronaves tripuladas ou VANTs (Veículos Aéreos Não Tripulados). A escolha da forma de obtenção da imagem deve estar atrelada aos requisitos de custo e qualidade que a análise a ser realizada sobre determinada área requer. Além da resolução, a questão do momento (data e hora) em que a imagem foi obtida deve ser observada com atenção. A diferença entre ciclos e safras, ou até mesmo a diferença entre luminosidade ou da localização das sombras ao longo do dia, podem interferir na análise ocasionando interpretações e decisões incorretas. A questão meteorológica do instante em que a imagem foi obtida também deve ser observada, tal como a presença de nuvens. As imagens obtidas com o uso de câmeras embarcadas em veículos aéreos, tripulados ou não, traz como vantagem uma maior flexibilidade na escolha do horário de coleta e das condições climáticas, e, em geral, tem menor custo do que aquelas obtidas por satélite. As imagens obtidas por satélites e distribuídas gratuitamente, tal como feito pelo aplicativo Google ${ }^{\mathrm{TM}}$ Maps, traz como maior desvantagem o não controle sobre a data e a hora de sua obtenção. 
"Uma das primeiras aplicações dos dados obtidos remotamente tem sido a detecção de diferenças na refletância, relacionadas à densidade da cobertura vegetal" (SHIRATSUCHI et al., 2014). Os princípios básicos de refletância de folhas e plantações tem sido incorporado em índices vegetativos relacionando combinações de bandas específicas com várias características de planta (HATFIELD et al., 2008). Esses índices "são medidas radiométricas adimensionais, as quais indicam a abundância relativa e a atividade da vegetação verde" (JENSEN, 2009). Um índice vegetativo muito utilizado é o índice de vegetação por diferença normalizada (NDVI, do inglês Normalized Difference Vegetation Index), que é calculado a partir de combinações de faixas específicas de luz, entre elas a visível e a infravermelha.

Além de os índices vegetativos poderem ser obtidos a partir de imagens aéreas, ferramentas de sensoriamento proximal têm sido construídas sobre o princípio de que o conteúdo do pigmento afeta fortemente os espectros de absorção foliar (HATFIELD et al., 2008). Tradicionalmente, a análise de pigmentos é realizada através de métodos químicos para extração das folhas com solventes orgânicos e determinação espectrofotométrica em solução. Mais recentemente, têm sido utilizados métodos ópticos não destrutivos, mais econômicos e rápidos, e possíveis de serem realizados em campo, como alternativa para análise de pigmentos da folha (GITELSON et al., 2003). Refinamentos em instrumentos e desenvolvimento de relações entre refletância e respostas das plantas têm expandido a habilidade de quantificar parâmetros agronômicos (HATFIELD et al., 2008). Sensores de refletância usam a propriedade de que as plantas absorvem a luz visível e refletem uma porção da luz invisível devido a propriedades estruturais da planta. A luz refletida é detectada pelo sensor e utilizada para fazer os cálculos de biomassa vegetativa que é diretamente proporcional à biomassa da planta e, então, as medidas são apresentadas em formas de índices vegetativos (SHIRATSUCHI et al., 2014).

Outra metodologia muito usada em sensoriamento local é a medida de condutividade elétrica do solo, podendo ser realizada com equipamentos relativamente simples e com grande eficiência operacional (GASCUEL-ODOUX \& BOIVIN, 1994).

Por fim, tem ganhado destaque a utilização de sistemas de monitoramento que através de uma abordagem integrada de sistemas de sensoriamento unem dados de múltiplas plataformas (sensores sem fio, imagens aéreas e de satélites, estações climáticas em tempo real e sensores embarcados) (PHILLIPS et al., 2014). Peets et al. (2012) relata a utilização de métodos e procedimentos para gerenciar dados em um sistema FMIS, abordando conceitos sobre a coleta de dados e considerando parâmetros relacionados ao trator e ao desempenho da máquina, como velocidade e consumo de combustível (PEETS et al., 2012). 


\subsection{Geoestatística}

A geoestatística nasceu da necessidade em aplicações em minas e foi desenvolvida por Matheron (1963) com base teórica coerente de observações sobre estudos práticos desenvolvidos por Daniel G. Krige, buscando estabelecer modelos matemáticos para estimativas dos fenômenos geológicos observados. Matheron encontrou uma abordagem alternativa à determinística tradicional para sua análise, ele usou uma abordagem que pode lidar com a incerteza inerente dos dados espaciais de forma estocástica (OLIVER, 2010a). Desde 1980, a equipe liderada por Burgess e Webster (1980a; 1980b, 1984a; 1984b) tem trabalhado no desenvolvimento e na aplicação de teorias geoestatísticas em ciências do solo.

Ter disponível informação precisa sobre a variação dos atributos do solo e da plantação é decisivo para gerenciamento preciso na agricultura. Para possibilitar aplicações a taxa variada em AP é necessário que ocorra amostragem adequada e que exista um mapa preciso dos nutrientes das culturas. A geoestatística é capaz de predizer com acurácia os atributos do solo e da plantação para construção de mapas. Essa acurácia depende da qualidade da informação sobre o solo e a plantação. Muitas predições espaciais quantitativas e muitas interpolações para criação de mapas são feitas pelo método geoestatístico de precisão de krigagem, para a qual a estimação do variograma é um passo intermediário essencial. Além disso, para se estabelecer um variograma confiável, a geoestatística requer dados espacialmente dependentes, em quantidade suficiente e de qualidade (OLIVER, 2010b; OLIVEIRA et al., 2013; KERRY et al, 2010; WEBSTER el al., 2006).

Na estatística clássica as amostras são aleatórias e independentes. Já a geoestatística leva em consideração a dependência espacial das variáveis amostradas. A geoestatística permite a inferência de valores não observados a partir de valores observados em localizações espaciais conhecidas. Todos os métodos de interpolação assumem implicitamente que os dados são espacialmente dependentes, isso significa que a amostragem deve ser realizada em um intervalo que esteja de acordo com a faixa de correlação da variação espacial (WEBSTER \& OLIVER, 2007; OLIVER, 2010a).

A dependência espacial ocorre em dados de campos em que blocos adjacentes são mais similares entre eles do que entre outros blocos mais distantes. São relatadas duas fontes causadoras de variação: a autocorrelacionada (espacialmente dependente) e a randômica (espacialmente não dependente - efeito pepita). 
Uma variável regionalizada é dependente de sua posição espacial relativa. Pode ser definida como qualquer função numérica com uma distribuição espacial, que varia de um lugar a outro com continuidade aparente, mas cujas variações não podem ser representadas por uma função determinística. Em geologia, todas as observações quantitativas feitas em duas ou três dimensões (área ou volume), podem ser consideradas como exemplos de variáveis regionalizadas (GEOLIG, 2013).

$\mathrm{Na}$ agricultura, a variabilidade pode ser avaliada sobre a produtividade final, percebendo a existência de áreas de maior ou menor produtividade, ou sobre fatores que possam indicar formas de intervir na produtividade, percebendo diferenças entre plantas ou regiões do solo que se refletem em indicadores. Para uma boa amostragem algumas questões-chave sobre a variabilidade devem ser respondidas: como identificar a escala de variabilidade da área a ser explorada para determinar a densidade/espaçamento da amostragem? Qual o nível de precisão da variabilidade desejado que se busca identificar? E como identificar se a amostragem realizada é efetiva para representar o campo satisfatoriamente em uma análise futura? Teorias de geoestatística mostram fornecer as informações mais adequadas para responder tais questões.

Um estudo geoestatístico é composto por uma análise prévia de dados, com verificação de erros e da distribuição espacial dos dados (tendências e manchas), seguida por uma análise sobre a estacionaridade, a normalidade (distribuição Gaussiana) e a dependências dos dados. No estudo geostatístico deve ser realizada uma análise espacial utilizando-se o variograma experimental e o variograma teórico ajustado, para obtenção dos parâmetros do modelo do variograma. Por fim é realizada a estimação espacial, mais comumente realizada através de interpolação por krigagem (WEBSTER \& OLIVER, 2007).

\subsubsection{O variograma}

Variograma é a representação gráfica da 'função variograma' que é um modelo espacial que descreve como as variáveis mudam com o incremento da distância de separação (h). É a ferramenta básica da geoestatística, que permite descrever quantitativamente a variação no espaço de um fenômeno regionalizado. A Figura 1 representa um variograma típico e suas propriedades (OLIVER,2010b). 


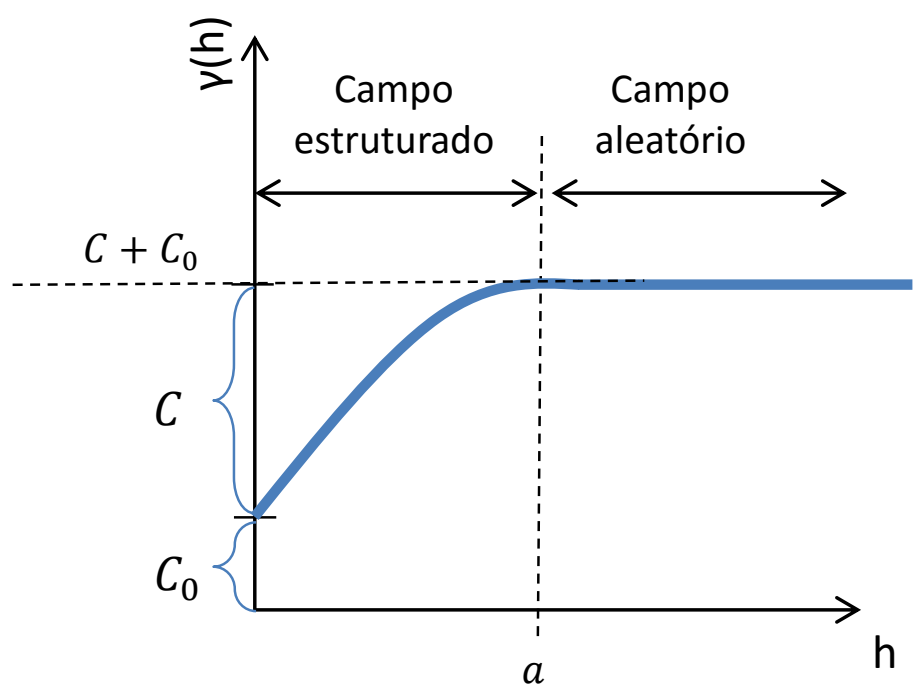

Figura 1. Variograma típico e suas propriedades.

Sendo:

- h: distância entre amostras (lag);

- $\gamma(h)$ : Variância - Representa a relação da variabilidade entre amostras em dependência da distância entre elas. Os pequenos valores de $\gamma(h)$ em pequenas distâncias $\mathrm{h}$ indica que as amostras são similares em pequenas distâncias entre elas, mas conforme a distância entre elas aumenta os valores se tornam cada vez mais dissimilares em média.

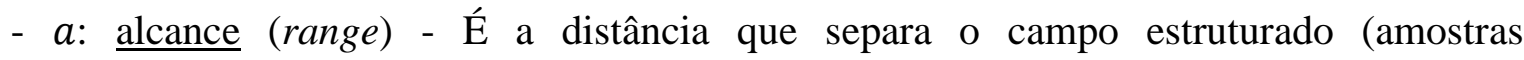
correlacionadas) do campo aleatório (amostras independentes). É a distância a partir da qual os pontos amostrais podem ser considerados independentes. Quanto maior for a distância, maior será a homogeneidade entre as amostras.

- $C+C_{0}$ : patamar (sill variance) - É o valor no qual o variograma estabiliza-se (no campo aleatório), ou seja, a partir desse patamar as amostras são independentes entre si. É a variância a priori do $\operatorname{processo}(\gamma(h))$.

- $C_{0}$ : efeito pepita (nugget) - é o valor da função variograma na origem $(\mathrm{h}=0)$. Deveria ser zero, pois duas amostras tomadas no mesmo ponto $(h=0)$ deveriam ter os mesmos valores. Em geral, atribui-se essa diferença a erros de amostragem devido à variabilidade natural do conjunto de amostras. É a variância aleatória.

- $C$ : variância espacial - É dada pela diferença entre o patamar e o efeito pepita. Representa a faixa de valores da variância para os quais existe correlação entre as amostras, desconsiderando o efeito pepita. 
Se o variograma de uma propriedade do solo em uma região pode ser estimado, então ele pode ser usado para estimar aquela propriedade sobre um bloco ou sobre um local não visitado, como uma combinação ponderada de valores observados, alcançando uma variância mínima sobre o erro (LARK, 2000). Mais detalhes sobre variogramas podem ser encontrados em Oliver (2010b).

Anisotropia é um fator que, em alguns casos, deve ser considerado, pois é uma característica qualitativa de variáveis regionalizadas e ocorre quando existe a presença de diferentes graus de variações dependendo da direção em que se toma as amostras, podendo ter variações graduais numa direção e rápidas ou irregulares em outra. A anisotropia está descrita matematicamente em McBratney et al. (1981).

\subsubsection{Variograma experimental}

O variograma experimental pode ser estimado a partir de dados empíricos. O Método de Momentos (MoM) de Matheron (1963) para estimação, é o método habitual para cálculo de semivariâncias empíricas dos dados $z\left(x_{1}\right), z\left(x_{2}\right), \ldots$. Sua equação é:

$$
\hat{\gamma}(h)=\frac{1}{2 m(h)} \sum_{i=1}^{m(h)}\left\{z\left(x_{i}\right)-z\left(x_{i}+h\right)\right\}^{2}
$$

onde $m(h)$ é o número de pares de pontos separados por uma distância $\mathrm{h}(\mathrm{lag}) ; z\left(x_{i}\right)$ é o valor da variável regionalizada no ponto $x_{i} ; z\left(x_{i}+h\right)$ é o valor da variável regionalizada no ponto $\left(x_{i}+h\right)$ (OLIVER, 2010b).

Além do MoM, o variograma experimental também pode ser analisado através de estudo dos componentes de variância, calculados através de Métodos de Verossimilhança (Maximum Likelihood - ML).

\subsubsection{Variograma teórico (fitting)}

Após o estudo inicial do variograma, o próximo passo é “ajustar” uma função matemática contínua para o variograma experimental. Isto permite que semivariâncias sejam calculadas para todas as distâncias entre pontos (h) nas equações de krigagem. Apenas algumas funções matemáticas são adequadas para este propósito e a escolha de um modelo de ajuste deve ser feito com cuidado (LARK, 2000). Entre os modelos mais comumente usados para este fim estão o esférico, exponencial, o circular e o gaussiano. 


\subsubsection{Amostragem}

Uma amostragem guiada por geoestatística não deve ser aleatória, pois a inferência estatística do variograma usa a estatística que considera o local específico da amostra e não apenas a aleatoriedade intrínseca. $\mathrm{Na}$ prática, cientistas geralmente usam algum tipo de amostragem sistemática para estimar o variograma, por exemplo, a distribuição de pontos em grades ou transectos. Alguns projetos são simples de implementar, mas, em algumas circunstâncias, pode-se desejar fazer um projeto mais elaborado para encontrar a melhor forma de amostragem, sendo evidente que algumas configurações de pontos amostrados serão melhores para estimar o variograma do que outras (LARK, 2002).

Todos os métodos de interpolação assumem implicitamente que os dados são espacialmente dependentes, isso significa que a amostragem deve ser realizada em um intervalo que esteja de acordo com a faixa de correlação da variação. A escala de amostragem deve levar em consideração a escala de variação e quantos pontos amostrados podem ser necessários para uma análise (KERRY et al., 2010).

Existem dois tipos de abordagens para amostragem que podem ser usadas para quantificar a variação espacial: a baseada em projeto (design-based) e a baseada em modelo (model-based). Amostragem e estimação baseada em projeto são domínios da estatística clássica e incluem projetos tais como amostragens aleatória, amostragem aleatória estratificada e amostragem aninhada. Amostragem e estimação baseadas em modelo são baseadas no variograma (PRICE et al., 2009).

Em geral, os métodos tradicionais de amostragem usam uma abordagem padrão, que não é suficiente para fornecer a quantidade necessária de dados para uma análise (KERRY et al., 2010).

"Projetos eficientes de esquemas de amostragem aleatória podem estimar quantidades totais ou médias de uma determinada variável em uma região. [..] Em muitos casos, no entanto, estimativas simples do total ou da média não são o desejado; muitos investigadores querem saber onde exatamente está presente a variável em questão, onde há deficiências em elementos ou concentrações excessivas de poluentes e químicos tóxicos em potencial. Para isso, o número total de amostras por si só é de pouca importância. O que importa é a densidade de amostragem em relação à escala espacial de variação. Qualquer região de interesse [...] tem suas próprias escalas espaciais de variação, e a amostragem deve ser suficientemente intensa para resolver a variação de lugar a lugar em uma ou mais escalas" (WEBSTER et al., 2006). 


\subsubsection{Quantidade de amostras}

A pesquisa de Webster e Oliver (1992), sobre amostragem em solo, aponta que a quantidade de amostras necessárias para construção de um variograma confiável é de, pelos menos, 100 amostras, sendo a quantia de 150 amostras satisfatória e que a quantia de 225 de confiança. Concluem que, pelo menos 100 amostras são necessárias para estimar um variograma confiável através de estimadores convencionais, mas para alguns campos agrícolas esse número pode ser muito pouco para resolver a variação presente se a escala é curta, enquanto que pode ser demais onde a escala é longa. Para chegar a esse resultado, na pesquisa foram realizadas comparações de estimativas da variância entre variogramas de amostras completas e de subamostras.

Kerry e Oliver (2007) mostraram que um variograma aceitável pode ser estimado a partir de 50 dados através de estimação por máxima verossimilhança residual.

Gascuel-Odoux e Boivin (1994) realizaram um estudo para analisar a precisão de análise geoestatística no que diz respeito à amostragem, particularmente quando o campo natural inclui a alternância entre áreas ricas e pobres. Os resultados apontam que o erro quadrático médio (mean squared error - MSE) sobre variogramas diminui significantemente para subamostras contendo acima de 1e pontos, e que um parâmetro único de qualquer modelo é mais precisamente estimado com 200 pontos. Concluem que o efeito do tamanho da amostra pode ser considerado fraco, se apenas o passo final da krigagem está envolvido, e que deve ser analisado também o efeito da escolha do sistema de amostragem (não só de estimativa de variogramas de amostragem), mas principalmente os modelos de ajuste (fitted models) e os cálculos geoestatísticos baseados em tais modelos, como a krigagem.

Kerry e Oliver (2004) afirmam que o intervalo no qual o solo é amostrado deve estar relacionado com a escala de variação espacial e utilizaram variogramas médios padronizados para determinar intervalos de amostragem ideais usando equações de krigagem.

\subsubsection{Variabilidade espacial e escala espacial de amostragem}

A variabilidade espacial pode ocorrer em escalas que diferem em diversas ordens de magnitude simultaneamente. Isto porque os processos físicos que criam o padrão de variação operam e interagem em diferentes escalas espaciais. Assim em qualquer região pode haver diversas fontes de escalas de variabilidade presentes (OLIVER \& WEBSTER, 1986). Propriedades do solo e das culturas podem variar acentuadamente em diferentes escalas 
espaciais, tanto dentro, como entre campos. Portanto, é essencial que a escala espacial de variação seja utilizada para guiar o projeto um esquema de amostragem (KERRY et al., 2010).

Ribeiro Jr afirma que "muitos associam a escala espacial de variabilidade com a distância a partir da qual os pontos amostrais podem ser considerados independentes (alcance prático). [...] Se todos os pontos amostrais forem mais distantes do que o alcance prático, então não haverá dependência espacial detectada e o mapa de predição terá um único valor constante para toda a área" (informação pessoal) ${ }^{1}$.

Amostragens muito espaçadas, maiores do que a faixa da dependência espacial, podem conduzir a variogramas 'fracos'. A consequência é que nada é aprendido sobre a estrutura espacial subjacente e não há sentido na tentativa de interpolação de dados nessas circunstâncias. Esse é uma das deficiências recorrentes em levantamento de dados. Já amostragens muito densas, com intervalos tão curtos que garantam que os dados resultantes sejam espacialmente dependentes, recaem no problema do alto custo das medições sobre o material colhido, tanto em campo, como em laboratório (WEBSTER et al., 2006).

Se o intervalo de amostragem for menor do que um décimo da faixa do variograma, provavelmente se estará desperdiçando esforços e gastando mais do que o necessário para alcançar o objetivo (WEBSTER et al., 2006). Também é sabido que não se pode obter boas estimativas do variograma para distância entre pontos (h) maiores do que metade da maior distância entre pares sobre a grade de amostragem, sendo estas considerações a base da regra de ouro (rules-of-thumb) para ser usado no planejamento de amostragem (LARK, 2002).

É necessária uma amostra que permita comparações ao longo de intervalos grandes, pequenos e intermediários em relação à escala da variação espacial (LARK, 2002). Ou seja, deve haver alguma densidade de amostragem intermediária que permita estimar o variograma mais economicamente. A questão é como descobrir essa densidade (WEBSTER et al., 2006).

Portanto, um estudo inicial da escala espacial e a estrutura da variação de uma propriedade de interesse no campo é necessário para permitir uma amostragem em uma intensidade apropriada para estimar o variograma precisamente (PRICE et al., 2009).

\section{Índices de oportunidade}

Oliveira et al. (2012) descrevem o índice de oportunidade para caracterizar a variabilidade espacial do solo utilizando técnicas quantitativas. O índice de oportunidade é utilizado para avaliar o potencial de uso das informações como apoio à decisão e à adoção de tecnologias em

\footnotetext{
${ }^{1}$ RIBEIRO Jr, Paulo Justiniano. Mensagem de e-mail recebida em 7 de abril de 2014.
} 
taxa variável que favoreçam o Manejo por Sítio-Específico (Site Specific Management). O modelo matemático está proposto em Oliveira (2009) e validado em Oliveira et al. (2011).

\subsubsection{Variogramas guiando a amostragem}

Para a construção de um mapa através de krigagem (interpolação) é necessário que exista um variograma estimado sobre amostras da região. Esse variograma deve ser confiável de forma que possibilite que o erro das estimativas de krigagem seja limitado a valores aceitáveis. Ou seja, a amostra da área a ser reproduzida em mapa deve ter qualidade suficiente em relação à quantidade e localização dos pontos amostrados para a construção de um variograma confiável.

No caso em que não exista nenhuma informação inicial sobre a variabilidade espacial do campo a ser amostrado, levantamentos e análises exploratórios podem fornecer uma primeira aproximação para o variograma. Essa aproximação pode ser usada para determinar a escala aproximada de variabilidade espacial e um intervalo de amostragem adequado para planejar um levantamento mais detalhado (SCHUELLER, 2010; KERRY et al., 2010; LARK, 2002).

O variograma pode ser usado para determinar um plano de amostragem apropriado ou de um intervalo para amostragem em grade:

"1 - Na ausência de qualquer informação prévia sobre a escala de variação espacial e na ausência de sinais visíveis de variação na propriedade de interesse, um levantamento e uma análise aninhados podem proporcionar uma primeira aproximação ao variograma. Esta aproximação pode então ser usada para determinar um intervalo de amostragem adequado para uma pesquisa mais detalhada.

2 - Na ausência de variogramas existentes de propriedades de solo ou planta e a propriedade de interesse aparece relacionada a dados auxiliares, tais como os de sensoriamento remoto ou próximo, modelos digitais de elevação, etc., estes podem ser usados para calcular variogramas que permitem avaliar a dimensão espacial aproximada de variação e o intervalo de amostragem adequado.

3 - Se variogramas de propriedades do solo ou planta estão disponíveis, eles podem ser usados para determinar quantos núcleos de solos ou de amostras de plantas devem ser tomados ao longo de um suporte para formar amostras de compósitos para análises laboratoriais.

4 - Se há variogramas de propriedades do solo ou da planta de levantamentos anteriores, eles podem ser usados com as equações de krigagem para determinar um intervalo de amostragem ideal, para um levantamento em grade futuro e com um erro tolerável específico para evitar excesso ou sub amostragem. Variogramas existentes também podem ser usados com a regra de ouro da metade da faixa.

5 - Se a escala de variação é larga e há entre 50 e 100 amostras, um variograma pode ser estimado por máxima verossimilhança residual e pode ser usado para realizar krigagem sobre os dados de uma amostra pequena, mas espacialmente dependente. Alternativamente, variogramas existentes de dados auxiliares, de propriedades do solo ou da planta, podem ser usados para calcular variogramas 
médios padronizados para realizar krigagem sobre os dados esparsos que foram normalizados" (KERRY et al., 2010).

Também deve-se levar em consideração a questão de como a disposição dos pontos amostrados pode ser otimizada para o propósito de estimar o variograma de tal forma que um número relativamente pequeno de amostras possa ser usado mais eficientemente (LARK, 2002).

\section{Regra de ouro}

Variogramas calculados a partir de dados auxiliares podem ser usados para determinar a dimensão aproximada de variação espacial, e então serem utilizados para orientar a amostragem baseado na "regra de ouro" (rule of thumb). A "regra de ouro" que diz que um intervalo menor do que a metade da faixa de dependência espacial (alcance do variograma) pode determinar um intervalo de amostragem ideal para alcançar um erro tolerável (KERRY et al., 2010).

\subsubsection{Amostragem em fases}

Mcbratney et al. (1981) e McBratney e Webster (1981), esquematizaram um roteiro para uma estratégia de amostragem ideal em grade, baseada na teoria de variáveis regionalizadas e variogramas, assumindo que o erro padrão máximo de uma estimativa de krigagem é uma medida razoável da qualidade do sistema de amostragem.

Em seu esquema para amostragem em grade, McBratney el al. (1981) e McBratney e Webster (1981), mostraram como variogramas e equações de krigagem podem ser utilizados para determinar um intervalo ideal de amostragem para predição por krigagem antes de se obter novos dados em uma exploração. A base de sua abordagem é que os pesos de krigagem, e também as variâncias de krigagem dependem da configuração dos pontos de amostragem em relação ao ponto alvo e ao variograma. Se há uma função variograma de uma exploração anterior de um campo, então pode-se determinar os erros de krigagem para qualquer tamanho de grade antes da amostragem, o que torna possível a otimização da amostragem através de esquemas com a tolerância ou precisão especificadas (KERRY et al., 2010).

Assim, McBratney et al. (1981) e McBratney e Webster (1981), sugeriram que o variograma pode ser aproximado a partir de um levantamento prévio da propriedade alvo do solo em tipos de solos parecidos ou estimado a partir de um levantamento exploratório, e que o levantamento principal deveria consistir de medidas feitas em grade regular com espaçamento escolhido para garantir que a variância de krigagem no centro de cada célula da grade seja inferior a algum 
limite especificado (MARCHANT \& LARK, 2010). Em trabalho posterior, McBratney e Pringle (1999) propõem variogramas médios e proporcionais estimados por propriedades do solo, concretizando a ideia de 1981. No roteiro proposto por McBratney et al. (1981) e McBratney e Webster (1981), a estratégia consiste em decisões (D), cálculos (C) e trabalho de campo (F), como descrito no Quadro 1.

D1 - Escolha o erro máximo permitido $\sigma_{\mathrm{kmax}}$ e tamanho do bloco.

D2 - Decida o nível de informação pré-levantamento exigida.

a) Se o semi-variograma é conhecido ou pode-se inferir, então, vá para C3.

b) Se a escala de variação é conhecida ou pode ser inferida, então vá para D3.

c) Senão, nada se sabe ou pode-se inferir sobre a variável na região de interesse e a escala de variação em primeiro lugar devem ser obtidas usando F1 e C1.

F1 - Obter a escala de variação usando um design aninhado (nested design) (Youden e Mehlich, 1937)

C1 - Calcular semi-variograma não direcional para design aninhado (Miesch, 1975).

D3 - Escolha intervalo de amostragem transecto (transversal) a partir do semi-variograma não direcional e predetermine $\sigma_{K \max }^{2}$, lembrando que esse intervalo de amostragem deve ser consideravelmente menor do que o espaçamento da grade final para se obter um semi-variograma experimental útil.

F2 - Amostre tranversalmente em 3 ou mais direções com pontos de partida aleatoriamente localizados.

C2 - Calcule o semi-variograma experimental e ajuste um modelo.

C3 - Obtenha o espaçamento de grade $a$ para uma direção de máxima variação $\phi$ usando o método descrito anteriormente (MCBRATNEY et al., 1981) para as duas grades triangulares e quadradas. 0 espaçamento da grade na direção $\phi+\pi / 2$ é $r a$, onde $r$ é a razão de anisotropia. Se o semivariograma é isotrópico, a grade pode ser orientada em qualquer direção e os espaçamentos da grade são iguais em ambas as direções.

D4 - Escolha a amostra em uma grade triangular ou quadrada. Apenas em circunstâncias excepcionais a vantagem da grade triangular sobrelevará os inconvenienties da viagem extra, localização e manuseio do computador.

F3 - Amostre na direção da grade $\phi$ rad com espaçamento $a$ e $\phi+\pi / 2$ rad com espaçamento $r a$.

Quadro 1. Roteiro para uma estratégia de amostragem ideal (MCBRATNEY et al.,1981).

Marchant \& Lark (2006) também propõem uma modelo de exploração realizada em etapas, baseado em uma abordagem adaptativa para otimizar explorações de prospecção. As observações dessa exploração de prospecção são coletadas em diferentes fases. Após cada fase, uma função de densidade de probabilidade da densidade de amostragem exigida da exploração principal é calculada dentro de um enfoque Bayesiano. O número e localização das observações dentro de outras fases são selecionados para reduzir de forma eficiente a incerteza da estimativa da densidade de amostragem necessária. As observações são analisadas on-line de tal modo que o número e localização das observações em um levantamento de prospecção pode ser otimizado para determinada variável sendo explorada, desde que seja passível de levantamento multifases. O intervalo do levantamento principal pode ser selecionado a partir de levantamentos de 
prospecção de modo que garanta, com uma confiança pré-especificada, que o limiar da variância de krigagem é cumprido. A abordagem adaptativa Bayesiana garante que o número de observações é adequado para a variável sendo explorada. O algoritmo também garante que as localizações são escolhidas de forma a utilizar esse número de observações de forma mais efetiva.

\subsubsection{Levantamento aninhado}

O variograma, quando é desconhecido antes da amostragem, pode ser inferido a partir de um levantamento de prospecção antes que uma exploração eficiente seja projetada. Os resultados dos levantamentos de prospecção estão sujeitos à incerteza, que depende do variograma e do número e da localização das observações (MARCHANT \& LARK, 2006).

O variograma convencional em geoestatística pode distinguir a variação espacial em uma ou mais escalas espaciais simultaneamente, mas raramente mais. No entanto, até que se saiba aproximadamente quais escalas são essas, não é possível projetar um esquema de amostragem que irá garantir que é possível estimar o variograma sensatamente. Além disso, a variação pode derivar a partir de duas ou mais fontes com escalas espaciais abrangendo várias ordens de magnitude. O objetivo é ser capaz de estimar as contribuições para a variância a partir de todas as distâncias desde a menor probabilidade de interesse até a maior. Isso pode ser feito por amostragem espacialmente aninhada (nested survey), seguida por uma análise hierárquica de variância (WEBSTER et al., 2006).

O levantamento aninhado é vantajoso quando há poucas ou nenhuma pista da escala espacial de variação na propriedade de interesse e os custos de gerenciamento são grandes, possibilitando que várias ordens de magnitude da escala espacial sejam examinadas em uma simples análise para determinar a escala aproximada de variação com não mais do que aproximadamente 108 amostras (KERRY et al., 2010).

O levantamento aninhado permite que várias magnitudes de escala espacial sejam investigadas em uma simples análise. Isso deriva de um modelo de variação aninhada, que é baseado na noção de que a população pode ser dividida em classes de dois ou mais níveis em uma hierarquia (PRICE et al., 2009). A população pode, então, ser amostrada com um esquema aninhado para estimar a variância em cada estágio, isto é, os componentes de variância. O 
componente individual para um dado estágio mede a variação atribuível a aquele estágio, e os componentes somam a variância total (KERRY et al., 2010). Os componentes de variância para cada espaçamento a partir dessa análise revelam sobre qual parte escala espacial a maioria das variações ocorrem (WEBSTER et al., 2006; WEBSTER \& OLIVER, 2007).

Os resultados de uma análise hierárquica de variância a partir de uma amostragem aninhada podem fornecer uma primeira aproximação para o variograma, traçando os componentes acumulados de variância para cada intervalo de amostragem contra o aumento da distância de separação (OLIVER \& WEBSTER, 1986; WEBSTER et al., 2006; WEBSTER \& OLIVER, 2007; PRICE et al., 2009).

Esse variograma aproximado pode indicar a faixa de escalas espaciais sobre a qual a maior parte da variação ocorre, tornando-se uma valiosa ferramenta de prospecção e essa informação pode ser usada para guiar a amostragem para uma exploração completa ou para obter um variograma mais preciso. As amostras da análise aninhada podem ser integradas com as amostras posteriores, desde que o intervalo de tempo de amostragem não seja muito grande para as propriedades da variável (KERRY et al., 2010).

Embora o levantamento aninhado seja baseado em projeto, os resultados da análise hierárquica da variância fornecem uma ligação entre estas duas abordagens de amostragem (baseada em projeto e baseada em modelo) (PRICE et al., 2009).

Explicações mais detalhadas sobre a construção de levantamentos aninhados podem ser encontradas em Oliver \& Webster (1986), Webster et al. (2006), Webster \& Oliver (2007) e Price et al. (2009).

\section{Amostragem balanceada}

A ideia sobre essa técnica é que uma população de unidades no campo pode ser dividida em classes em dois ou mais níveis ou estágios categóricos de forma hierárquica. Em cada estágio a população é subdividida em classes consistindo de unidades que são geograficamente próximas umas das outras. A população é primeiro dividida em classes no nível mais alto (estágio 1), cada uma dessas classes é subdividida em subclasses no nível abaixo (estágio 2), e assim em diante até que as subdivisões sejam as menores de interesse no estágio $m$ - 1 . Pontos são selecionados aleatoriamente dentro dessas subdivisões finas, e é nestas que o material de interesse é medido para fornecer o dado no nível mais baixo (estágio $m$ ). Em cada caso, a classe no nível mais baixo está contida completamente dentro daquela imediatamente acima dela, e cada ponto de amostragem está contido em uma e apenas uma classe em cada um e todos os níveis. Os projetos de amostragem são chamados completamente balanceados quando todas as 
classes em cada estágio particular são subdivididas igualmente, dessa forma, o tamanho da amostra dobra a cada estágio adicional (WEBSTER et al., 2006; WEBSTER \& OLIVER, 2007).

\section{Amostragem desbalanceada}

Oliver e Webster (1986) mostraram que a replicação total em cada estágio não é necessária e descreveram a aplicação de uma análise aninhada hierárquica desbalanceada, que pode trazer economia ao se replicar apenas uma parte dos centros amostrados em um ou mais estágios (PRICE et al., 2009; KERRY et al., 2010).

Webster \& Oliver (2007) explicam que para que se atinja uma boa resolução espacial, podem ser necessários muitos estágios no esquema balanceado, resultando em uma amostragem proibitivamente cara para prospecção. Quando isso acontece, a replicação completa em cada etapa é desnecessária porque os quadrados médios para cada estágio mais baixo são estimados mais precisamente do que para aqueles mais altos.

Em geral, a aproximação desbalanceada pode ser preferível em AP porque mais estágios podem ser usados com menos esforço de amostragem” (KERRY et al., 2010).

\section{Estimação de componentes de variância}

Os componentes de variância podem ser estimados pelo MoM a partir de uma Análise Hierárquica de Variância (Hierarchical Analysis of Variance) (ANOVA) e também podem ser estimados por métodos de ML. Convencionalmente, os variogramas são estimados com modelos ajustados em dois estágios separados através do MoM, e geralmente através do uso de tabelas ANOVA (MARCHANT \& LARK, 2006).

Os componentes estimados a partir de ANOVA tendem a ser estimativas bastante imprecisas das verdadeiras semivariâncias porque cada uma é geralmente baseada em alguns graus de liberdade, especialmente para os primeiros dois ou três estágios, e eles não consideram a anisotropia. Também se deve ter em conta que eles não são inteiramente independentes um do outro, e a variação em diferentes direções não pode ser distinguida (WEBSTER \& OLIVER, 2007).

Pardo-Igúzquiza e Dowd (1998) sugeriram que modelos de variogramas sejam ajustados diretamente de observações por ML. Uma vantagem da ML é que não há necessidade de guardar as distâncias entre pontos (h) em classes e, portanto, não há riscos de que a informação espacial possa ser perdida por excessiva suavização do variograma estimado (MARCHANT \& LARK, 2006). 
A estimação por ML dos componentes de variância calcula a verossimilhança do dado e então usa os estimadores dos parâmetros que maximizam o log-verossimilhança (loglikelihood). Os estimadores de ML dos componentes de variância são tendenciosos em pequenas amostras e subestimam os valores verdadeiros. A tendência ocorre porque os graus de liberdade fixos não são removidos antes que os componentes sejam estimados. Por esta razão, Patterson e Thompson (1971) desenvolveram o método de Máxima Verossimilhança Residual (Residual Maximum Likelihood - REML), algumas vezes chamado Máxima Verossimilhança Restrita (Restricted Maximum Likelihood), que ajusta para degraus de liberdade fixos antes da estimação da variância dos parâmetros (WEBSTER et al., 2006).

Lark (2000), Webster el al. (2006), Kerry e Oliver (2007) e Price et al. (2009), entre outros, realizaram estudos comparativos entre os diferentes métodos de cálculo de variogramas (ANOVA, ML e REML). Seus resultados indicam que:

- para esquemas balanceados, o ANOVA e o REML fornecem os mesmos resultados, mas para os desbalanceados em geral não;

- o método REML é preferível para explorações aninhadas desbalanceadas porque fornecem um resultado único, enquanto que existem diversos métodos para construir tabelas ANOVA, resultando em estimativas não necessariamente únicas;

- menor quantidade de dados é necessária para calcular um variograma fiável utilizando uma abordagem de ML, tal como o REML, por causa da eficiência do método, no entanto, os resultados podem variar de acordo com a natureza da variação espacial.

- os métodos ML e, mais frequentemente, o REML são preferidos porque estes estimadores têm propriedades de que em amostras muito grandes eles são imparciais e com variância mínima.

\subsubsection{Krigagem}

Krigagem é um método de regressão usado em geoestatística para aproximar ou interpolar dados, assumindo que existe correlação espacial entre eles, e se refere a fazer inferências sobre valores não observados a partir de dados observados em localizações espaciais conhecidas (OLIVER, 2010a). 
A krigagem, depende da existência de variogramas precisos e dados espacialmente dependentes dos quais se faz a predição. Todos os métodos de interpolação assumem implicitamente que os dados são espacialmente dependentes, isso significa que a amostragem deve ser realizada em um intervalo que esteja de acordo com a faixa de correlação da variação espacial (KERRY et al., 2010).

Se o variograma de uma propriedade do solo em uma região pode ser estimado, então, ele pode ser usado para estimar aquela propriedade sobre um bloco ou sobre um local não visitado, como uma combinação ponderada de valores observados, alcançando uma variância de erro mínima (LARK, 2000).

\subsubsection{Indicadores de qualidade}

Em um questionamento sobre se existe algum valor, algum critério ou alguma função que indique quando uma dada amostragem tem qualidade satisfatória, Ribeiro Jr afirma que "é impossível dizer assim, porque talvez haja recomendações genéricas na literatura, mas possivelmente vagas se dentro de cada contexto, dependendo de vários fatores, tais a precisão desejada, o padrão de dependência espacial, alocações dos pontos amostrais e restrições práticas. A amostragem espacial vai certamente refletir algum compromisso entre qualidade desejada da estimação e possibilidade de obtenção de dados" (informação pessoal) ${ }^{2}$.

A seguir são descritos alguns métodos encontrados na literatura para avaliação da qualidade da amostragem.

"McBratney el al. (1981) e McBratney e Webster (1981) mostraram como o variograma e equações de krigagem podem ser usadas para determinar um intervalo ideal de amostragem para predição por krigagem antes de obter novos dados de uma exploração. A base de sua abordagem é que os pesos de krigagem, e também as variâncias de krigagem dependem da configuração dos pontos de amostragem em relação ao ponto alvo e ao variograma. Eles não dependem dos valores observados nesses pontos. Se há uma função variograma de uma exploração anterior de um campo, então pode-se determinar os erros de krigagem para qualquer tamanho de grade antes da amostragem. É possível otimizar a amostragem através do projeto de um esquema para encontrar uma tolerância ou precisão específica. Embora uma grade triangular seja mais eficiente, grades quadras ou retangulares são preferidas porque são mais fáceis de implementar, e na prática há uma pequena diferença na precisão entre elas" (KERRY et al., 2010).

A amostragem pode ser otimizada de vários modos, dependendo da função objetivo escolhida para minimizar ou maximizar as restrições impostas. Por exemplo, é possível minimizar a variância de krigagem média através da região de estudo, dando um tamanho de

\footnotetext{
${ }^{2}$ RIBEIRO Jr, Paulo Justiniano. Mensagem de e-mail recebida em 7 de abril de 2014.
} 
amostra fixo. Na prática, é possível haver um interesse maior em encontrar o tamanho de amostra de tal forma que uma variância de krigagem alvo através da região de estudo seja alcançada apenas quando uma amostra desse tamanho é distribuida de forma otimizada. Neste caso, o custo de amostragem é minimizado para que se atinja as previsões da precisão desejada (MARCHANT \& LARK, 2010).

Gascuel-Odoux \& Boivin (1994) realizaram uma avaliação do tamanho da amostra necessária para obter estimativas precisas da salinidade do solo através de subamostragem de um conjunto de dados. Para cada tamanho de subamostra, realizaram uma análise através de cálculos com MSE dos variogramas das subamostras relativas ao "variograma da amostra real", e de modo semelhante a modelos ajustados. Para finalizar, estudaram o efeito dessa incerteza comparando as estimativas de krigagem com os valores observados. Indicaram que o método de amostragem simples utilizado e os critérios de MSE funcionaram satisfatoriamente para avaliar a precisão de análises geoestatística no que diz respeito à amostragem, particularmente quando o campo natural inclui a alternância de áreas ricas e pobres. Porém, a raiz do erro quadrático médio (root mean squared error - RMSE) devido à amostragem diminui de uma etapa a outra na análise geoestatística, de modo que o efeito do tamanho da amostra pode ser considerado como fraco, se apenas o passo final da krigagem está envolvido. Além disso, o estudo apontou o interesse na análise do efeito da escolha do sistema de amostragem, não apenas na estimação de variogramas de amostragem, mas principalmente em modelos ajustados (fitted models) e em cálculos geoestatísticas baseados em tais modelos, como a krigagem.

Segundo Kerry et al. (2010), para um variograma MoM há um aumento acentuado no MSE, conforme o intervalo de amostragem aumenta e a taxa de desvio quadrático médio (mean squared deviation ratio - MSDR), é inferior a 1. Para o variograma estimado por REML o aumento em MSE com o aumento do intervalo de amostragem é menos nítido. O MSDR para algumas sub-amostras e o estimador REML gira em torno de 2, o que mostra que a variância de krigagem (kriging variance) é subestimada pelo modelo relevante. O MSE, no entanto, indica que o tamanho da amostra afeta menos os variogramas estimados por REML e como consequência há menos perda na precisão nas predições. Este resultado tem importantes implicações para AP porque, em geral, os agricultores não podem se dar ao luxo de amostrar intensivamente.

McBratney et al. (1981) assumem que o erro padrão máximo de uma estimativa de krigagem é uma medida razoável da qualidade do sistema de amostragem.

Lark (2011) fala sobre funções objetivo para otimização. A função objetivo é "baseada sobre a matriz de covariância esperada para erros nas estimativas dos componentes de variância, 
e assim depende do que são estes componentes". Lark (2011) cita funções que podem ser usadas, tais como: a variância da estimação dos componentes de variância, ou pode-se minimizar a variância de estimação de algumas combinações dos componentes de variância de interesse particular, ou dar maior ou menor peso para a variância de estimação em escalas particulares.

Van-Groenigen (2000) apresentou dois critérios de otimização para esquemas de amostragem espacial, ambos lidando com otimizar a qualidade do interpolador por krigagem e utilizando o Spatial Simulated Annealing (SSA). Os critérios apresentados foram a variância média de krigagem e a variância máxima de krigagem. Van-Groenigen relata que minimizar a variância média de krigagem resulta em diferentes esquemas de amostragem daqueles que minimizam a variância máxima de krigagem, sendo que esquemas de amostragem que minimizam a variância máxima de krigagem resultam em observações muito próximas das bordas da área, o que é comum em levantamento de solos. Van-Groenigen conclui que, embora a variância de krigagem seja uma indicação valiosa da precisão da previsão quando a hipótese intrínseca detém, a natureza específica das pesquisas espaciais pode requerer outros critérios de otimização.

Toda discussão de amostragem geoestatística encontrada até agora assume que a variância de krigagem alvo para predições pode ser facilmente especificada. Segundo Marchant \& Lark (2010) essa afirmativa requer mais atenção no contexto de AP, levantando questionamentos sobre se o aumento do esforço na amostragem irá reduzir a variância de krigagem média ao longo de um campo; e em que ponto o custo de um esforço extra atinge o benefício da melhoria das previsões? A resposta a esses questionamentos depende:

\begin{abstract}
"da forma de uma função de perda que descreve como o custo para o agricultor da incerteza sobre o valor de uma propriedade em algum local depende da variância prevista da propriedade naquele local. Que depende, por sua vez, dos custos associados com a sobre- ou sub-aplicação de um insumo em qualquer localização, e assim nos custos dos insumos, respostas da cultura, preços da safra e custos de externalidades (tal como poluição devido a aplicação excessiva de fertilizantes ou pesticidas). Tal modelo sofisticado de decisão é necessário como base para a gestão racional de amostragem em AP, e para plena exploração do poder de abordagens geoestatísticas para amostragem e predição" (MARCHANT \& LARK, 2010).
\end{abstract}

\title{
Loglik, AIC e BIC
}

Em uma inferência clássica, a função verossimilhança (likelihood) é considerada como uma função de variáveis não aleatórias, já em uma inferência Bayesiana, é considerada como uma função de variáveis aleatórias (DIGGLE \& RIBEIRO Jr, 2007). 
Para muitas aplicações que envolvem funções de verossimilhança é mais conveniente trabalhar com o logaritmo natural da função de verossimilhança, o log-verossimilhança (loglikelihood). Encontrar o máximo de uma função muitas vezes envolve tomar a derivada de uma função e resolver para o parâmetro a ser maximizado, e isso muitas vezes é mais fácil quando a função a ser maximizada é um log-verossimilhança, porque o logaritmo é uma função monotonamente crescente, o logaritmo de uma função atinge o seu valor máximo nos mesmos pontos da própria função.

Se uma boa estimativa para a log-verossimilhança puder ser obtida através dos dados observados, esta estimativa poderá ser utilizada como critério para comparar modelos.

O Critério de Informação Akaike (Akaike Information Criteria - AIC) é uma medida da qualidade relativa de um modelo estatístico para um certo conjunto de dados.

$$
A I C=-\ln (L)+2 \cdot p
$$

onde $L$ é a função de verossimilhança maximizada e $p$ é o número de parâmetros.

O Critério de Informação Bayesiana (Bayesian Information Criteria - AIC) é dado por:

$$
B I C=-\ln (L)+p \cdot \log (n)
$$

onde $n$ é o número de dados.

Por definição, os indicadores loglik, AIC e BIC, devem ser usados comparativamente, ou seja, a indicação de qualidade está atrelada à comparação entre diferentes amostragens com os indicadores dizendo qual é a melhor entre elas. 
3 Materiais 


\subsection{Conjuntos amostrais}

Para realizar a validação do método proposto, foram utilizados dois diferentes tipos de amostras, relatadas detalhadamente a seguir. O primeiro conjunto amostral é formado por dados de simulação, e o segundo conjunto é formado por dados reais obtidos com sensoriamento embarcado. Os dois conjuntos foram obtidos sobre áreas de mesma coordenada, mas dimensões diferentes.

\subsubsection{Conjunto amostral I}

Num primeiro momento e buscando uma validação inicial do método, era desejável utilizar dados que apresentassem variabilidade perceptível. Para tanto, foi feita a escolha pela utilização de dados simulados que garantissem a análise da variabilidade, mas sem uma preocupação inicial de que esses dados representassem situações reais.

\section{Dados de imagens}

Informações retiradas de imagens no padrão RGB foram utilizadas de forma a permitir a representação de variabilidades fazendo referência a variações de tons de cores entre pixels. A cada pixel de uma imagem é atribuído um valor no padrão RGB, cores ou tons diferentes são obtidos através da variação dos valores da escala RGB. As imagens utilizadas para formar o Conjunto Amostral I foram configuradas para a representação da escala de níveis de cinza (NC), a partir de uma adaptação do padrão RGB. A escala de níveis de cinza utilizada varia de 0 a 255 , indicando tons que variam de mais escuros a mais claros, respectivamente. Cada pixel foi considerado como equivalentes à leitura de um dado de sensor, e assim, diferentes níveis de cinza representam diferentes valores de amostra.

Por exemplo, a imagem da Figura 2 é formada por 4 pixels com os valores 50, 100, 150 e 200, referentes à escala de níveis de cinza. 


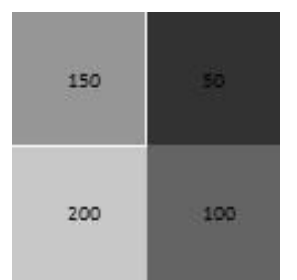

Figura 2. Representação de pixels como dados de sensores

\section{Imagens aéreas}

Para obtenção do Conjunto Amostral I, foram utilizadas imagens de satélite obtidas a partir do aplicativo Google ${ }^{\mathrm{TM}}$ Maps.

O Google fornece gratuitamente imagens de satélite através do Google ${ }^{\mathrm{TM}}$ Maps utilizando a aplicação "Static Maps API V2" (GOOGLE, 2014). Esse aplicativo permite que, por meio da inserção da coordenada geográfica central do local desejado através de um endereço web (URL) em forma de código, seja feito o download da imagem.

Por exemplo, A imagem representada na Figura 3 e possui coordenada central formada pela latitude -21,396538 e pela longitude -48.288185. A imagem possui 640 pixels na vertical e 640 pixels na horizontal, sendo que cada pixel é equivalente a 1,1023 m (parâmetro de configuração do Google ${ }^{\text {TM }}$ Maps para nível de zoom igual a 17).

\section{Área I}

A imagem representada na Figura 4, cuja área foi denominada como Área 1, foi escolhida como imagem padrão para formar o Conjunto Amostral I para os testes. Tal imagem foi escolhida por apresentar regiões com diferentes intensidades de variabilidade que a tornam interessante nos estudos para o desenvolvimento do método, lembrando que não foi preocupação, neste momento do estudo, a fidelidade dos dados simulados com a realidade. A Área I é um quadrado, com aproximadamente $14163 \mathrm{~m}^{2}$ (1,41 ha), com largura máxima de 118,3 m e comprimento máximo de 118,3 m.

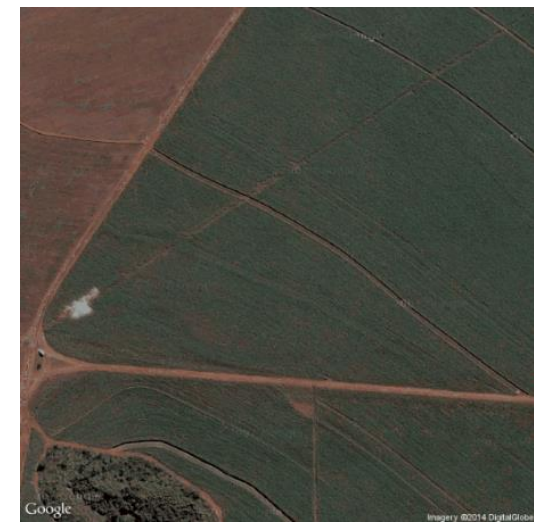

Figura 3. Imagem aérea obtida no Google ${ }^{\mathrm{TM}}$ Maps

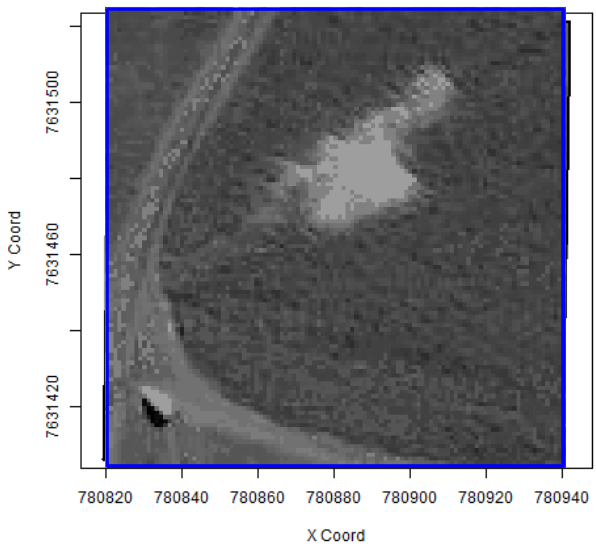

Figura 4. Imagem da Área I que compõe o Conjunto Amostral 1. 


\subsubsection{Conjunto amostral II}

Após validação inicial do método utilizando dados simulados, deu-se enfoque para a validação utilizando dados reais e coletados a partir de sensores embarcados para formar o Conjunto Amostral II. Nesta etapa, foram utilizados dados de sensores de refletância e sensores de condutividade. Tais dados foram coletados em amostragem prévia, sendo utilizados no trabalho de forma a simular uma coleta em tempo real.

Os dados de sensores do Conjunto Amostral II foram obtidos em experimentos realizados pela Embrapa Instrumentação, com sede em São Carlos, e gentilmente cedidos para realização de parte deste trabalho.

\section{Sensor de refletância}

Como sensor de refletância foi utilizado o sensor Crop Circle, da Holland Scientific (HOLLAND, 2011), que fornece informações sobre refletância através dos índices NDVI e NDRE (Normalized Differrence Red Edge) e informações de altitude. O modelo Crop Circle ACS-210 utilizado é um sensor ativo de refletância que fornece informações sobre índices vegetativos da planta e possui fonte própria de emissão de luz, o que permite utilizar o sensor em medições em condições diversas de iluminação ambiente, tais como, céu nublado, sol, escuridão completa ou iluminação artificial. Quando a luz emitida a partir do sensor é direcionada para o dossel da planta, uma parte dessa luz é refletida de volta para o sensor, que é detectada com um conjunto de fotossensores espectralmente sensíveis. Essa luz refletida é interpretada em termos quantitativos e relacionada com índices de vegetação.

\section{Sensor de condutividade}

Como sensor de condutividade foi utilizado um sensor modelo Veris adaptado, que fornece informação sobre condutividade elétrica do solo (CE) rasa e profunda e informação de altitude. A unidade de medida de CE é miliSiemmens $/ \mathrm{m}^{2}\left(\mathrm{mS} / \mathrm{m}^{2}\right)$. O sensor Veris, produzido pela Veris Technologies, é um sensor de arrasto, capaz de medir a condutividade elétrica do solo. Sua utilização requer que ele seja conduzido por um veículo motorizado para realizar as medidas antes de qualquer atividade de manejo da região (RABELLO et al., 2011).

Os dados utilizados forma obtidos a partir de um modelo adaptado do Veris, numa abordagem com a medida de condutividade elétrica do solo sendo realizada adaptada a um 
implemento agrícola de uso normal na propriedade, um subsolador, reduzindo assim o tempo, os gastos de combustível e custo do equipamento com a coleta de medidas (INAMASU et al., 2007; RABELLO, 2008a,b). O equipamento adaptado, descrito por Rabello et al. (2011), realiza a medição da condutividade elétrica baseado no sistema de quatro pontos, que utiliza quatro hastes metálicas de material bom condutor de corrente elétricas, alinhadas sequencialmente com espaçamentos conhecidos. Uma corrente elétrica é injetada nos dois eletrodos externos e a tensão é medida entre as duas hastes internas, sendo assim possível calcular a resistividade, e por conseguinte, a condutividade do solo por onde passou essa corrente.

No caso dos dados do sensor Veris, foi realizado um tratamento prévio sobre estes, através de interpolação por krigagem, para eliminar falhas e vazios que estavam presentes no conjunto de dados.

\section{Área II}

Os dados do Conjunto Amostral II estão localizados dentro da Área II, representada pelo contorno azul na imagem da Figura 5. Essa área tem aproximadamente $34905 \mathrm{~m}^{2}$ (3,49 ha) de extensão.

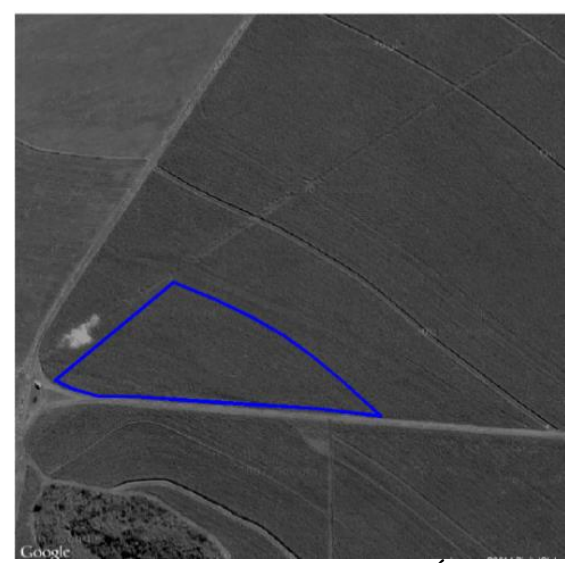

Figura 5. Imagem aérea da Área II.

Portanto, o Conjunto Amostral II é formado por dados de refletância obtidos sobre plantação de cana-de-açúcar (Figura 6 (a)) e por dados de condutividade do solo (Figura 6 (b)). A Figura 7 representa os dados do sensor de condutividade ajustados por interpolação, e representam dados em CE rasa (a) e profunda (b). 


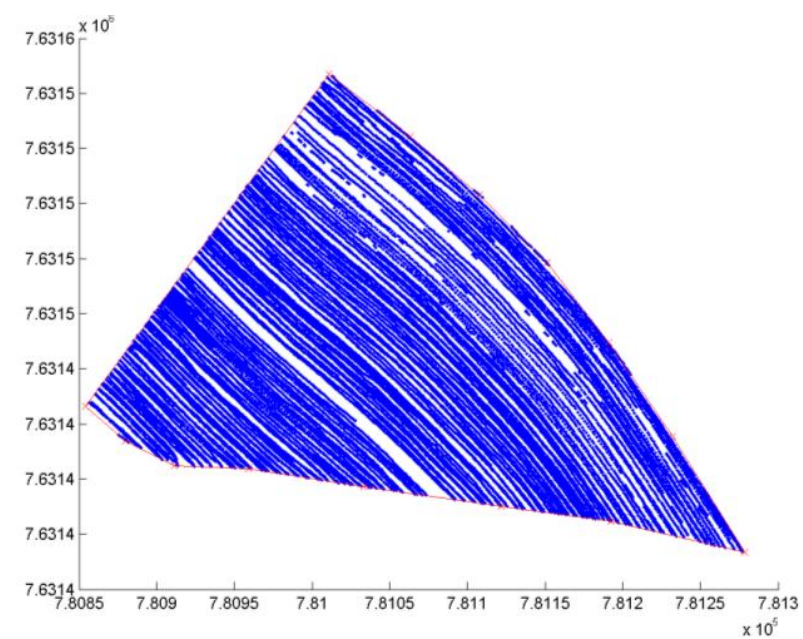

(a)

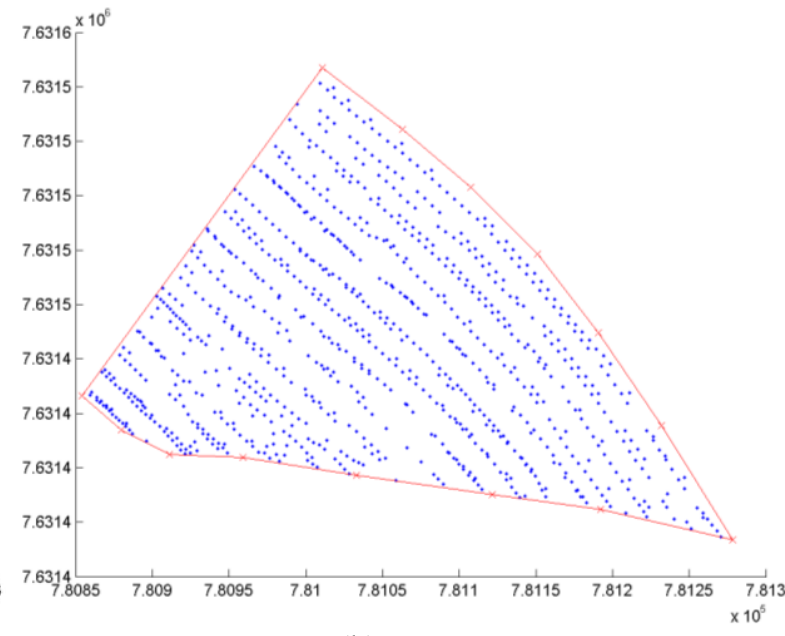

(b)

Figura 6. Conjunto Amostral II, dentro da Área II, localização dos pontos do conjunto composto por dados de sensor de refletância (a) e dados de sensor de condutividade (b) dentro da Área II

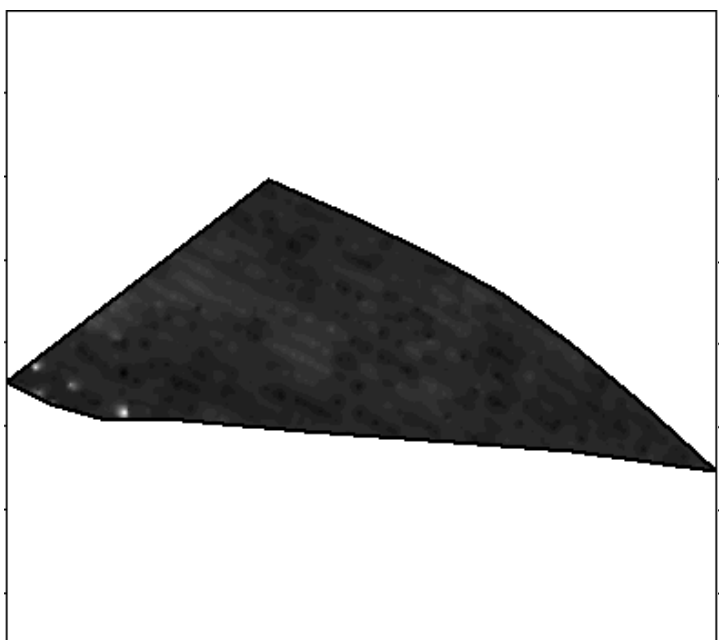

(a)

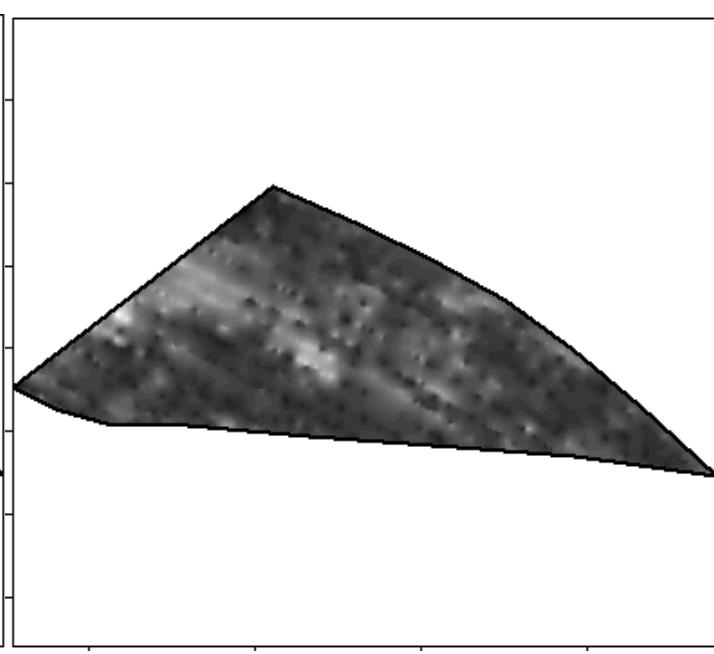

(b)

Figura 7. Resultado de interpolação sobre dados do sensor de condutividade para CE rasa (a) e para CE profunda (b). 


\subsection{Estruturação do ambiente}

A disposição de uma plantação em um campo está diretamente relacionada com o tipo de cultura e das características físicas das máquinas utilizadas no seu cultivo. Na tarefa de exploração, o veículo deve se deslocar por entre os corredores sem danificar a plantação.

O método proposto é direcionado para plantações com estrutura similar às da cana-deaçúcar e milho, que devido ao seu tipo de cultivo mecanizado apresentam, em geral, um espaçamento constante entre linhas de plantio. Por exemplo, podem ser estabelecidos espaçamentos entre linhas com valores em torno de $0,7 \mathrm{~m}$ ou $1,5 \mathrm{~m}$ ou o valor que a máquina que realiza o plantio consegue oferecer.

O espaçamento constante cria um padrão e facilita o planejamento e a exploração do campo sem a necessidade do conhecimento exato da localização de cada corredor. Este tipo de ambiente é considerado aqui como semiestruturado por apresentar um padrão uniforme e repetitivo dos locais por onde se pode transitar.

Para facilitar o entendimento do restante do texto, são definidos os significados de algumas expressões relacionadas ao ambiente utilizados no trabalho:

- Borda: contorno que engloba a área total a ser explorada, delimitada por um conjunto de coordenadas geográficas que representam os vértices da borda do campo;

- Linha de plantio: refere-se ao espaço ocupado pelas plantas, dispostas em uma única linha;

- Corredor: neste trabalho, corredor representa a faixa de linhas sobre a qual o veículo tem a capacidade de percorrer. O planejamento de trajetória é feito em relação a esses corredores;

- Largura de corredores: distância entre linhas de plantio considerada em plantios realizados mecanicamente. Por exemplo, caso seja utilizado um espaçamento de 0,7 m entre linhas de plantio essa área terá corredores de largura de $0,7 \mathrm{~m}$. Fazendo uma aproximação prática, uma área que contém 10 linhas de plantio terá uma largura de $7 \mathrm{~m}$, desconsiderando o espaço ocupado pela planta.

- Linha de referência horizontal: conjunto de pontos coordenados que representam o percurso de cada corredor a ser percorrido durante a exploração.

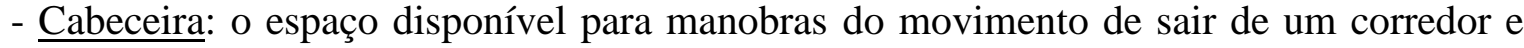
entrar em outro, está diretamente relacionado com as dimensões das máquinas que trabalharam naquele campo. 


\subsubsection{Linhas de referência}

Visando possibilitar a ligação entre as análises matemáticas e a exploração realizada por veículo autônomo, o campo foi estruturado levando em consideração as características de suas dimensões. Essa etapa ocorre apenas uma vez, no início do processo.

O usuário deve fornecer o par de coordenadas central da área a ser amostrada e o conjunto de pontos que determinam a borda da plantação. Na Figura 8 (a), o destaque em azul indica o contorno dentro do qual estarão os dados a serem amostrados; é dentro dessa área que será realizada a exploração por veículo autônomo.

Além da marcação do contorno, duas linhas de referência devem ser demarcadas: a linha de referência horizontal (Figura 8 (b)) e a linha de referência vertical (Figura 8 (c)). A linha de referência horizontal deve acompanhar o percurso de um corredor no sentido em que a máquina irá se deslocar em campo. A linha de referência vertical deve acompanhar um dos lados do contorno, de preferência o lado que seja o mais perpendicular possível em relação a linha de referência horizontal. Os pontos que compõem as linhas de referência estão em destaque em vermelho na Figura 8 (b) e na Figura 8 (c).

A partir das linhas de referência horizontal e vertical originais, são determinadas linhas paralelas a elas ao longo de todo o campo (Figura 8 (d) e Figura 8 (e), respectivamente). Essas linhas paralelas são marcadas considerando a largura dos corredores da plantação, ou a distância entre linhas de plantio, no caso deste trabalho foi considerada uma distância de 0,7 m entre linhas de plantio. Utilizando em conjunto as linhas paralelas de referência horizontal e vertical forma-se uma matriz (Figura 8 (f)), cuja interconexões determinam os pontos passíveis de serem amostrados e analisados no método proposto (Figura $8(\mathrm{~g})$ ).

Assim, a Área I, que tem aproximadamente $14163 \mathrm{~m}^{2}$ (1,41 ha) com 118,3 m de largura máxima e 118,3 m de comprimento máximo, terá o campo estruturado em 169 linhas de referência horizontal e 169 linhas de referência vertical, resultando em um total de 28561 pontos a serem utilizados conforme seja desejado.

A Área II, que tem aproximadamente $34905 \mathrm{~m}^{2}$ (3,49 ha), terá o campo estruturado em 248 linhas de referência horizontal e 427 linhas de referência vertical, que representa uma largura máxima horizontal de 173,6 m e uma largura máxima vertical de 298,9 m. O número total de pontos contidos nessa área é igual a 66319. 


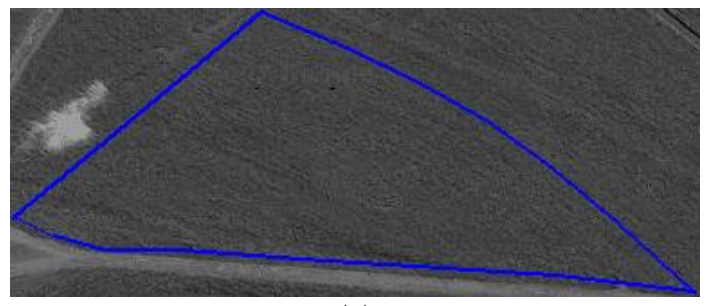

(a)

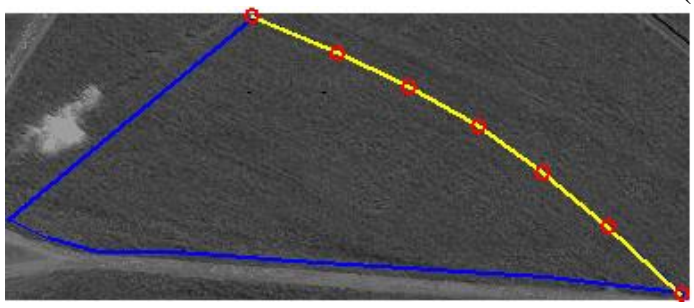

(b)

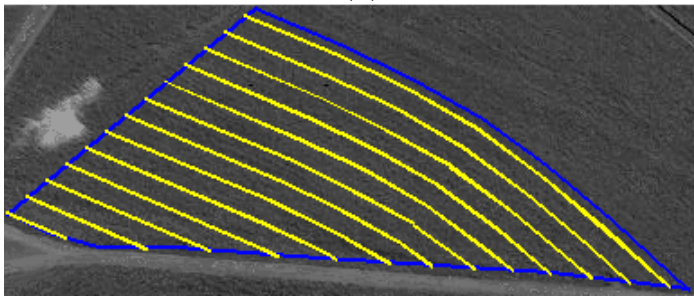

(d)

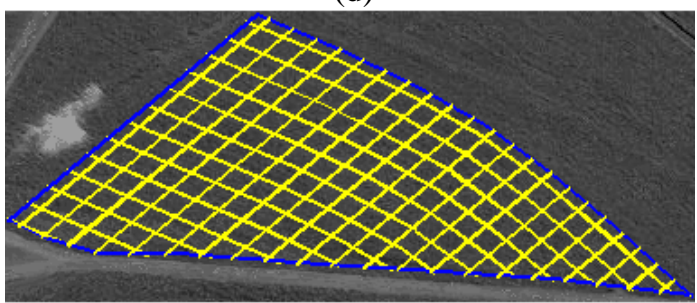

(f)

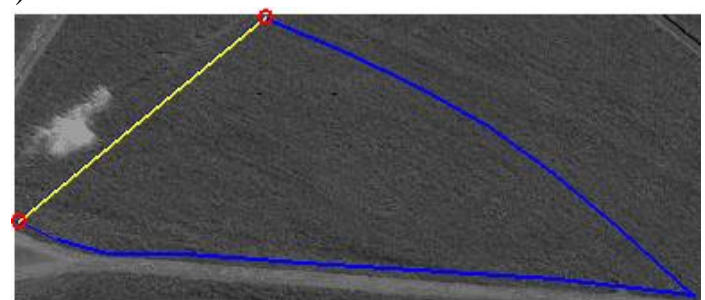

(c)

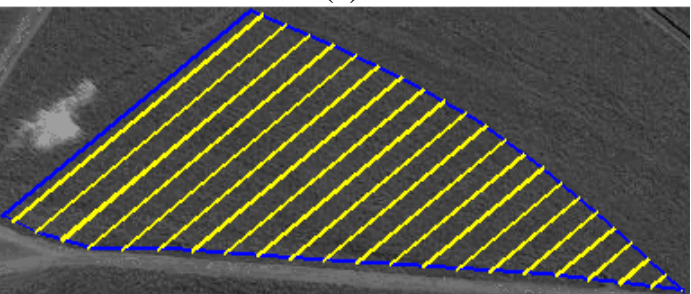

(e)

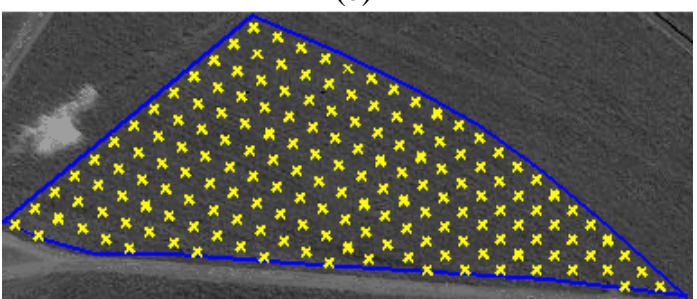

(g)

Figura 8. Esquema representativo da estruturação do ambiente em linhas de referência da Área II. Sendo (a) contorno do campo, (b) linha de referência horizontal, (c) linha de referência vertical, (d) réplicas da linha de referência horizontal, (e) réplicas da linha de referência vertical, (f) matriz de cruzamento das linhas de referência horizontal e vertical e $(\mathrm{g})$ pontos de cruzamento entre as linhas de referência. 


\subsection{Softwares}

Os softwares utilizados para o desenvolvimento desse projeto foram escolhidos levando em consideração: a flexibilidade de acesso e desenvolvimento de funções, e a capacidade de interoperabilidade e de troca de informações facilitada entre as diferentes plataformas.

Abaixo estão listados os softwares escolhidos dentro desta perspectiva.

\section{Matlab ${ }^{\circledR}$}

A base do método foi desenvolvida em ambiente Matlab® (MATrix LABoratoy), que é um software interativo de alta performance voltado para cálculos numéricos, com vasto suporte e operabilidade no desenvolvimento de funções. O algoritmo desenvolvido nessa ferramenta foi responsável pelo controle das ações em loop de amostragem, análise e divisões, determinando esquemas, planejando trajetórias, simulando a coleta de dados, e fazendo a ligação entre as análises realizadas no software R.

\section{$\boldsymbol{R}$}

R é um software com linguagem e ambiente desenvolvidos para computação estatística, além de fazer do projeto GNU, isto é, um software desenvolvido sobre a ideologia de um sistema operacional livre. O software R fornece uma rota Open Source para a participação nas atividades da linguagem $\mathrm{S}$, que é, muitas vezes, o veículo escolhido para pesquisa em metodologias estatísticas. O software R fornece uma ampla variedade de técnicas estatísticas e gráficas, e é altamente extensível, permitindo da incorporação de pacotes com funções específica, desenvolvidos por grupos independentes e com interesses diversos.

O pacote geoR fornece funções para análise geoestatística de dados usando o software R. Os modelos geoestatísticos utilizados no pacote geoR estão descritos em Ribeiro Jr \& Diggle (2012) e Diggle \& Ribeiro Jr (2007).

O pacote aRT implementa todos os passos necessários para realizar leitura e escrita de um banco de dados no formato estipulado pelo Terraview.

\section{Terraview}

O aplicativo Terraview é um SIG de código aberto e de interface amigável. O Terraview foi desenvolvido por um instituto brasileiro, o INPE (Instituto Nacional de Pesquisas Espaciais) e 
é constituído por uma biblioteca de geoprocessamento chamada TerraLib e possui todos os recursos computacionais existentes nos melhores SIGs comerciais. Tem como vantagem poder ser usado em redes de computadores, podendo também ser instalado em diversas máquinas com compartilhamento de informação por outros usuários. Esta ferramenta foi escolhida por possuir um modelo de base público que possibilita a integração entre os outros softwares utilizados pelo método. O Terraview disponibiliza toda a informação necessária para o controle e troca de informações com o banco de dados, os outros softwares envolvidos utilizam a base de dados do Terraview para consultar dados geográficos e para escrever os resultados dos processamentos. Nesse processo, o Terraview pode ser utilizado para visualização espaço-temporal dos mapas em todas as etapas do processo.

\section{Integração entre Matlab ${ }^{\circledR}, R$ e Terraview}

A integração entre as ferramentas Matlab®, R e Terraview se deu através de banco de dados geográficos utilizando o gerenciador MySQL, e seguindo o modelo de dados definido pelo Terraview. Este modelo de dados pode ser consultado em Terralib (2014).

O Terraview estabelece toda uma hierarquia que define como a informação deve ser armazenada para utilização em seu SIG, estabelecendo a forma de alocação da informação em pastas e subpastas, indexando e organizando. $\mathrm{O}$ acesso aberto a tais definições permitiu a leitura e escrita de dados pelo Matlab® e pelo R.

O esquema da Figura 9 ilustra como se deu essa troca de informações através do banco de dados. O esquema apresenta o diagrama da sequência dos passos do processamento realizado no método de exploração e permite visualizar a forma de colaboração entre as ferramentas utilizadas, a interação entre elas e o fluxo de informações. Observa-se que o Terraview é o repositório de dados de todas as ferramentas utilizadas nesse processo. Para o caso da simulação de dados coletados, o usuário realiza a importação do mapa no sistema Terraview, podendo visualizá-lo e realizar ajustes referentes a visualização, edições, etc. O mapa é formado por pontos coordenados com valores, podendo ser delimitado por um polígono, e pode ser em qualquer formato compatível com o software. O Matlab® consulta essa base de dados e seleciona os pontos conforme determinado pelo método e atualiza o banco de dados. O software $\mathrm{R}$ executa cálculos geoestatísticos sobre os pontos selecionados no Matlab® e também atualiza o banco de dados. 


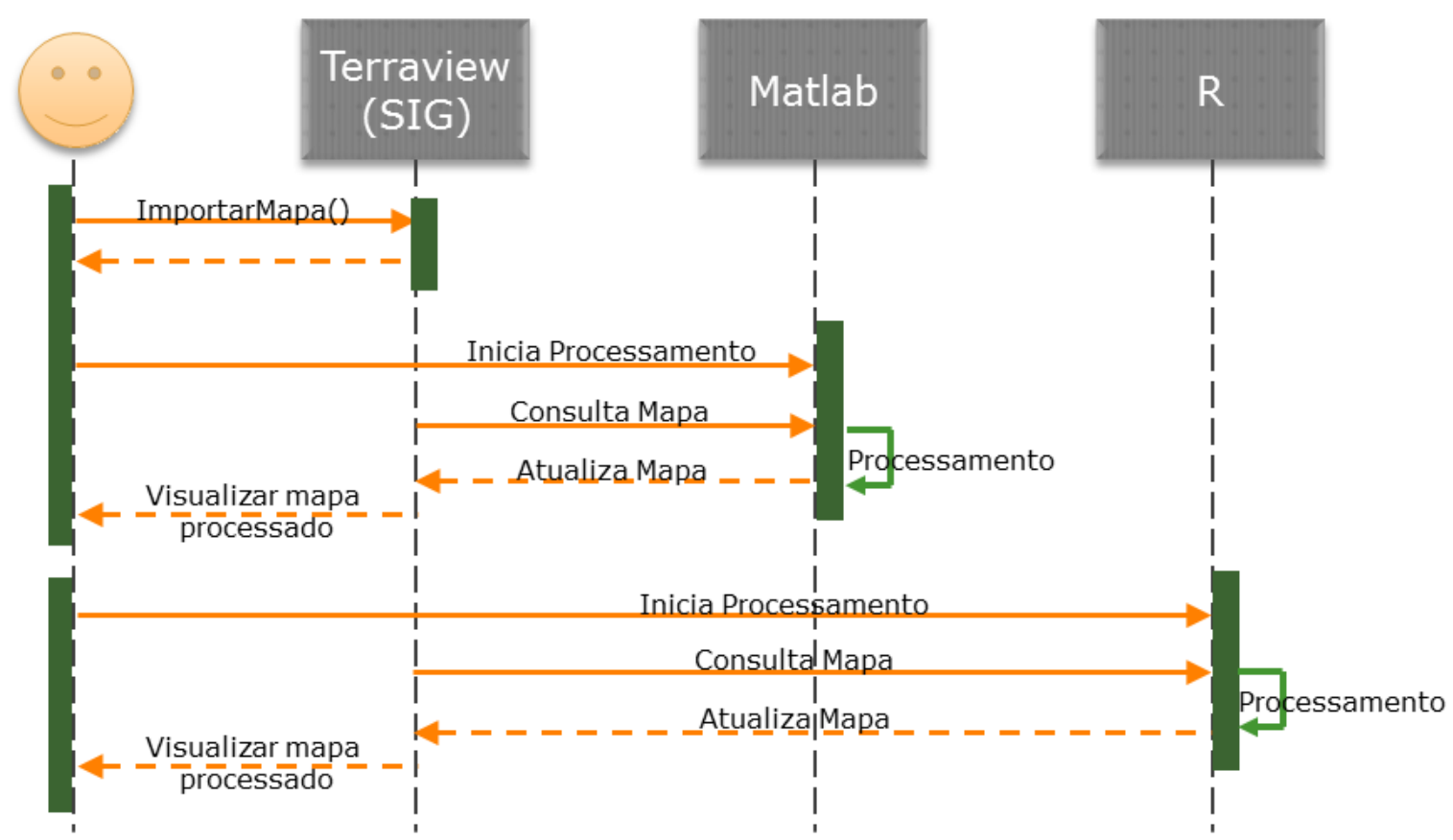

Figura 9. Esquemático de interligação entre softwares. 


\section{Metodologia}

O método de exploração proposto busca prover a coleta de dados de forma objetiva e econômica em campos de grande extensão fazendo uso de veículos autônomos e sensores embarcáveis. O método é voltado para aplicações em plantações cujo plantio é realizado de forma mecanizada, construindo espaçamento constante entre linhas, que estejam sobre grandes extensões, e nas quais seja possível a entrada de veículos de exploração com sensores embarcados.

Caso exista variabilidade no campo, a exploração irá identificar subáreas de variabilidade, dividindo, se necessário, o campo em áreas de diferentes densidades de amostragem. Áreas com maior variabilidade devem ser mais densamente amostradas, áreas com menor variabilidade podem ser menos densamente amostradas.

Os dados coletados devem ser capazes de reproduzir e representar confiavelmente as propriedades do campo para posterior análise com mapas interpolados. Busca-se aqui determinar a quantidade e a localização (coordenadas geográficas) dos pontos suficientes e necessários para representação de uma área em um campo.

A metodologia apresentada a seguir visa esclarecer questões sobre a variabilidade no campo, utilizando estatística clássica e geoestatística como base teórica e fazendo uso de tecnologias robóticas e de sensoriamento para viabilizar o método. 


\subsection{Esquema geral}

Em 1981, McBratney et al. apresentaram um roteiro de ações que viabilizam estratégias para amostragem em grade baseadas em teorias geoestatísticas. Interessante notar que, no ano em que tal roteiro para identificação de variabilidade foi proposto, o GNSS e a AP ainda não eram conceitos amplamente difundidos, somente na década seguinte que estas ferramentas vieram começar a se consolidar como prática comercial. Tal particularidade, ressalta o aspecto teórico sobre qual o roteiro de McBratney et al. (1981) foi desenvolvido, mas não diminui sua importância, visto que é amplamente utilizado em pesquisas na área até hoje. O roteiro descrito por McBratney et al. (1981) está ilustrado no Quadro 1, Capítulo 2.3.2.4.

Para fazer uso deste conhecimento na investigação de variabilidade, foram realizadas adaptações sobre o roteiro de McBratney et al. (1981), de forma a viabilizar sua aplicação em sistemas mais práticos e dinâmicos, tal como o proposto neste trabalho. No Quadro 2 é apresentado um roteiro, baseado e adaptado do modelo proposto por McBratney et al. (1981). As principais diferenças entre os roteiros original e o adaptado estão sobre o formato da amostragem e as etapas de realização desta amostragem. Em McBratney et al. (1981), o esquema se limita ao formato de uma grade; no novo roteiro adaptado, além da grade inicial, a amostragem se expande para um formato final que segue o plano de trajetórias em linhas com diferentes espaçamentos. Em McBratney et al. (1981), as ações de amostragem se limitam a basicamente duas etapas: uma de prospecção em que se faz estudo de informações prévias a partir de variogramas já existentes ou coletada a partir de um levantamento exploratório e a outra de levantamento principal; no roteiro adaptado são previstas a etapa de levantamento exploratório e uma ou mais etapas de levantamento principal, dependendo da informação que os dados sendo coletados fornecem. Além disso, no roteiro adaptado são consideradas análises sobre parcelas da área total inicial, ou suas subáreas, de forma a se obter um estudo mais detalhado das partes que apresentem maior variabilidade.

As etapas que constituem o roteiro adaptado são: determinação de esquema de amostragem (EA), planejamento de trajetória (PT), exploração de campo (E), análises (A), decisões (D) e subdivisões de áreas (S).

Primeiro deve-se tomar decisões (passos D.1 e D.2) sobre o erro máximo permitido na determinação da escala de variação espacial baseadas na análise de informações prévias disponíveis sobre uma determinada área. 
Num segundo momento, deve-se executar a etapa de levantamento exploratório, na qual primeiro deve-se definir o esquema de amostragem aninhado a ser utilizado (passo EA.1), ou seja, localização dos pontos de amostragem inicial no formato de amostragem aninhada. Na sequência, deve ser determinado o plano da trajetória (passo PT.1) a ser seguida na exploração de campo (passo E.1) para coleta dos pontos definidos na amostragem aninhada (passo EA.1). Após os dados de levantamento exploratório serem obtidos em campo, devem ser feitas análises (passo A.1) estatísticas e geoestatísticas sobre eles para definição da escala espacial de variabilidade (alcance do variograma) inicial e definição dos parâmetros de decisão para os levantamentos da próxima etapa.

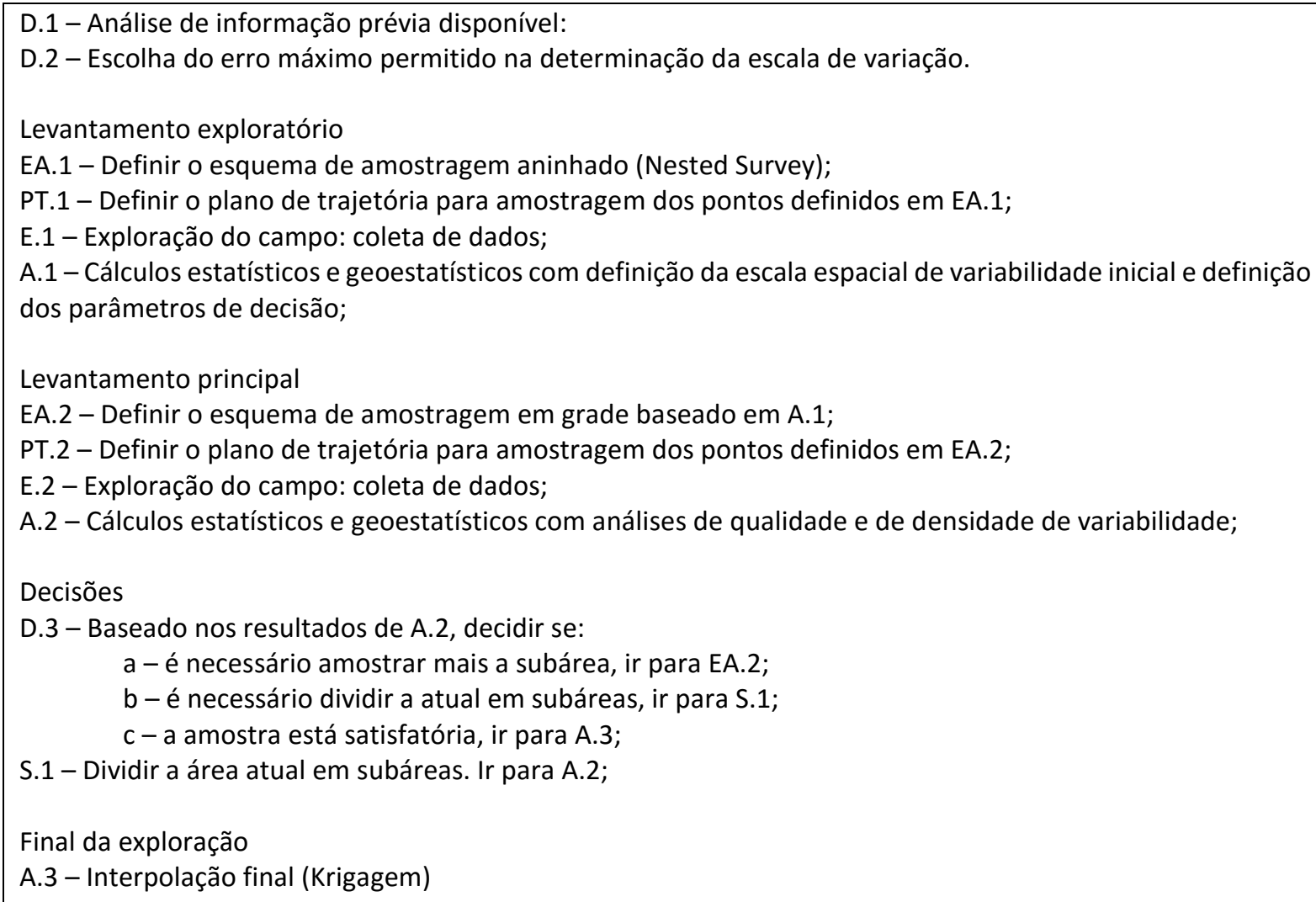

Quadro 2. Roteiro para estratégia de amostragem considerando a variabilidade.

Para execução da etapa de levantamento principal, primeiro deve-se definir o esquema de amostragem (passo EA.2) a ser seguido com base nas informações obtidas passo A.1. Definido o esquema e seus pontos, deve-se definir o plano de trajetória (passo PT.2) a ser seguido para execução da exploração em campo (passo E.2) para coleta de dados de tais pontos. Dados coletados, novas análises (passo A.2) devem ser realizadas sobre eles para decidir (passo D.3) se a informação coletada (a) é insuficiente para representar a área em questão e novos 
levantamentos devem ser realizados (retornando o processo para o passo EA.2), (b) tem alta variabilidade e deve ser realizada a divisão da área em análise para melhor interpretação (seguir para o passo S.1), ou (c) a amostra está satisfatória para representação da área total (seguir para o passo A.3). No passo de análise final (A.3) é realizada a interpolação da informação por krigagem. Os passos de análise são realizados através de processamentos computacionais sobre os dados coletados.

A Figura 10 ilustra em um esquemático os passos do roteiro descritos acima. No início é considerada a "Área Total” e sobre ela são realizadas as decisões iniciais (D.1 e D.2). Na sequência é realizado o "Levantamento Exploratório", no qual são definidos o esquema de amostragem (EA.1) e a trajetória a ser seguida (PT.1), e é executada a exploração do campo (E.1) para coleta de dados. Sobre os dados coletados no levantamento exploratório é realizada a "Análise Inicial” (A.1), que levantará os parâmetros que definirão o modo de exploração de campo (E.2) a ser realizado no "Levantamento Principal", tais como o esquema que define os pontos a serem amostrados (EA.2) e o plano de trajetória a ser seguido (PT.2). Pode ser que ocorra mais de uma exploração de campo (E.2) na etapa de "Levantamento Principal", dependendo das informações fornecidas pela Análise Principal (A.2).

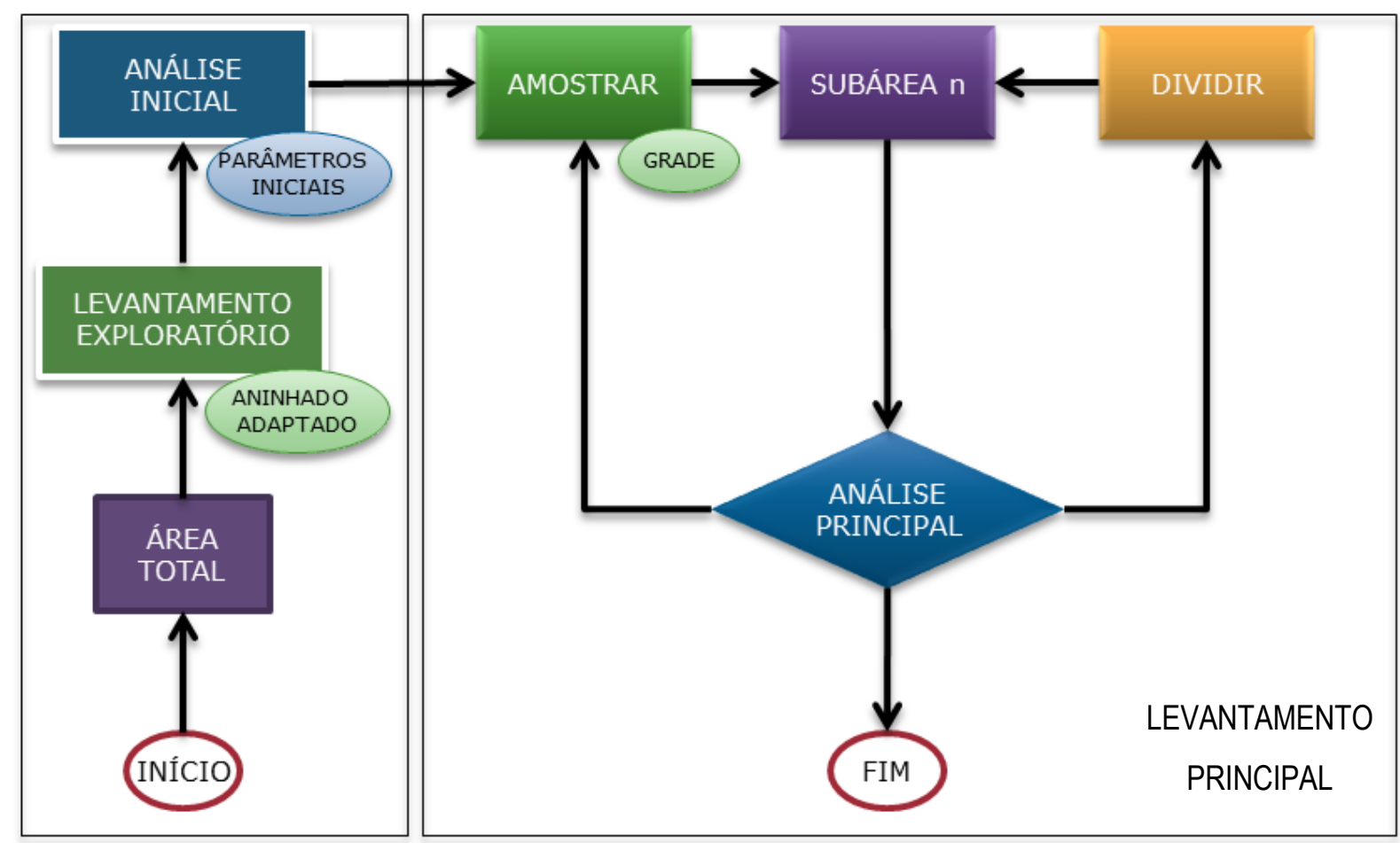

Figura 10. Esquema de navegação por densidade de variabilidade.

Após a "Análise Principal" é tomada a decisão (D.3) sobre a continuidade ou não do processo de amostragem. Tal decisão gira em torno da qualidade e quantidade de informação 
coletada. Caso seja necessária uma quantidade maior de informações sobre a área, deve-se decidir entre "Amostrar" ou "Dividir". "Amostrar" mais a área (D.3a) ocorrerá caso existam poucos dados para uma correta análise. "Dividir" ocorrerá caso a área apresente uma variabilidade muito grande e seja necessária uma análise mais detalhada das partes (D.3b que leva a S.1). Caso a quantidade e a qualidade da informação esteja satisfatória, o processo é dado como finalizado e a informação fica disponível para um analise final (A.3).

Para melhor entendimento do passo a passo do roteiro adaptado, nos capítulos seguintes são apresentados maiores detalhes sobre os conceitos mencionados. 


\subsection{Critérios de decisão e parâmetros de análise}

No Quadro 3 está listada uma sequência lógica, baseada em critérios, que determina a tomada de decisões sobre "Amostrar" ou "Dividir". Tais decisões são tomadas baseadas em critérios de qualidade, de escala e de densidade de variabilidade.

Os critérios de qualidade da amostra são determinados por parâmetros de localização, quantidade, qualidade de krigagem (AIC, BIC, loglik e variância média de krigagem). Os critérios de escala são divididos em escala de exploração (característica das máquinas), escala de precisão (definido pelo usuário) e escala espacial de variabilidade (definido pelo alcance do variograma). O critério de densidade de variabilidade é determinado pelos parâmetros: desvio padrão, coeficiente de variabilidade, coeficiente de assimetria, AIC, BIC, loglik. Nas próximas seções tais critérios e seus parâmetros são descritos com maiores detalhes.

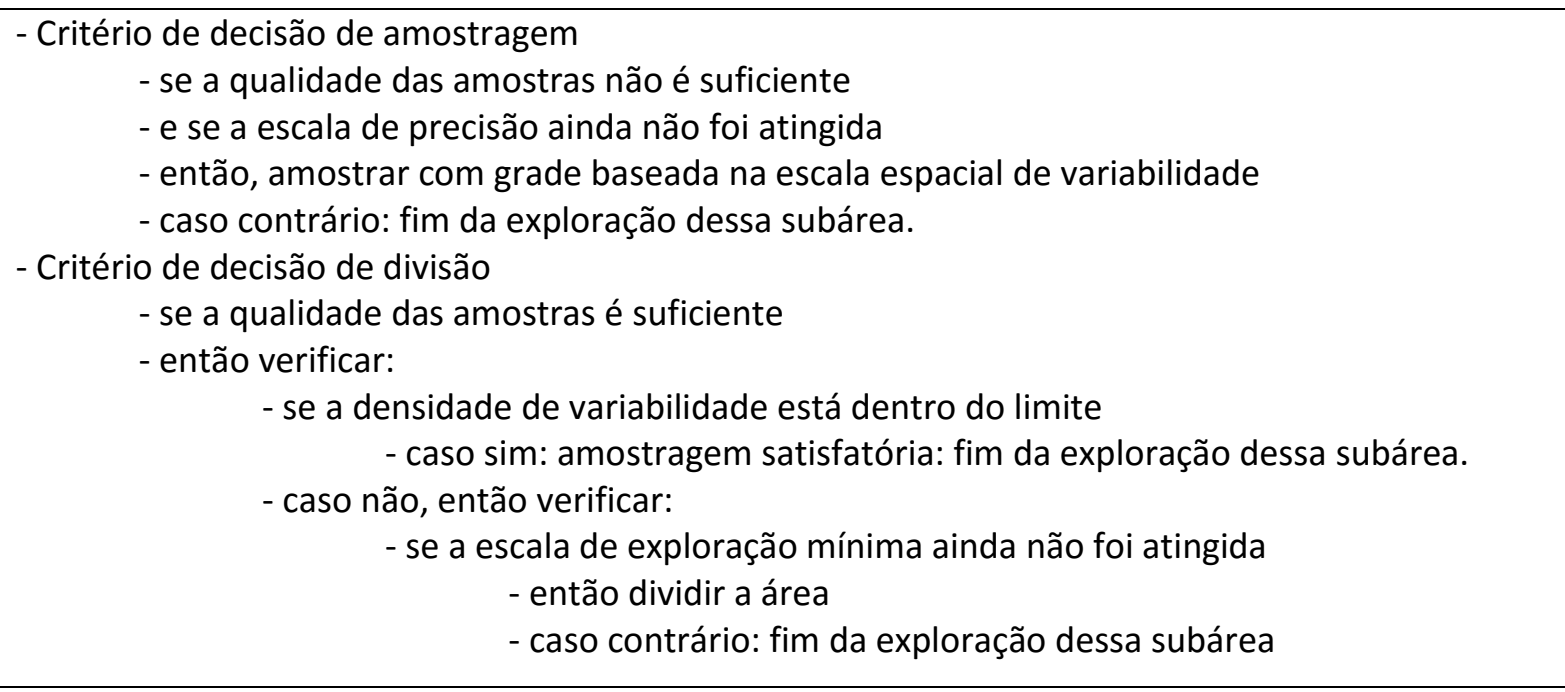

Quadro 3. Sequência lógica para decisão de amostragem ou divisão, baseada em critérios.

Seguindo a lógica do Quadro 3, para que se tome a decisão de realizar nova amostragem sobre uma área, deve-se considerar se a qualidade das amostras é suficiente em comparação com critério de qualidade estabelecido. Caso não seja, deve-se avaliar se a escala de precisão ainda não foi atingida. Assim, se a qualidade não é suficiente e a escala de precisão não foi atingida, nova amostragem deve ser realizada com espaçamento de grade baseado na escala espacial de variabilidade. Caso contrário, se a qualidade não é suficiente, mas a escala de precisão já foi atingida, não será realizada nova amostragem nessa área. 
Para que se tome a decisão de realizar a divisão da área em quadrantes para análise mais detalhada, primeiro deve-se garantir que a qualidade da amostra é suficiente. Caso seja suficiente, então deve-se verificar as amostras sobre o critério de densidade de variabilidade. Se a área apresenta uma variabilidade dentro do limite estabelecido, quer dizer que a amostragem está satisfatória e é determinado o fim da amostragem desta área. Caso a variabilidade esteja acima do limite estabelecido, então deve-se verificar se não foi atingido o valor de escala de exploração mínima, ou seja, se a área já não foi dividida à dimensão mínima permitida. Caso a escala de exploração mínima não tenha sido atingida, realiza-se a divisão da área em quadrantes. Caso contrário é estabelecido o fim da exploração desta área.

Figura 11 ilustra em forma de esquemático este mesmo raciocínio baseado em critérios.

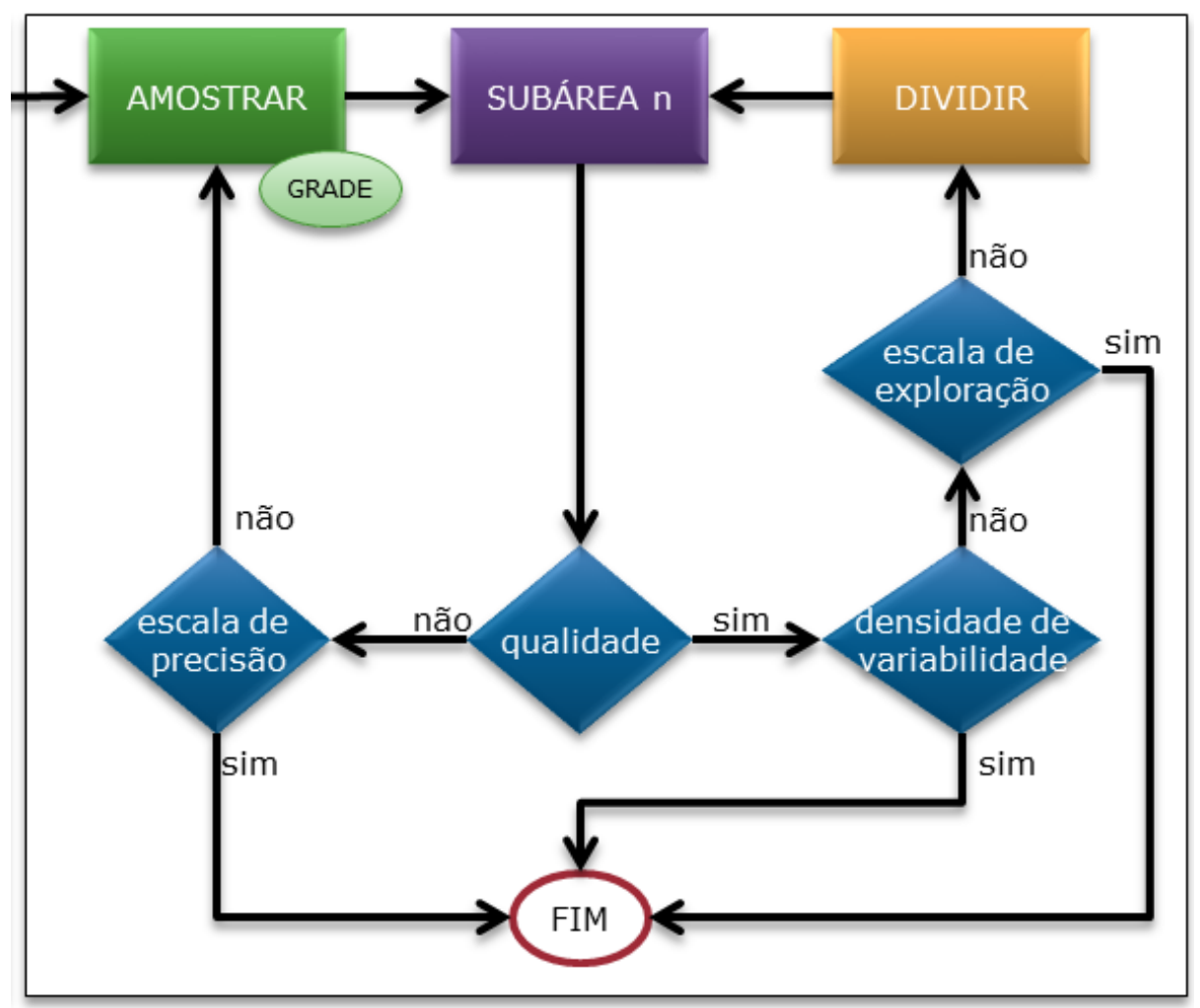

Figura 11. Esquemático dos critérios para decisão de amostragem ou divisão.

Em resumo, se há uma área com uma densidade de variabilidade grande, em teoria deve-se dividir essa área até que a densidade de variabilidade fique dentro do limite estipulado ou até que o limite da escala de exploração seja atingido. Caso os dados que estejam dentro de cada nova subárea não atinjam uma qualidade mínima, uma amostragem mais densa deve ser realizada para essa área, dependendo se a escala de precisão não foi atingida. 


\subsubsection{Qualidade da amostra}

No critério ‘qualidade' busca-se determinar a partir de qual limite um valor é considerado aceitável para uma boa amostragem. Para estabelecer esse critério são tomados em consideração os seguintes parâmetros: localização, quantidade de amostras e indicadores de qualidade da krigagem. Um critério de qualidade mal escolhido fará com que a área seja amostrada de forma inadequada, caso estipule um limite muito estreito fará com que a amostra ocorra em excesso, ou caso estipule um limite muito amplo fará com que a amostra não tenha qualidade suficiente.

\section{Localização das amostras}

A disposição dos pontos amostrais na área influencia na qualidade da amostra.

\section{Quantidade de amostras}

O conjunto final da amostra deve conter a quantidade suficiente para representar de forma confiável determinada área. Segundo a literatura, para estimações utilizando máxima verossimilhança residual, 50 dados de amostra são suficientes para estimar um variograma aceitável e 200 dados de amostra estimam um variograma confiável (KERRY \& OLIVER, 2007; GASCUEL-ODOUX \& BOIVIN, 1994).

Para ilustrar a importância da quantidade de pontos amostrais, foram feitas comparações sobre os resultados de krigagem entre diferentes quantidades amostrais para a mesma área buscando identificar qual quantidade mínima de amostras por área é suficiente para uma análise adequada.

\section{Qualidade de krigagem}

A verificação da qualidade de krigagem é realizada através da comparação de indicadores de krigagem entre diferentes amostras. Para determinação do critério de qualidade de krigagem foram analisados os indicadores:

- loglik, AIC e BIC;

- a variância média de krigagem e a variância máxima de krigagem (VAN-GROENIGEN, 2000). 


\subsubsection{Escala de precisão}

A escala de precisão determina qual a escala mínima que se deseja explorar, ou seja, qual o mínimo espaçamento de grade que se deseja atingir na exploração.

A escala de precisão é definida pelo usuário do sistema, que pode estar interessado em observar variabilidades na ordem de centímetros até quilômetros, por isso, deve determinar qual o menor valor de precisão que deseja que o sistema obtenha.

$\mathrm{Na}$ elaboração do esquema de levantamento de exploração, a dimensão do último estágio aninhado é determinada com base na escala de precisão.

Na elaboração do esquema do levantamento principal, a dimensão da menor grade permitida é determinada com base na escala de precisão.

\subsubsection{Escalas de exploração}

As escalas de exploração determinam quais dimensões mínimas em que a área pode ser explorada. Os valores das escalas de exploração estão relacionados com as características construtivas da máquina agrícola e suas capacidades de aplicação de insumos a taxa variada. A largura da máquina ou do aplicador de insumo determina a escala de exploração chamada aqui de escala de exploração horizontal. A capacidade da máquina de aplicação de insumos a taxa variada no sentido de seu deslocamento determina a escala de exploração chamada aqui de escala de exploração vertical.

\subsubsection{Escala espacial de variabilidade}

A escala espacial de variabilidade é considerada, neste trabalho, como sendo igual ao alcance $(a)$ do variograma obtido a partir de uma amostragem de prospecção no levantamento exploratório. 


\subsubsection{Densidade de variabilidade}

O critério de decisão 'densidade de variabilidade' indica se os dados de uma determinada área possuem uma maior ou menor variabilidade. Os parâmetros estatísticos e geoestatísticos utilizados para analisar a densidade de variabilidade foram:

- desvio padrão: $S=\sqrt{\frac{\sum\left(x_{i}-\bar{x}\right)^{2}}{N-1}}$

- variabilidade: $\sigma^{2}$

- coeficiente de variabilidade: $C V=\frac{s}{\bar{x}}$

Sendo $\bar{x}$ a média e $\mathrm{N}$ o número de amostras.

O desvio padrão, permite avaliar a dispersão dos dados em relação à media (ou valor esperado) e é definido como a raiz quadrada da variância.

O coeficiente de variabilidade $(\mathrm{CV})$ oferece uma ideia da precisão ou da dispersão de um conjunto de dados, fornecendo a variação dos dados obtidos em relação à média. Quanto menor for o seu valor, mais homogêneos serão os dados. É considerado baixo (dados bem homogêneos) se menor ou igual a $25 \%$ (valor em consenso encontrado na literatura sobre CV). Por ser um valor relativo, permite comparar séries de valores que apresentam unidade de medidas distintas.

A decisão sobre densidade de variabilidade está diretamente ligada com a etapa de levantamento exploratório. Isto porque o levantamento exploratório é capaz de fornecer uma boa estimativa das características totais do campo, sendo assim utilizado para definir os limites dos parâmetros de decisão.

Portanto, no processo de tomada de decisão do levantamento principal, cada análise é avaliada comparativamente com os limites estipulados no levantamento exploratório.

Se o valor do parâmetro da subárea sendo analisada é menor do que o limite estabelecido para esse parâmetro, então a densidade de variabilidade está satisfatória e essa área não será mais dividia, amostrada ou analisada, caso contrário, essa área deve ser dividida

Com o intuito de definir a melhor abordagem no processo de decisão da densidade de variabilidade, foram realizadas investigações a respeito da escolha dos limites e dos parâmetros mais adequados ao método. 


\subsection{Exploração em fases}

Baseado no modelo de exploração em fases apresentado por Marchant \& Lark (2006), a exploração adotada no método proposto também é realizada em fases, compostas por uma etapa na fase de levantamento exploratório, e uma ou mais etapas na fase do levantamento principal, conforme o necessário para a correta amostragem do campo.

\section{Levantamento exploratório: Aninhado adaptado}

No levantamento exploratório é feito um estudo inicial das propriedades estatísticas e geoestatísticas da variabilidade do campo. A estimação dos parâmetros geoestatísticos é realizada por máxima verossimilhança residual (REML) (WEBSTER et al., 2006; LARK, 2000).

O objetivo do levantamento exploratório é permitir uma análise inicial do campo de forma a estabelecer automaticamente valores de referência para os parâmetros utilizados nas decisões do método. No levantamento exploratório é possível calcular uma aproximação inicial da escala espacial de variabilidade do campo, essa aproximação será utilizada para definir o espaçamento da grade inicial para a fase de levantamento principal.

Neste trabalho, o levantamento exploratório foi elaborado com base no modelo de levantamento aninhado desbalanceado (desbalanced nested survey) (OLIVER \& WEBSTER, 1986) e foi adaptado para a situação de amostragem com sensores embarcados coletando dados ao longo de linhas de plantio. No processo de análise de dados coletados no ajuste do variograma teórico foi utilizado o modelo matemático exponencial.

\section{Levantamento principal: grade}

No levantamento principal, são realizadas amostragens em grade quadrada em uma ou mais etapas, conforme o necessário. A estimação dos parâmetros geoestatísticos é realizada por REML.

O espaçamento da grade na primeira etapa do levantamento principal é determinado no levantamento exploratório, através da análise da escala espacial de variabilidade e da escala de precisão. 
Caso seja necessário realizar uma amostragem mais densa do que aquela realizada na primeira etapa, um novo esquema é montado, sendo o novo espaçamento da grade igual a metade do espaçamento da grade da etapa anterior.

Dessa forma, na segunda etapa, o espaçamento da grade é metade do espaçamento da grade da primeira etapa; na terceira etapa, o espaçamento da grade é metade do espaçamento da grade da segunda etapa; e assim por diante até que seja determinado o fim da amostragem.

Entre cada etapa são realizadas análises que determinam se os dados coletados até o momento são suficientes para uma boa representação do campo ou se são necessárias novas etapas de amostragem. 


\subsection{Exploração em subáreas}

Segundo a estatística clássica, a disposição de um conjunto de amostras sobre uma área é aleatória, assim se dividirmos essa área e analisarmos uma subamostra, provavelmente os resultados serão os mesmos. Já segundo a geoestatística, existe uma relação de dependência espacial, na qual, dados mais próximos são mais parecidos do que dados mais distantes. Assim, segundo a geoestatística, se dividirmos uma área em subáreas, dentro de cada subárea haverá dados com valores mais parecidos, do que entre diferentes subáreas.

O método de exploração propõe a subdivisão de áreas por semelhanças de valores como parte da determinação da estratégia de amostragem. Sendo que, o critério para decisão para divisão é baseado na densidade de variabilidade, ou seja, áreas com alta densidade de variabilidade deverão ser divididos e, caso necessário, mais amostrados, áreas com baixa densidade de variabilidade que atingiram uma boa qualidade de amostragem não necessitam mais serem divididos ou amostrados.

A Figura 12 indica como as divisões são realizadas em quadrantes. Dada a área total (a) a primeira divisão resulta em quatro subáreas, as subáreas (b), (c), (d) e (e). Em uma nova divisão sobre a subárea (b), novas quatro subáreas surgirão, as subáreas (f), (g), (h) e (i). E assim sucessivamente até que não sejam necessárias novas divisões ou que se atinja a meta.
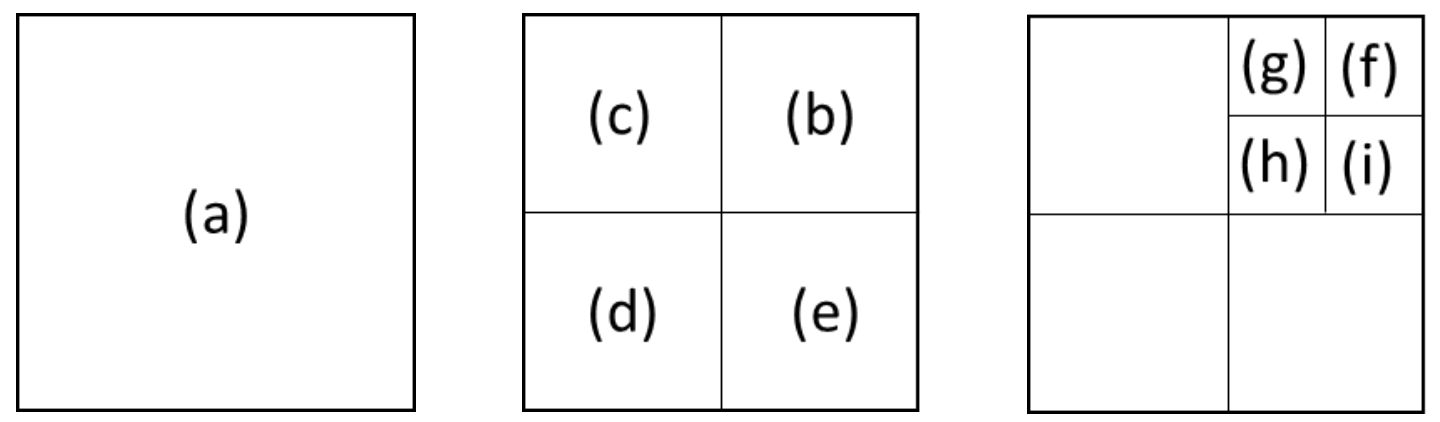

Figura 12. Exemplo divisões de áreas, sendo (a) a área total, (b) subárea I-I, (c) subárea I-II, (d) subárea I-III, (e) subárea I-IV, (f) subárea I-Ia, (g) subárea I-Ib, (h) subárea I-Ic, (i) subárea I-Id 


\subsection{Ciclos de Amostragem}

A amostragem é a coleta de dados em si, ou seja, quando se vai a campo com sensores adequados coletar informações sobre a plantação. Por exemplo, no levantamento exploratório é realizado um ciclo de amostragem para coleta de dados, no levantamento principal são realizados outros ciclos. O ciclo de amostragem representa cada ida em campo para coleta de dados.

O método proposto foi desenvolvido para situações em que se faz necessário o uso de um veículo com capacidade de superar as adversidades físicas de campos agrícolas, que se movimente por entre as linhas de plantio, sem ferir ou modificar a estrutura da plantação, carregando os sensores responsáveis pela coleta da informação sobre a variável de interesse, que apresente mobilidade de manobras e que seja capaz de seguir uma trajetória especificada de forma autônoma.

Cada ciclo de amostragem é composto pelas seguintes etapas: definição do esquema de amostragem; planejamento de trajetória; coleta de dados; e filtragem dos pontos no padrão estabelecido. Fazendo um paralelo com o roteiro estabelecido no Capítulo 4.1, a etapa de definição do esquema de amostragem faz parte dos passos EA.1 ou EA.2; o planejamento de trajetória faz parte dos passos PT.1 e PT.2; as etapas de coleta e de filtragem dos pontos padrão se encaixam nos passos A.1 e A.2.

\section{Definição do esquema de amostragem}

$\mathrm{Na}$ etapa de definição do esquema de amostragem será definida a distribuição dos pontos a serem amostrados no espaço, e suas respectivas localizações em coordenadas geográficas.

No levantamento exploratório o esquema de amostragem é definido conforme estabelecido em um esquema aninhado adaptado, explicado com mais detalhes no Capítulo 4.6, logo adiante.

No levantamento principal são realizados esquemas de exploração em grade. No primeiro ciclo do levantamento principal, o espaçamento da grade é determinado na análise dos dados do levantamento exploratório. Nos ciclos subsequentes, após cada análise, se ficar estabelecido que novos dados são necessários para cada subárea, então o espaçamento da grade será igual a metade do espaçamento da grade da área de origem.

A Figura 13 mostra esquemas de distribuição de pontos a serem amostrados pelo método proposto. A Figura 13 (a) indica o esquema de distribuição dos pontos a serem amostrados em 
um levantamento exploratório, que considera uma distribuição aninhada mas aqui adaptado ao formato de coleta em linhas. As Figura 13 (b), (c) e (d) indicam os esquemas do levantamento principal que é constituído por 3 etapas, sendo que em (b) se realiza uma amostragem em grade simples; em (c) uma das subáreas (divisão em quadrantes) foi amostrada mais densamente com uma grade menor; e em (d) outras duas subáreas também foram amostradas mais densamente.

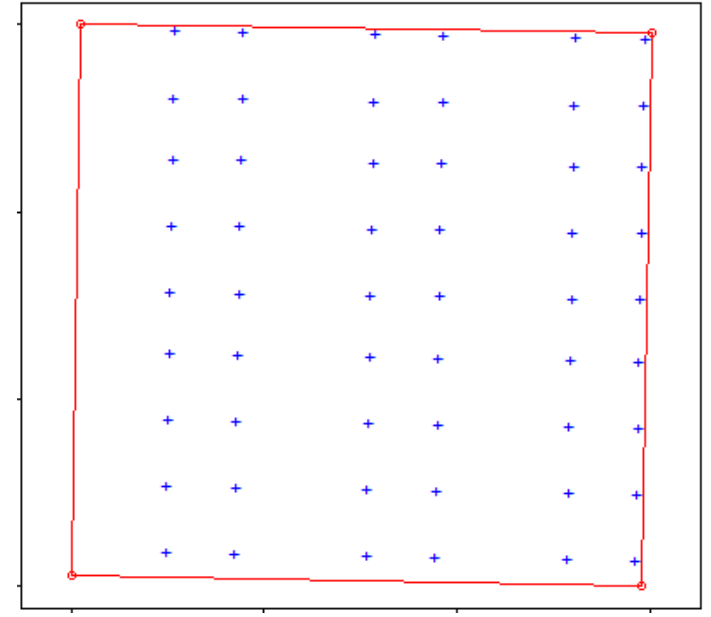

(a)

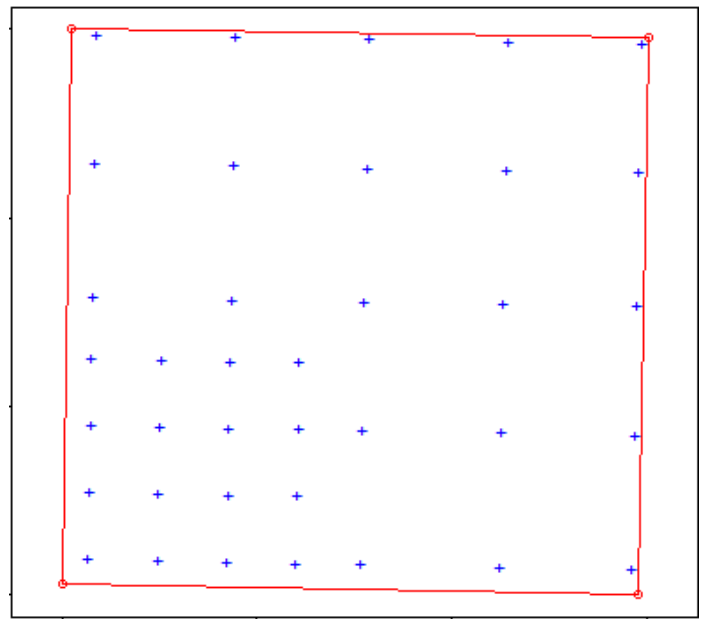

(c)

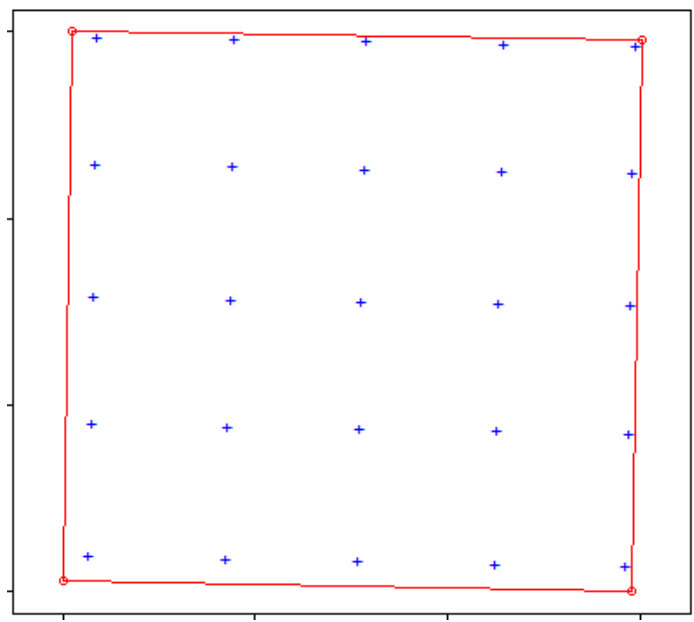

(b)

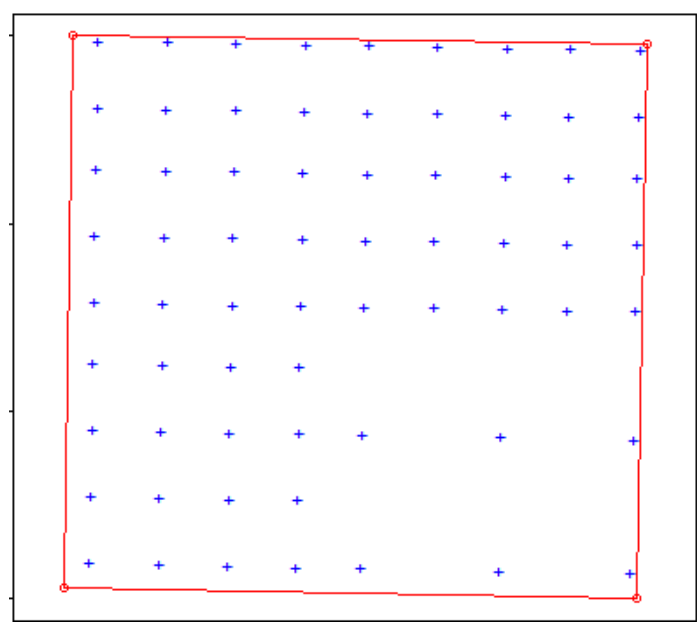

(d)

Figura 13. Exemplo de esquemas de amostragem para o levantamento exploratório (a) e para as etapas do levantamento principal (b), (c) e (d).

\section{Planejamento de trajetória}

Definido o esquema de amostragem, então é realizado o planejamento de trajetória que definirá o percurso que o veículo autônomo deve executar para coletar os dados desejados utilizando os sensores embarcados. Lembrando que o percurso que o veículo realiza é limitado pela distribuição da plantação em linhas de plantio. 
$\mathrm{Na}$ etapa de definição do esquema de amostragem foram definidas as localizações dos pontos que se deseja amostrar. Agora, na etapa de planejamento de trajetórias, serão definidas as linhas de plantio pelas quais o veículo autônomo deve passar para coletar todos os pontos. São definidos também a melhor sequência de exploração das linhas e quais tipos de movimentos devem ser executados para realizar a amostragem. Leva-se em consideração características físicas e operacionais do veículo autônomo (largura do veículo e capacidades de manobras) e características da plantação (espaçamento entre linhas de plantio, dimensões e bordas) para determinar a melhor forma de explorá-lo.

Os modelos propostos por Bochtis \& Vougioukas (2008), Bochtis \& Sorensen (2009) e Bochtis et al. (2010) foram utilizados como base teórica. Estes modelos expandem o Problema do Caixeiro Viajante (PCV) (no qual um único vendedor deve passar por todos os pontos de venda uma única vez) para o Problema do Roteamento de Veículos (PRV), através de modelos mais complexos e voltados para planejamento de trajetórias em ambiente agrícola.

No problema apresentado aqui, ao invés de pontos, as linhas de referência do campo estruturado representam os destinos pelos quais o caixeiro deve passar. Cada linha de referência é composta por um conjunto de pontos que compõem seu percurso, sendo dois desses pontos os extremos referentes ao local de entrada ou de saída da linha.

Para sair de uma linha e entrar em outra, o veículo autônomo deve realizar manobras na cabeceira que permitam essa transição. Em uma análise mais complexa, devem ser considerados todos os tipos de manobra de cabeceira reais possíveis de serem realizados. Nesse estudo foi considerada uma manobra de cabeceira hipotética e simples, executada em linha reta e ligando dois extremos no mesmo lado do campo.

Se a intenção fosse uma exploração completa do campo, o veículo autônomo deveria passar por todas suas linhas. Como o objetivo é escolher por quais linhas será necessário passar, então é possível que nem todas as linhas sejam exploradas.

Assim, dado um conjunto de linhas de referência que representam os corredores por onde o veículo autônomo deve passar, deverá ser determinada a trajetória que permite que o veículo passe uma vez sobre todos os pontos alvos no campo, e apenas uma vez sobre cada um.

Por exemplo, considerando as representações de esquemas da Figura 13, se todas as linhas do campo fossem numeradas em forma crescente da direita para a esquerda, teríamos mais de 170 linhas de plantio a serem representadas. Levando em consideração o esquema de amostragem da Figura 13 (a), do levantamento exploratório, e fazendo uma equivalência entre a localização dos pontos e a quais linhas eles pertencem, teríamos que os pontos a serem amostrados pertencem às linhas de referência horizontais 3, 23, 63, 83, 123 e 143. 
Para o esquema de amostragem da Figura 13 (b), da etapa 1 do levantamento principal, fica estabelecido que os pontos a serem amostrados pertencem às linhas de referência 3, 43, 83, 123 e 163.

Para o esquema de amostragem da Figura 13 (c), da etapa 2 do levantamento principal, fica estabelecido que os pontos a serem amostrados pertencem às linhas de referência 3, 43, 83, 103, 123,143 e 163.

Para o esquema de amostragem da Figura 13 (d), da etapa 3 do levantamento principal, fica estabelecido que os pontos a serem amostrados pertencem às linhas de referência $3,23,43,63$, $83,103,123,143$ e 163.

Se contabilizarmos todas as linhas que possuem pontos que devem ser amostrados, no total, 9 linhas devem ser percorridas, sendo elas: 3, 23, 43, 63, 83, 103, 123, 143 e 163.

Na Figura 14 é feita uma representação esquemática do planejamento de trajetórias aplicado aos exemplos da Figura 13. A Figura 14 (a) indica em linhas azuis todas as linhas de plantio que deverão ser percorridas $(3,23,43,63,83,103,123,143$ e 163).

A Figura 14 (b) indica a sequência a ser percorrido (linhas vermelhas), numa primeira excursão em campo (esquema do levantamento exploratório da Figura 13(a): linhas 3, 23, 63, 83, 123 e 143.), sendo o ponto de partida indicado por um círculo vermelho, o ponto final por uma estrela vermelha. A Figura 14b (c), representa a segunda excursão em campo, ou seja, outro ciclo de amostragem, no qual deverão ser percorridas somente as linhas que ainda não foram percorridas em ciclos de amostragens anteriores. Ou seja, entre o ciclo de amostragem do esquema da Figura 13 (a) e da Figura 13 (b), somente as linhas 43 e 63 ainda não haviam sido exploradas. A Figura 14 (d), representa a terceira excursão em campo, relativa ao esquema da Figura 13 (c), e na qual só foi necessário percorrer a linha 103 para se obter dados que ainda não haviam sido coletados. Os ciclos de amostragens são realizados dessa mesma forma em todas as excursões subsequentes. Assim, por exemplo, não existirá uma excursão para a etapa 3 do levantamento principal (Figura 13 (d)), pois todas as linhas já foram percorridas nas etapas anteriores. 


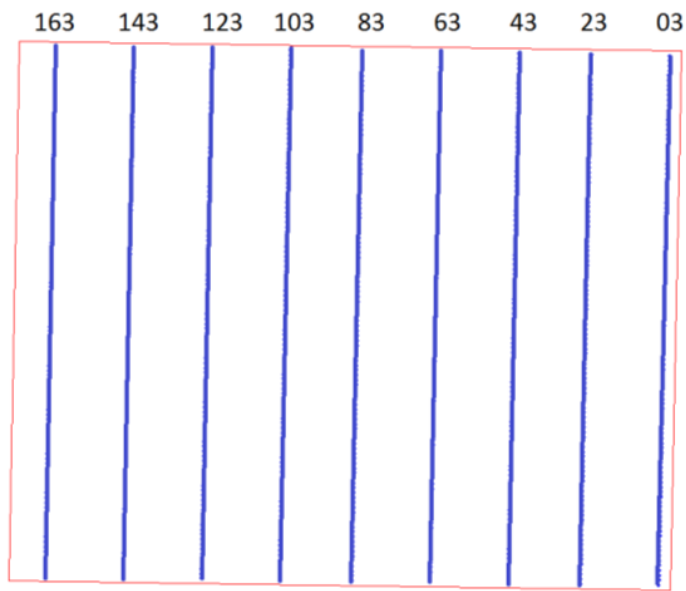

(a)

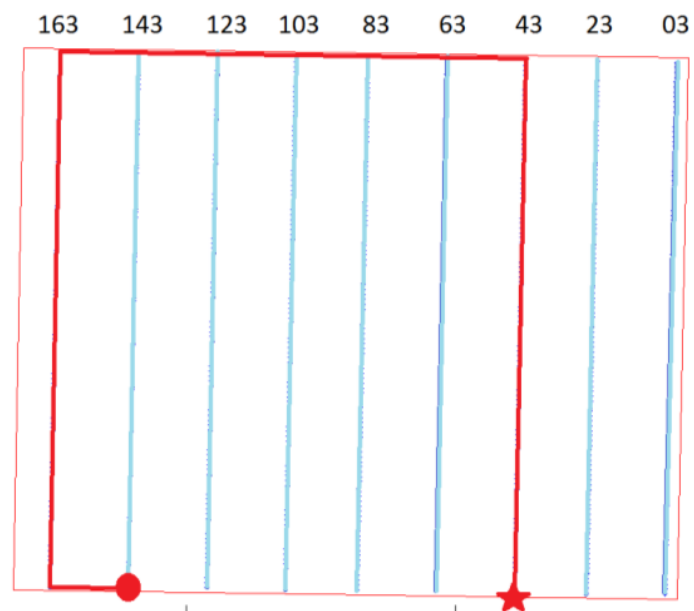

(c)

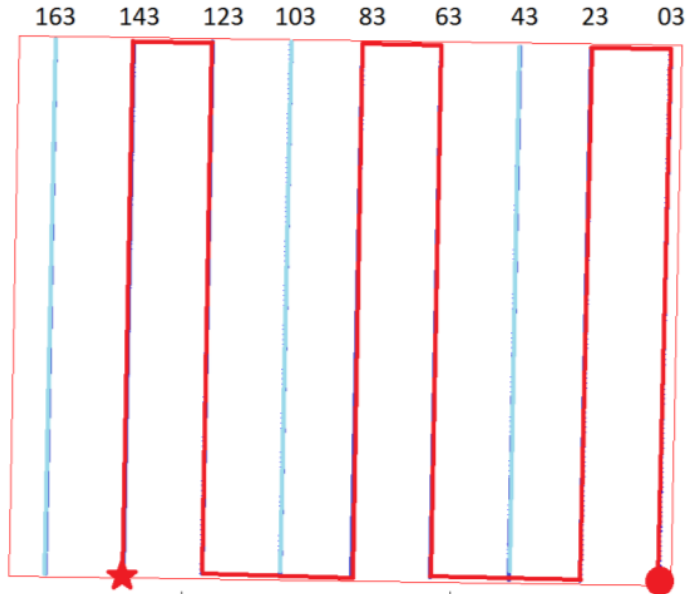

(b)

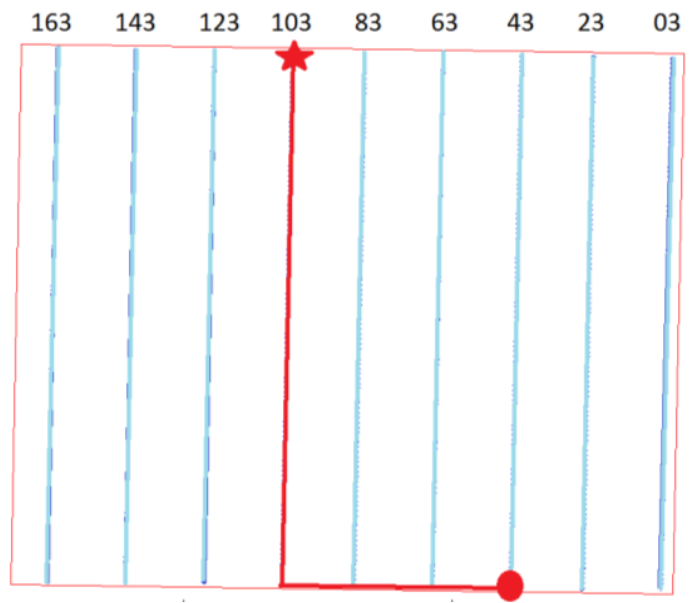

(d)

Figura 14. (a) todas linhas a serem percorridas; (b) planejamento de trajetória para o levantamento exploratório (c) planejamento de trajetória para a etapa 1 do levantamento principal (c) planejamento de trajetória para a etapa 2 do levantamento principal.

Ou seja, na etapa de planejamento de trajetórias devem ser estabelecidas quais são as linhas que devem ser percorridas para coletar os dados nos pontos escolhidos e em que sequência elas deverão ser abordadas.

Em relação ao processamento computacional que executa tanto a etapa de definição do esquema de amostragem quanto a etapa de planejamento de trajetória, esse processamento deve realizado antes que o veículo autônomo realize a excursão em campo para a coleta de dados. Ou seja, um novo processamento computacional que determina a trajetória a ser seguida deverá ser realizado entre cada ciclo de amostragem.

\section{Coleta de dados}

A cada ciclo de amostragem, a coleta de dados é executada por um veículo autônomo percorrendo o campo com sensores embarcados e coletando os dados no esquema e no 
planejamento estabelecido. São coletados e armazenados todos os dados lidos em cada linha pela qual o veículo autônomo deve passar, ou seja, é armazenada a informação completa coletada em cada linha de plantio.

\section{Filtragem dos pontos no padrão estabelecido}

Tendo sido coletados todos os dados das linhas definidas no planejamento de trajetória, na sequência devem ser selecionados somente aqueles pontos cuja localização coincidem com os pontos definidos no esquema de amostragem. São esses pontos selecionados que ficarão disponíveis para futuras análises.

O processamento computacional que realiza a filtragem de pontos deve ocorrer após o veículo autônomo realizar completamente a coleta de dados. Após ser feita a filtragem, são esses dados que estarão disponíveis para a nova análise, ou novo processamento computacional, que determinará se outro ciclo de amostragem deve ser realizado, e consequentemente um novo plano de trajetória. 


\subsection{Levantamento aninhado adaptado}

O esquema aninhado adaptado é constituído por $\mathrm{n}$ grupos de amostras, ou, como denominado daqui em diante, $\mathrm{n}$ estágios. $\mathrm{O}$ valor atribuído a um estágio tem relação direta com a distância estabelecida entre outros estágios. Ou seja, cada estágio é constituído por um grupo de amostras e é estabelecida uma escala gradual de distâncias entre diferentes estágios num mesmo processo. O estágio 1 é o estágio de maior distância $\left(\mathrm{d}_{1}\right)$, e o último estágio, ou estágio $\mathrm{n}$, é o estágio de menor distância $\left(\mathrm{d}_{\mathrm{n}}\right)$.

A determinação dos valores de distâncias de todos os estágios segue algumas regras básicas:

- Primeiro deve ser determinado o valor de distância do último estágio $\left(\mathrm{d}_{\mathrm{n}}\right)$.

- $\mathrm{O}$ valor $\mathrm{d}_{\mathrm{n}}$ é determinado com base na escala de precisão.

- Depois são determinadas as distâncias entre os outros estágios até que se determine a distância do estágio 1 .

- A distância entre cada estágio é igual a três vezes o estágio subsequente. Por exemplo, em um esquema constituído por 3 estágios $(n=3)$, se no estágio 3 a distância entre as linhas é $\mathrm{d}_{3}=11 \mathrm{~m}$, no estágio 2 a distância entre as linhas será $\mathrm{d}_{2}=33 \mathrm{~m}$, e no estágio 1 a distância entre as linhas será $\mathrm{d}_{1}=99 \mathrm{~m}$.

- Para a determinação da distância $d_{1}$ deve-se levar em consideração as dimensões do campo. Para garantir que haja uma quantidade mínima de pontos amostrais, fica definido que o valor de $\mathrm{d}_{1}$ deve ser menor do que a metade da largura do campo.

Ou seja, a determinação de distância entre estágios é limitada por uma distância mínima para o último estágio, relacionada com uma escala de precisão, e por uma distância máxima para o primeiro estágio, relacionada com as dimensões do campo.

Após determinada a distância entre estágios, são distribuídos os pontos amostrais e determinadas suas localizações, começando pelo estágio 1 . Ao longo da extensão de todo o campo são estabelecidas localizações de diversos pontos distantes um do outro por uma distância $d_{1}$, geralmente essa primeira distribuição ocorre em formato de grade. A partir dos pontos do estágio 1 são estabelecidas as localizações dos pontos do estágio 2, que devem estar a uma distância $\mathrm{d}_{2}$ dos pontos do estágio 1 , ou seja, é estabelecido uma distribuição aleatória mas obedecendo uma forma circular orbitando o ponto $1 \mathrm{com}$ um raio $\mathrm{d}_{2}$. A partir dos pontos do estágio 2 são estabelecidas as localizações dos pontos do estágio 3, que devem estar sobre 
um raio de distância $\mathrm{d}_{2}$ dos pontos do estágio 2. E assim por diante, até que sejam estabelecidos os pontos do estágio n. Geralmente, um ponto de um estágio menor dá origem a dois novos pontos de um estágio maior e assim sucessivamente.

Para aplicação da teoria de levantamento aninhado, foram realizadas adaptações sobre o esquema de distribuição de pontos para considerar a disposição das amostras em linhas de plantio. Ao invés da distribuição dos pontos conforme o esquema aninhado balanceado clássico, foi utilizado um modelo aninhado desbalanceado, com replicação entre estágios de apenas uma nova linha para cada linha do estágio anterior. Ou seja, cada novo estágio replica apenas uma nova linha a partir das linhas do estágio anterior. Assim, se no estágio 1 existem duas linhas, no estágio 2 haverá duas novas linhas distantes $\mathrm{d}_{2}$ das linhas do estágio 1 , e no estágio 3 haverá mais duas novas linhas distantes $\mathrm{d}_{3}$ apenas das linhas do estágio 2 , totalizando 6 linhas na final A Figura 15 ilustra uma distribuição de estágios no esquema aninhado desbalanceado utilizado. Em azul estão representadas as linhas do estágio 1, em vermelho, as linhas do estágio 2 e em amarelo, as linhas do estágio 3.

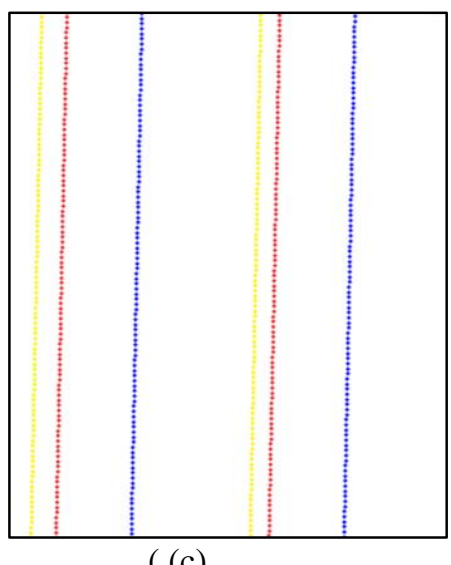

Figura 15. Configurações para o esquema aninhado desbalanceado. 


\subsection{Levantamento principal}

O espaçamento da grade do levantamento principal é determinado a partir da escala espacial de variabilidade, da escala de precisão e das dimensões da área.

Como o interesse é verificar se existem diferentes densidades de variabilidade ao longo de toda a área e suas subáreas, ou seja, subáreas com escala de variabilidade maior ou menor do que aquela indicada no levantamento exploratório para a área total, então foi utilizada uma abordagem diferente daquela do conceito da regra de ouro (veja Capítulo 2.3.2.3), que afirma que um intervalo de amostragem menor do que a escala espacial de variabilidade é suficiente para uma boa amostragem.

Neste trabalho, o espaçamento de grade inicial é determinado arbitrariamente como sendo igual ao dobro da escala espacial de variabilidade (a). A Figura 16 mostra algumas considerações necessárias para determinação do espaçamento da grade inicial. Para isso foram estabelecidas algumas restrições: o espaçamento inicial deve ser maior que o dobro da escala de precisão, caso ele não seja, então o espaçamento inicial é determinado como sendo igual a duas vezes a escala de precisão. Outra restrição, estabelecida para garantir uma quantidade mínima de linhas, é que: o espaçamento inicial máximo deve ser tal que, no mínimo, caibam quatro linhas de grade dentro da largura da área total, caso ele não seja, então o espaçamento é igual à largura do campo dividida por quatro.

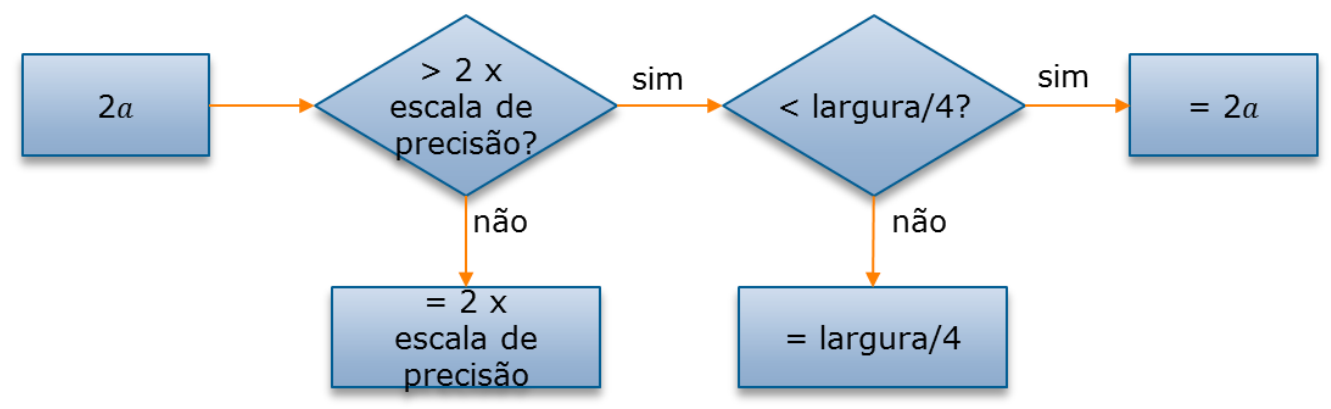

Figura 16. Esquema de determinação da grade inicial de amostragem no levantamento principal.

Além disso, por questões de restrições de desenvolvimento do algoritmo, o espaçamento de grade inicial deve ser escolhido de forma que seja um número que permita que todas as grades seguintes estejam localizadas exatamente na metade da grade anterior. Para escolha do número que determinará o espaçamento da grade inicial, foi criado um procedimento para comparação entre o valor determinado pelas restrições descritas na Figura 16 e essa nova restrição. 
Primeiro, cria-se um vetor formado por algumas sequências de números que obedecem uma relação de proporção inteira entre seus valores. Na determinação deste vetor, somente devem estar contidos valores que sejam menores que a largura do campo.

$$
\begin{aligned}
& \left\{2^{1}, 2^{2}, 2^{3}, \ldots, 3 \times 2^{1}, 3 \times 2^{2}, 3 \times 2^{3}, \ldots, 5 \times 2^{1}, 5 \times 2^{2}, 5 \times 2^{3}, \ldots, 7 \times 2^{1}, 7 \times 2^{2}, 7 \times 2^{3}, \ldots\right\} \\
& =\{2,4,8, \ldots, 6,12,24, \ldots, 10,20,40, \ldots .14,28,56, \ldots\}
\end{aligned}
$$

Multiplicando todos os elementos dessa sequência pelo espaçamento do corredor (no caso deste projeto foi utilizado o espaçamento de $0,7 \mathrm{~m}$ ), obtém-se a nova sequência:

$\{1,4 ; 2,8 ; 5,6 ; \ldots, 4,2 ; 8,4 ; 16,8 ; \ldots, 7 ; 14 ; 28 ; \ldots, 9,8 ; 19,6 ; 39,2\}$

Em seguida, é escolhido como valor para espaçamento da grade inicial, o elemento dessa sequência resultante que esteja mais próximo do espaçamento de grade determinado conforme as restrições da Figura 16.

Por exemplo, para um campo de $100 \mathrm{~m}$ de largura e com uma escala de precisão igual a 7 $\mathrm{m}$, se o levantamento aninhado adaptado obtém uma leitura de alcance de variabilidade igual a $15 \mathrm{~m}$, então, o espaçamento da grade inicial deveria ser de $30 \mathrm{~m}$. A sequência de adaptação é igual a: $\{1,4 ; 2,8 ; 4,2 ; 5,6 ; 7 ; 8,4 ; 9,8 ; 11,2 ; 14 ; 16,8 ; 19,6 ; 22,4 ; 28 ; 33,6 ; 39,2 ; 44,8 ; 56 ; 67,2$; $78,4 ; 89,6\}$. Escolhendo o valor pertencente à sequência que seja o mais próximo de 30m, então, o valor do espaçamento da grade inicial será igual a $28 \mathrm{~m}$. 

5 Resultados 


\subsection{Escalas de precisão e exploração}

Nesta seção, é relatado o estudo realizado sobre o comportamento do método em relação ao uso de diferentes valores para os critérios de decisão, sendo avaliados os critérios escala de precisão e escalas de exploração.

Os experimentos foram realizados com a aplicação do método de amostragem sobre o Conjunto Amostral I, analisando os dados de NC, referente a Área I. Para todos os testes, o critério de qualidade foi estabelecido com uma quantidade mínima de 4 amostras por área. $\mathrm{O}$ critério de densidade de variabilidade foi estabelecido pelo desvio padrão, sendo seu limite fixado em metade do desvio padrão obtido no levantamento exploratório. A escala espacial de variabilidade foi estabelecida a partir do levantamento exploratório inicial. Para simplificar o entendimento do estudo, as escalas de exploração horizontal e vertical foram consideradas tendo o mesmo valor e foram chamadas apenas de escala de exploração.

Na Figura 17 pode-se visualizar como seria a distribuições das grades sobre a área sendo explorada, sendo que as grades foram estabelecidas para os espaçamentos de 4,2 m, $7 \mathrm{~m}, 14 \mathrm{~m}$ e $21 \mathrm{~m}$ na Área I.

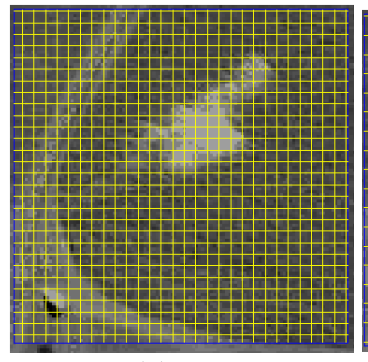

(a)

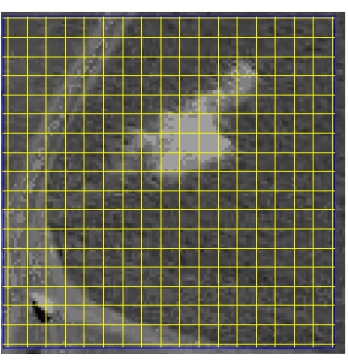

(b)

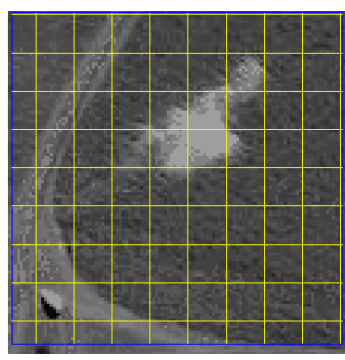

(c)

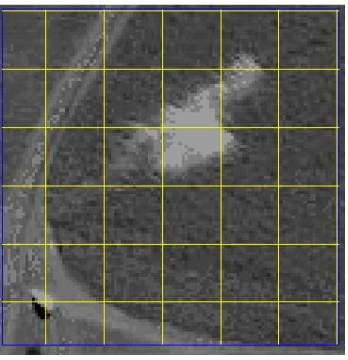

(d)

Figura 17. Área I com grades com espaçamento de (a) 4,2 m, (b) 7 m, (c) 14 m, e (d) $21 \mathrm{~m}$.

A Tabela 1, a Figura 18 e a Figura 19 mostram os resultados obtidos para os experimentos realizados sobre a Área I utilizando diferentes combinações de critérios de decisão (escala de precisão, escala exploração e escala espacial de variabilidade). A correspondência entre os padrões de amostragem obtidos na Figura 18 e os experimentos está indicada na coluna 'amostras' da Tabela 1. A correspondência entre os padrões de subáreas obtidos na Figura 19 e os experimentos está indicada na coluna 'subáreas' da Tabela 1.

A Figura 18 mostra os esquemas de amostragem resultantes, ou seja, a distribuição dos pontos amostrais sobre área, para as diferentes combinações dos critérios de decisão. 
A relação entre as escalas de precisão e de exploração e o resultado final de divisão em subáreas pode ser observada na Figura 19

Numa análise sobre a Tabela 1, é possível observar a influência da escala de precisão sobre o esquema do levantamento exploratório. Como observado anteriormente, diferentes escalas de precisão estabelecem diferentes esquemas de levantamento de exploração. Esses diferentes esquemas acabam refletindo em pequenas diferenças na leitura do alcance ( $a$ ) do variograma (diretamente relacionado com a escala espacial de variabilidade), e consequentemente, refletindo nos espaçamentos do levantamento principal.

Portanto, para escalas de precisão de 1,4m, 2,1m, 2,8m, 3,5m, 4,2m, 7m, 14m e 21m, ocorreram leituras das escalas espaciais de variabilidade de 9,45m, 10,05m, 7,73m, 8,23m, $12,02 \mathrm{~m}, 14,05 \mathrm{~m}, 14,44 \mathrm{~m}$ e $10,65 \mathrm{~m}$, respectivamente. E a partir destas escalas espaciais de variabilidade foram estabelecidos os espaçamentos do levantamento principal, sendo as grades iniciais de 19,6m, 19,6m, 16,8m, 16,8m, 22,4m, 28m, 28m e 39,2m, respectivamente.

A escala de precisão, agora em conjunto com a escala de exploração, também exerce influência sobre o mínimo espaçamento de grade alcançado. Por exemplo, para uma escala de precisão de 1,4m e escala de exploração de 1,4m, tem-se que o mínimo espaçamento de grade alcançado foi de $1,4 \mathrm{~m}$. Para a mesma escala de precisão $(1,4 \mathrm{~m})$ e para uma escala de exploração de $7 \mathrm{~m}$, o espaçamento mínimo alcançado foi de $2,8 \mathrm{~m}$. Isso quer dizer que, no primeiro caso, a mínima grade que pode ser utilizada é estabelecida pela escala de precisão, mas já no segundo caso, esse espaçamento foi limitado pelo fato de as divisões em áreas já terem alcançado o seu mínimo e isso não permitir nova divisão da grade, ou seja foi limitado também pela escala de exploração.

Ainda utilizando os dois exemplos anteriores, comparando a densidade de amostragem que se pode alcançar no primeiro caso e no segundo caso, a quantidade de amostras chega a diminuir a menos da metade (2408 contra 1060) e os esquemas de amostragem (Figura 18 (a) e Figura 19(a)) e as divisões em subáreas (Figura 18 (c) e Figura 19(d)) mostram diferenças quanto à sua disposição espacial. Comparando os exemplos em que a escala de precisão é diferente, por exemplo a escala de precisão de 1,4 m com a escala de precisão de 4,2 m e ambas com escala de exploração de 3,5 os esquemas de amostragem e as divisões em subáreas mostram diferenças maiores ainda.

Portanto, pode-se concluir que a qualidade da amostragem está diretamente relacionada com a escala de precisão e as escalas de exploração. Analisando a Figura 18 em conjunto com a Tabela 1, pode-se observar que a quantidade de amostras tem relação direta com a escala de precisão, ou seja, quanto menor a escala de precisão, maior será a quantidade de amostras. A 
escala de exploração também exerce certa influência sobre a quantidade de amostras, sendo que, quanto menor a escala de exploração, maior a quantidade de amostras. A influência da escala de exploração sobre a quantidade de amostras é limitada pela escala de precisão, pois quanto maior a escala de precisão, variações da escala de exploração exercem menor influência sobre a quantidade de amostras.

Pode-se observar também que, como desejado, as áreas que apresentavam maior variabilidade foram as áreas mais amostradas (Figura 18 (a)), sendo que o nível de detalhamento que se consegue sobre a variabilidade está diretamente relacionado com os critérios de decisão estabelecidos. Critérios de decisão mal dimensionados não oferecem um nível de detalhamento satisfatório para análise do campo, como no caso do esquema mostrado na Figura 18 (m), que será o esquema resultante para a configuração de escala de precisão de $21 \mathrm{~m}$ e escala de exploração de $14 \mathrm{~m}$. 
Tabela 1. Resultados do estudo das escalas de precisão e de exploração na Área I.

\begin{tabular}{|c|c|c|c|c|c|c|c|c|c|}
\hline 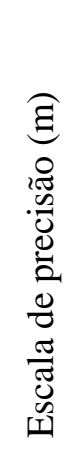 & 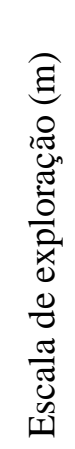 & 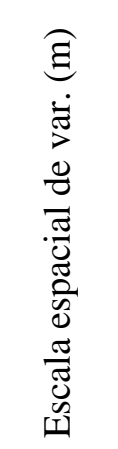 & 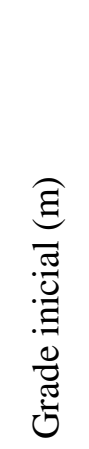 & 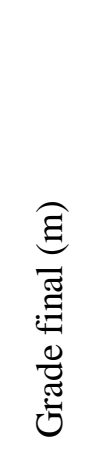 & 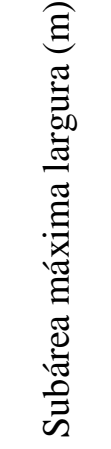 & 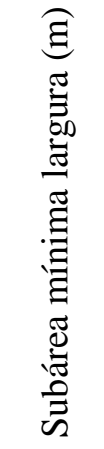 & 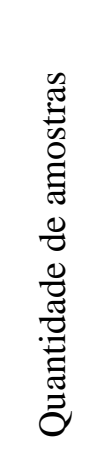 & 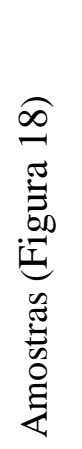 & 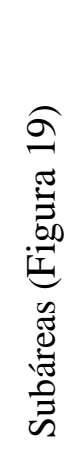 \\
\hline 1,4 & 1,4 & 9,45 & 19,6 & 1,4 & 118,3 & 1,4 & 2408 & (a) & (a) \\
\hline 1,4 & 3,5 & 9,45 & 19,6 & 1,4 & 118,3 & 3,5 & 1507 & (b) & (c) \\
\hline 1,4 & 7 & 9,45 & 19,6 & 2,8 & 118,3 & 7 & 1060 & (c) & (d) \\
\hline 1,4 & 14 & 9,45 & 19,6 & 5,6 & 118,3 & 14,7 & 399 & (f) & (i) \\
\hline 2,1 & 2,1 & 10,05 & 19,6 & 2,8 & 118,3 & 3,5 & 9994 & (d) & (b) \\
\hline 2,1 & 2,8 & 10,05 & 19,6 & 2,8 & 118,3 & 3,5 & 994 & (d) & (b) \\
\hline 2,1 & 3,5 & 10,05 & 19,6 & 2,8 & 118,3 & 3,5 & 994 & (d) & (b) \\
\hline 2,8 & 2,8 & 7,73 & 16,8 & 4,2 & 118,3 & 3,5 & 511 & (e) & (e) \\
\hline 3,5 & 2,8 & 8,23 & 16,8 & 4,2 & 118,3 & 3,5 & 511 & (e) & (e) \\
\hline 3,5 & 3,5 & 8,23 & 16,8 & 4,2 & 118,3 & 3,5 & 511 & (e) & (e) \\
\hline 3,5 & 4,2 & 8,23 & 16,8 & 4,2 & 118,3 & 7 & 511 & (e) & (f) \\
\hline 3,5 & 7 & 8,23 & 16,8 & 4,2 & 118,3 & 7 & 511 & (e) & (f) \\
\hline 3,5 & 14 & 8,23 & 16,8 & 4,2 & 118,3 & 14,7 & 511 & (e) & (k) \\
\hline 3,5 & 21 & 8,23 & 16,8 & 8,4 & 118,3 & 29,4 & 166 & (k) & (n) \\
\hline 4,2 & 2,1 & 12,02 & 22,4 & 5,6 & 118,3 & 7,7 & 271 & (g) & (g) \\
\hline 4,2 & 2,8 & 12,02 & 22,4 & 5,6 & 118,3 & 7,7 & 271 & (g) & (g) \\
\hline 4,2 & 3,5 & 12,02 & 22,4 & 5,6 & 118,3 & 7,7 & 271 & (g) & (g) \\
\hline 4,2 & 4,2 & 12,02 & 22,4 & 5,6 & 118,3 & 7,7 & 271 & (g) & (g) \\
\hline 4,2 & 7 & 12,02 & 22,4 & 5,6 & 118,3 & 7,7 & 271 & (g) & (g) \\
\hline 4,2 & 14 & 12,02 & 22,4 & 5,6 & 118,3 & 14,7 & 271 & (g) & $(\mathrm{j})$ \\
\hline 4,2 & 21 & 12,02 & 22,4 & 11,2 & 118,3 & 29,4 & 121 & (j) & (n) \\
\hline 7 & 2,1 & 14,05 & 28 & 7 & 118,3 & 7,7 & 179 & (h) & (h) \\
\hline 7 & 2,8 & 14,05 & 28 & 7 & 118,3 & 7,7 & 179 & (h) & (h) \\
\hline 7 & 3,5 & 14,05 & 28 & 7 & 118,3 & 7,7 & 179 & (h) & (h) \\
\hline 7 & 4,2 & 14,05 & 28 & 7 & 118,3 & 7,7 & 179 & (h) & (h) \\
\hline 7 & 7 & 14,05 & 28 & 7 & 118,3 & 7,7 & 179 & (h) & (h) \\
\hline 7 & 14 & 14,05 & 28 & 7 & 118,3 & 14,7 & 179 & (h) & (l) \\
\hline 7 & 21 & 14,05 & 28 & 7 & 118,3 & 29,4 & 151 & (i) & (n) \\
\hline 14 & 2,1 & 14,44 & 28 & 14 & 118,3 & 14,7 & 67 & (1) & (m) \\
\hline 14 & 2,8 & 14,44 & 28 & 14 & 118,3 & 14,7 & 67 & (l) & (m) \\
\hline 14 & 3,5 & 14,44 & 28 & 14 & 118,3 & 14,7 & 67 & (l) & (m) \\
\hline 14 & 4,2 & 14,44 & 28 & 14 & 118,3 & 14,7 & 67 & (l) & (m) \\
\hline 14 & 7 & 14,44 & 28 & 14 & 118,3 & 14,7 & 67 & (l) & (m) \\
\hline 14 & 14 & 14,44 & 28 & 14 & 118,3 & 14,7 & 67 & (l) & (m) \\
\hline 14 & 21 & 14,44 & 28 & 14 & 118,3 & 29,4 & 67 & (l) & (n) \\
\hline 21 & 14 & 10,65 & 39,2 & 39,2 & 118,3 & 118,3 & 9 & (m) & (m) \\
\hline 21 & 21 & 10,65 & 39,2 & 39,2 & 118,3 & 118,3 & 9 & (m) & (m) \\
\hline
\end{tabular}




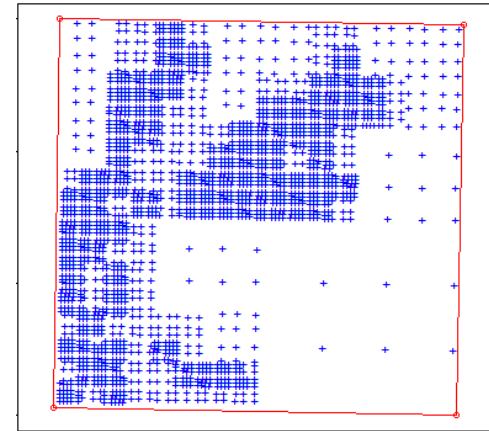

(a)

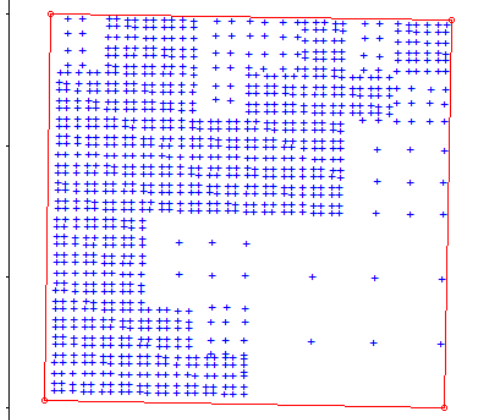

(d)

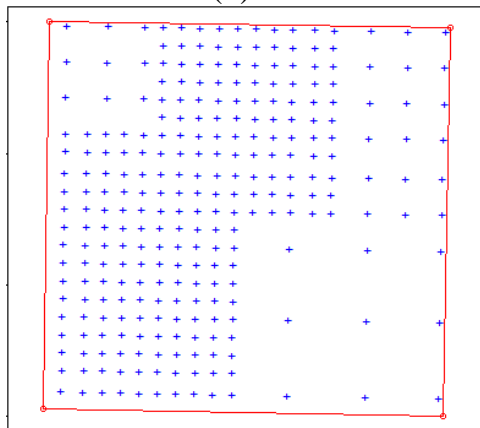

(g)

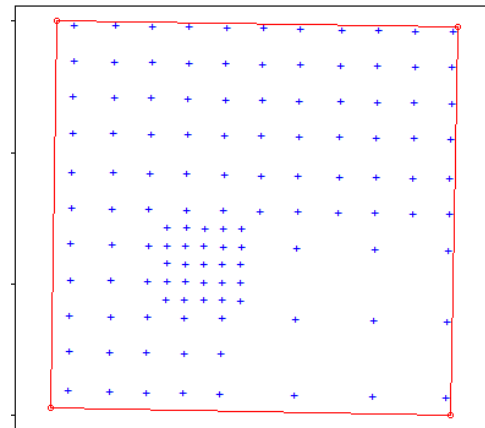

(j)

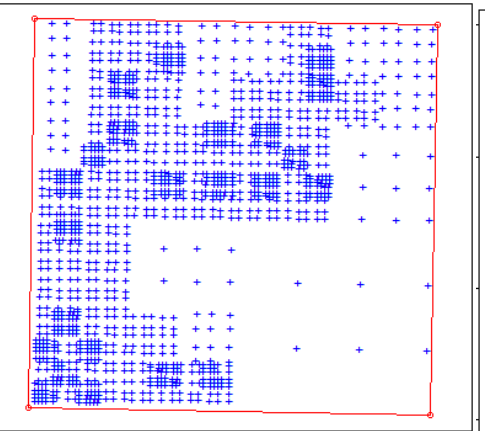

(b)

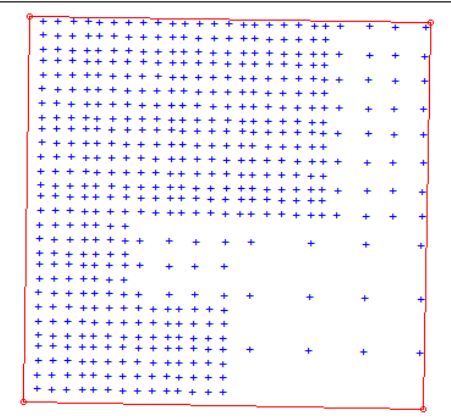

(e)

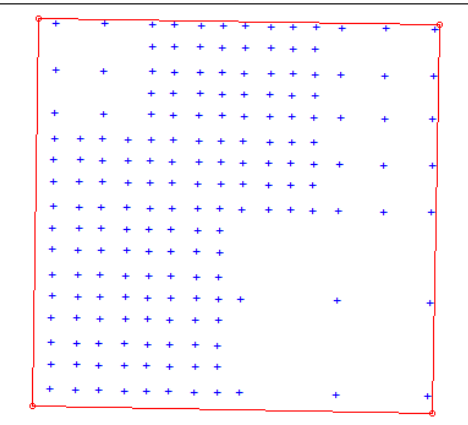

(h)

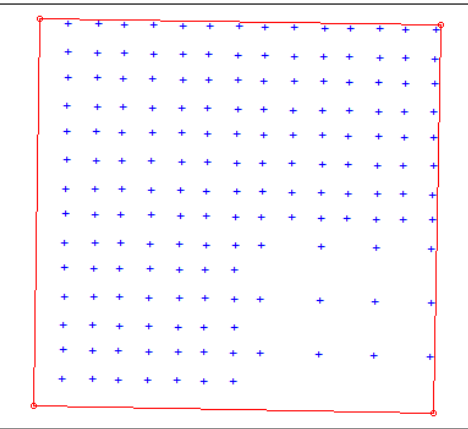

(k)

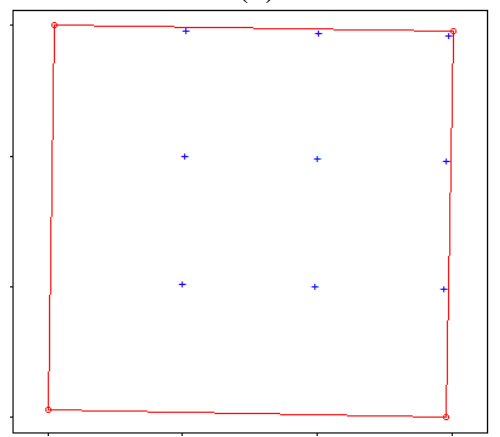

(m)

Figura 18. Esquema de amostragem final, do estudo de escalas de precisão e de exploração na Área I.

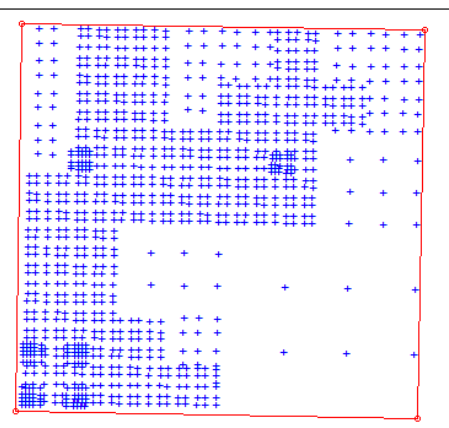

(c)

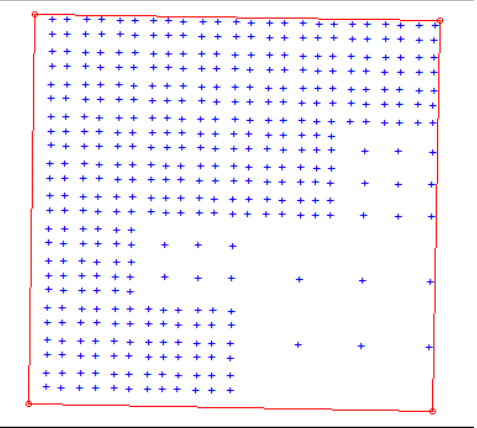

(f)

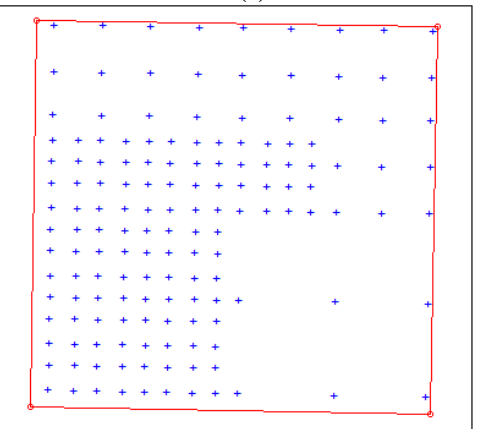

(i)

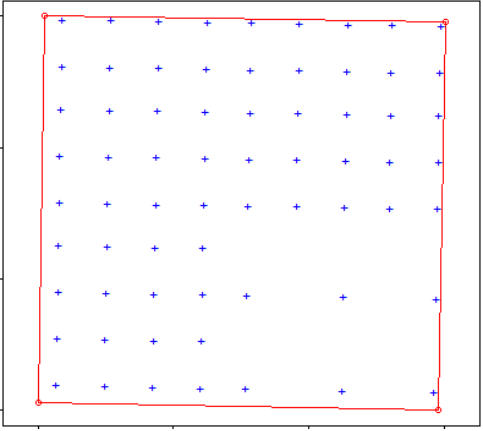

(1) 


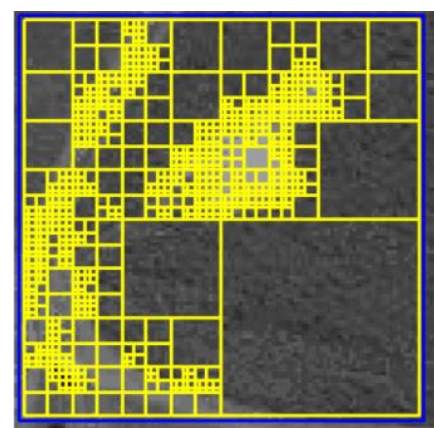

(a)

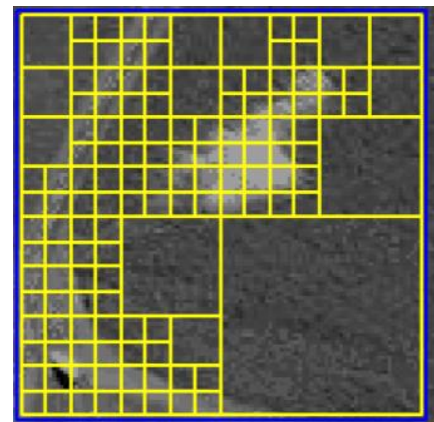

(d)

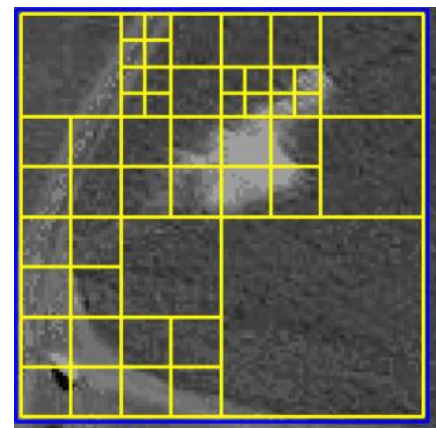

(g)

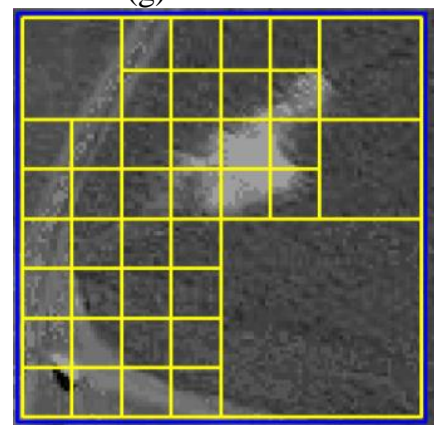

(j)

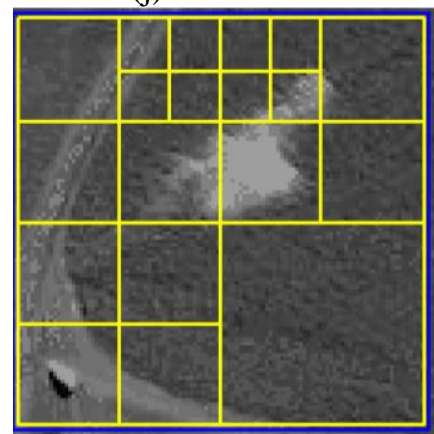

(m)

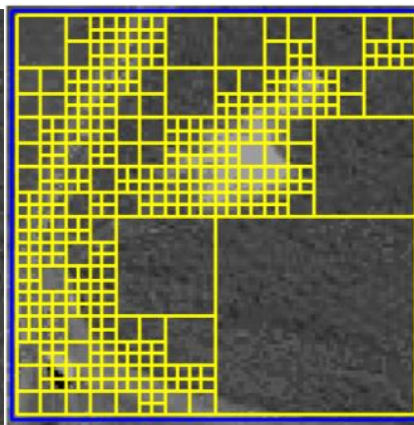

(b)

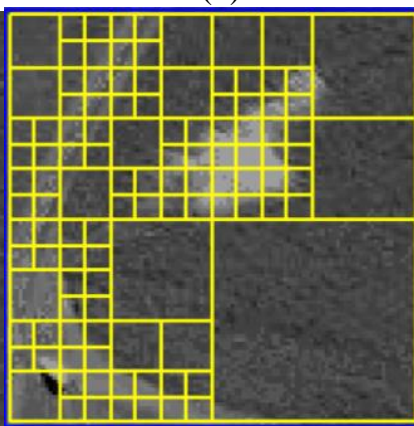

(e)

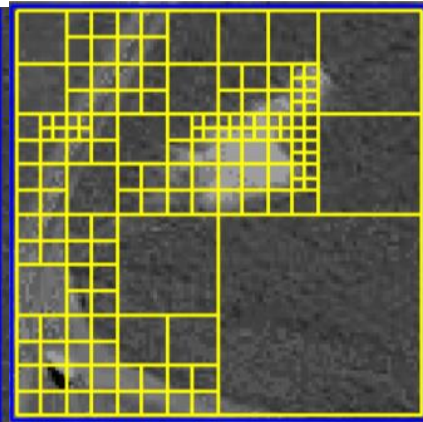

(h)

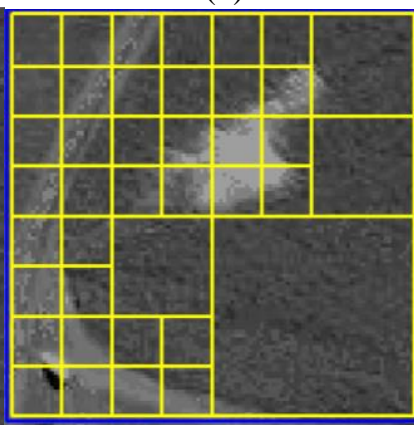

(k)

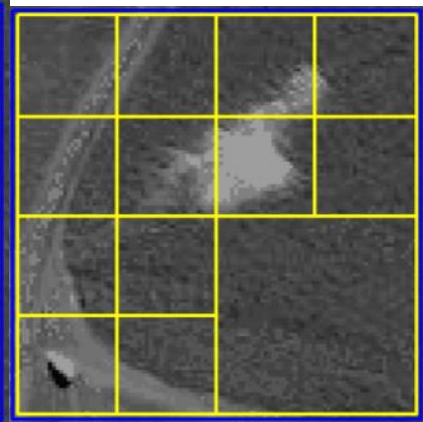

(n)

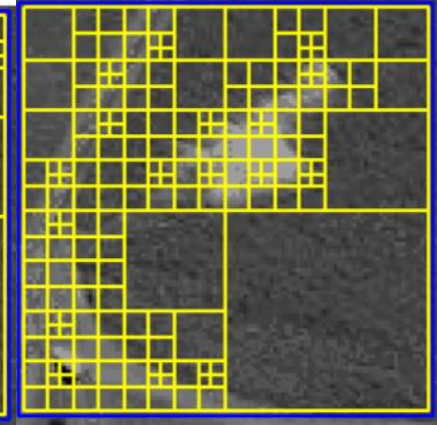

(c)

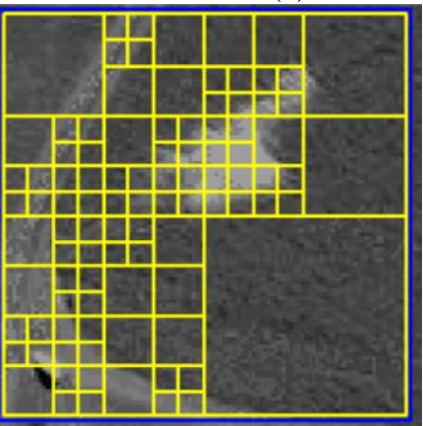

(f)

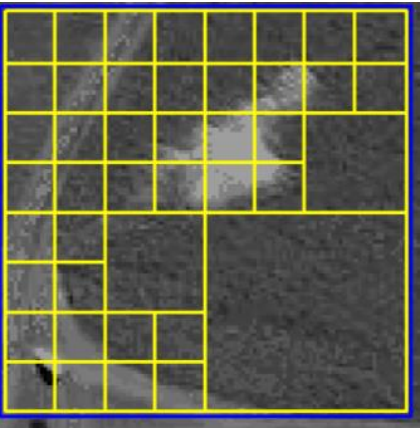

(i)

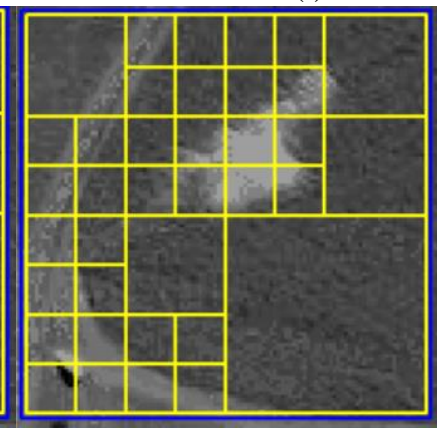

(1)

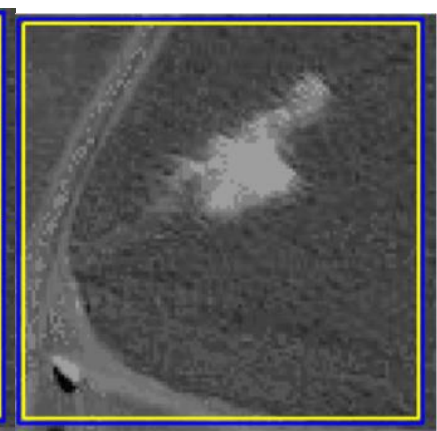

(o)

Figura 19.Esquema final de subáreas, do estudo de escalas de precisão e de exploração na Área I. 


\subsection{Qualidade}

Nesta seção, é relatado o estudo realizado sobre o comportamento do método em relação ao critério de decisão de qualidade. Para a análise desse critério foram considerados os parâmetros de quantidade de dados e de qualidade de krigagem.

Os experimentos a seguir foram realizados com a aplicação do método de amostragem sobre o Conjunto Amostral I, analisando os dados de NC, referente a Área I. Para os critérios de decisão, foram estabelecidas escala de precisão e escalas de exploração com valores iguais a 3,5m. O critério de densidade de variabilidade foi estabelecido pelo desvio padrão, sendo seu limite fixado em metade do desvio padrão obtido no levantamento exploratório.

\section{Critério de decisão de qualidade: quantidade mínima de amostras.}

Primeiro foram realizados testes em relação à diferentes quantidades mínimas de amostras, sendo o método executado para as quantidades mínimas de dados iguais a 4, 8, 16 e 20 amostras. As Figura 20 (a), (b), (c) e (d) ilustram os esquemas de amostragem resultantes para as diferentes quantidades mínimas de 4, 8, 16 e 20 amostras, respectivamente. As Figura 20 (e), (f), (g) e (h) ilustram os esquemas de divisões resultantes para estes valores mínimos de amostras. Vale lembrar que a quantidade de dados é analisada em relação à área ou subárea que está sendo analisada no momento.

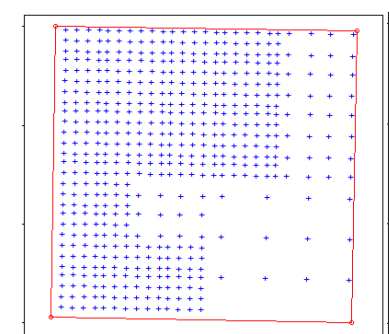

(a)

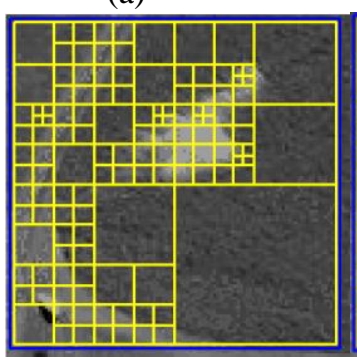

(e)

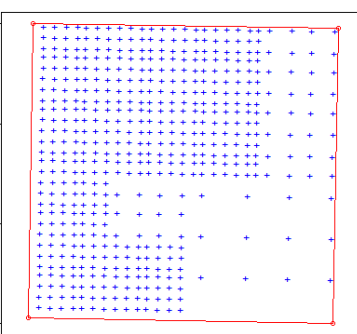

(b)

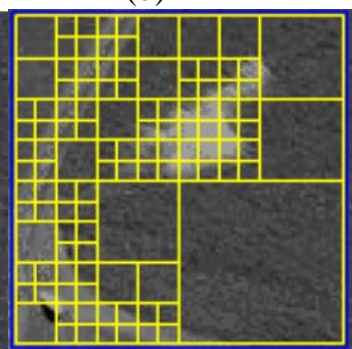

(f)

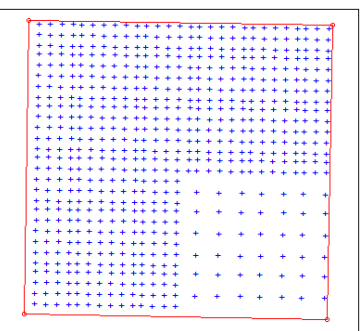

(c)

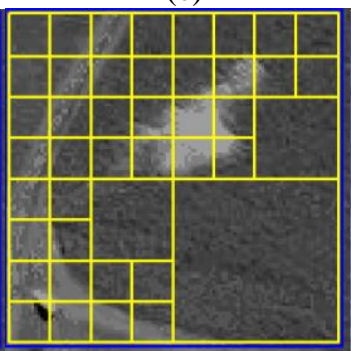

(g)

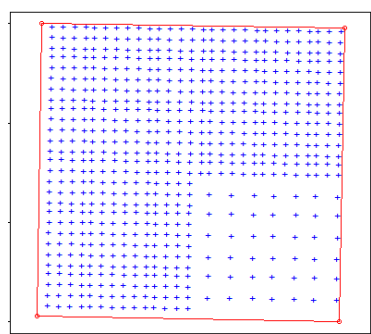

(d)

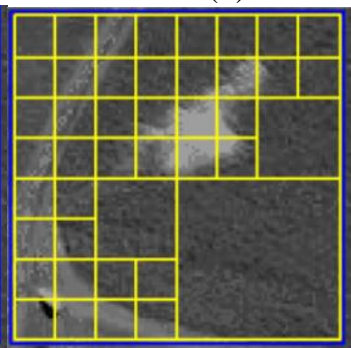

(h)

Figura 20. Resultados do estudo sobre qualidade em relação à quantidade mínima de dados. Esquemas de amostragem para limites iguais a (a) 4, (b) 8, (c) 16 e (d) 20 dados. Esquemas de divisões para limites iguais a (e) 4, (f) 8 , (g) 16 e (h) 20 . 
Pode-se observar pelas Figura 20 que, mesmo estabelecendo-se uma quantidade mínima de 4 amostras, mantém-se um esquema de amostragem equivalente às maiores quantidades. $\mathrm{Ou}$ seja, 4 amostras é uma quantidade mínima aceitável para ser utilizada como critério de decisão em análises futuras.

Estabelecida a quantidade mínima de 4 amostras como a mais adequada para o critério de qualidade, os experimentos realizados daqui em diante utilizam essa quantidade de amostras como valor de critério de decisão de qualidade.

\section{Critério de decisão de qualidade: relação dos indicadores de krigagem com a} qualidade.

Para os testes sobre o critério de decisão relacionado com a qualidade de krigagem, foi realizado um estudo inicial utilizando amostragem em grade aplicada sobre a Área I e sobre sua divisão em quadrantes (Figura 23), resultando também na análise das subáreas I-I, I-II, I-III e I-IV. O método foi repetido em cada subárea utilizando-se diferentes espaçamentos de grade de (3,5m, $7 \mathrm{~m}$ e $21 \mathrm{~m})$. Os resultados destes testes estão apresentados na Tabela 2.

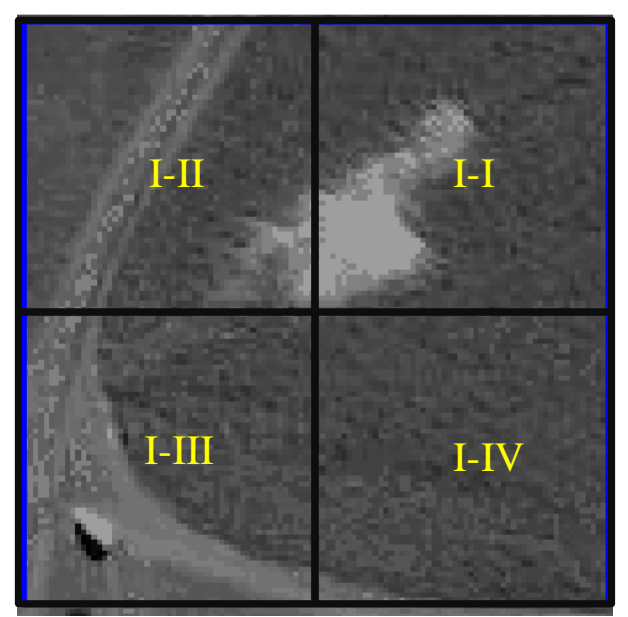

Figura 21. Área I e suas subáreas I-I, I-II, I-III e I-IV.

O critério para decidir a qualidade da amostragem por índices de krigagem parte da consideração inicial que existe uma relação de qualidade da amostra com a densidade de amostragem, ou seja, uma amostra com uma quantidade maior de dados para uma área em comparação com outras amostras com menores quantidades para a mesma área, pode intuitivamente ser classificada como uma amostra de melhor qualidade. Ao se fazer a relação dessa qualidade com os índices de krigagem, pode-se fazer a avaliação sobre a qualidade da mostra observando apenas os índices de krigagem. Tais avaliações devem ser feitas comparativamente entre diferentes grupos de amostras, já que os índices citados não possuem 
uma escala absoluta de valores, ou seja, seus valores dependem do conjunto de amostras em análise.

Na Tabela 2, observando comparativamente os valores dos indicadores loglik, AIC e BIC aplicados sobre o Conjunto Amostral I para diferentes espaçamentos de grade, tais valores indicam que quanto mais espaçada a grade, menor é o valor absoluto do índice. Por exemplo, para a grade com espaçamento 3,5 m (mais densa) aplicada sobre a Área I, os valores de loglik, AIC e BIC foram de -4617, 9241 e 9257, respectivamente, já para a grade de $21 \mathrm{~m}$ (menos densa) os valores lidos foram -159, 325 e 330, respectivamente.

Com o intuito de se estabelecer um indicador que reduzisse a dependência da indicação da qualidade em relação à quantidade de dados, foi realizado um ajuste matemático sobre o índice AIC, dividindo-o pela quantidade de dados. O novo indicador "AIC/quantidade" mantém a proporção com a qualidade, mas agora invertido, ou seja, amostras mais densas (supõem-se de melhor qualidade) são indicadas com valores menores do que amostras menos densas. Por exemplo, para a grade de 3,5m na Área I, o indicador “AIC/quantidade” possui o valor 7,99 e para a grade de $21 \mathrm{~m}$, indicou 9,03 .

Para os indicadores de variância de krigagem média e máxima também ocorre proporção entre seus valores e a densidade das grades, sendo que grades mais densas apresentam valores menores para ambos. Por exemplo, para a grade de 3,5m na Área I, os valores de variância de krigagem média e máxima indicam 76,20 e 161,89, respectivamente, e para a grade de $21 \mathrm{~m}$ os valores são 392,99 e 559,10, respectivamente.

Portanto, pelas análises apresentadas, conclui-se que uma melhor qualidade da amostra é indicada por maiores valores absolutos dos indicadores loglik, AIC e BIC, comparativamente. Melhor qualidade também é indicada por valores menores do indicador "AIC/quantidade", comparativamente. E valores menores dos indicadores de variância de krigagem média e máxima estão relacionados com uma melhor qualidade da amostra, também comparativamente. 
Tabela 2. Resultados para amostragem realizada sobre o Conjunto Amostral I, sobre dados em NC, para amostragem em grade com espaçamentos de 3,5m, $7 \mathrm{~m}$ e $21 \mathrm{~m}$, para a

\begin{tabular}{|c|c|c|c|c|c|c|c|c|c|c|c|c|c|c|c|}
\hline & \multicolumn{5}{|c|}{ Grade $3,5 \mathrm{~m}$} & \multicolumn{5}{|c|}{ Grade $7 \mathrm{~m}$} & \multicolumn{5}{|c|}{ Grade $21 \mathrm{~m}$} \\
\hline & 1 & $I-I$ & $I-I I$ & I-III & I-IV & I & $I-I$ & I-II & I-III & I-IV & I & I-I & I-II & I-III & I-IV \\
\hline Quantidade de amostras & 1156 & 289 & 289 & 289 & 289 & 289 & 81 & 81 & 81 & 81 & 36 & 9 & 9 & 9 & 9 \\
\hline Amostras por ha & 816,18 & 880,17 & 880,17 & 880,17 & 880,17 & 204,04 & 246,68 & 246,69 & 246,69 & 246,69 & 25,41 & 27,40 & 27,40 & 27,40 & 27,40 \\
\hline Média (NC) & 80,11 & 82,60 & 83,56 & 88,31 & 71,25 & 80,01 & 82,72 & 85,06 & 88,40 & 71,69 & 80,94 & 82,22 & 83,44 & 94,22 & 67,22 \\
\hline Mediana (NC) & 73 & 70 & 78 & 85 & 69 & 73 & 71 & 83 & 85 & 69 & 70,50 & 68 & 78 & 79 & 66,00 \\
\hline Moda (NC) & 65 & 158 & 75 & 113 & 65 & 68 & 158 & 73 & 113 & 69 & 68 & 58 & 78 & 79 & 58,00 \\
\hline Desvio padrão (dp) & 21,97 & 29,50 & 18,58 & 21,89 & 10,80 & 20,94 & 29,94 & 20,15 & 24,10 & 12,25 & 23,55 & 32,73 & 20,66 & 37,10 & 8,02 \\
\hline CV & 0,27 & 0,35 & 0,22 & 0,24 & 0,15 & 0,26 & 0,36 & 0,23 & 0,27 & 0,17 & 0,29 & 0,39 & 0,24 & 0,39 & 0,11 \\
\hline Variabilidade (C) & 437,29 & 947,42 & 390,62 & 454,08 & 126,14 & 433,53 & 1008,65 & 429,01 & 582,61 & 249,68 & 563,85 & 3097,26 & 427,02 & 2626,62 & 64,44 \\
\hline Alcance $(a)$ & 8,89 & 19,07 & 7,28 & 4,53 & 3,20 & 13,62 & 20,35 & 7,72 & 5,30 & 16,52 & 10,65 & 74,88 & 0,51 & 45,41 & 0,61 \\
\hline Predição de krig. média (NC) & 80,28 & 82,53 & 83,48 & 87,69 & 70,89 & 80,47 & 82,88 & 84,71 & 87,40 & 70,83 & 81,88 & 90,41 & 83,44 & 103,36 & 67,22 \\
\hline Predição de krig. mediana (NC) & 72,90 & 69,96 & 79,20 & 82,96 & 70,21 & 74,15 & 71,06 & 81,67 & 82,04 & 69,26 & 78,89 & 78,66 & 83,44 & 93,39 & 67,22 \\
\hline Predição de krig. moda (NC) & 68,07 & 67,09 & 75,62 & 73,51 & 67,99 & 68,38 & 68,13 & 75,65 & 74,43 & 68,26 & 70,39 & 66,91 & 83,44 & 75,20 & 67,23 \\
\hline Predição de krig. dp & 20,29 & 28,13 & 16,08 & 18,289 & 6,93 & 18,44 & 27,38 & 15,09 & 17,02 & 8,44 & 13,06 & 28,41 & 0,61 & 29,04 & 0,29 \\
\hline loglik & -4617 & -1165 & -1160 & -1230 & -1073 & -1183 & -349 & -343 & -362 & -300 & -159 & -38 & -35 & -39 & -28 \\
\hline AIC & 9241 & 2336 & 2326 & 2467 & 2153 & 2373 & 705 & 693 & 730 & 607 & 325 & 82 & 77 & 84 & 62 \\
\hline BIC & 9257 & 2347 & 2337 & 2478 & 2164 & 2384 & 712 & 700 & 738 & 614 & 330 & 83 & 77 & 85 & 62 \\
\hline AIC/quantidade & 7,99 & 8,08 & 8,05 & 8,53 & 7,45 & 8,21 & 8,70 & 8,55 & 9,02 & 7,50 & 9,03 & 9,21 & 8,57 & 9,44 & 6,89 \\
\hline Variância de krig. média & 76,20 & 76,93 & 81,89 & 148,88 & 56,24 & 100,06 & 150,32 & 160,62 & 299,97 & 45,62 & 392,99 & 466,37 & 473,69 & 632,35 & 71,43 \\
\hline Variância de krig. máx & 161,89 & 126,64 & 130,09 & 226,32 & 82,20 & 266,28 & 208,65 & 217,62 & 395,80 & 63,16 & 559,10 & 1331,22 & 474,47 & 1645,24 & 71,60 \\
\hline
\end{tabular}





\section{Critério de decisão de qualidade: comparação entre indicadores de krigagem.}

Comparando os resultados dos índices (Tabela 2) para o método aplicado nas subáreas I-I, I-II, I-III e I-IV e para o mesmo espaçamento de grade, observa-se que, para os indicadores loglik, AIC e BIC, há semelhança entre os valores dos índices comparados entre estas subáreas, mas em comparação com os dados da área de origem, a Área I, há uma considerável diferença na dimensão do valor.

Por exemplo, na Área I com grade de 3,5m, o AIC é igual a 9241, já nas subáreas I-I, I-II, I-III e I-IV os valores são iguais a 2336, 2326, 2467 e 2153, praticamente uma diferença de 75\%. Já para os indicadores “AIC/quantidade” essa diferença é menor, em torno de 7\%, com o valor de 7,99 para a Área I e 8,08, 8,05, 8,53 e 7,45 para as subáreas I-I, I-II, I-III e I-IV, respectivamente. Para as variâncias de krigagem média e máxima aparentemente essa diferença também é menor, mas existe uma diferença considerável entre os valores das subáreas, fato que não ocorre com os outros indicadores. Por exemplo, para variância de krigagem média das subáreas I-I, I-II, I-III e I-IV, com valores 76,93, 81,89, 148,88 e 56,24, existe uma diferença de até $62 \%$, já para os outros indicadores essa diferença a máxima diferença entre subáreas é de $13 \%$.

Considerando que a qualidade da amostra no que diz respeito à densidade de amostragem (quantidade de amostras por área), deveria ser a mesma para as diferentes áreas apresentadas. Se considerarmos a menor variação dos indicadores entre as diferentes áreas, o indicador "AIC/quantidade" é o que apresenta menor variação, consequentemente é o que mantém uma melhor relação de indicação de qualidade da amostra. Portanto, conclui-se que, neste caso, o melhor indicador para qualidade de krigagem é o indicador "AIC/quantidade", que reduz o impacto da quantidade de amostras sobre seu valor. Consequentemente, o índice “AIC/quantidade” foi escolhido para representar o critério de decisão de qualidade.

\section{Critério de decisão de qualidade: especificação de limite do indicador de} krigagem.

Buscando estabelecer os limites que guiam a decisão relacionada com o critério de qualidade de krigagem, o método foi executado novamente, com as mesmas considerações especificadas anteriormente, mas considerando-se diferentes valores de limite para a qualidade de krigagem. Baseado na análise anterior, o indicador "AIC/quantidade" foi escolhido como critério de decisão de qualidade de krigagem.

Para que seja tomada a decisão se uma amostra é de qualidade aceitável, o valor de índice de krigagem obtido para a subárea atual deve ser comparado com valor de índice de krigagem 
obtido para a área que a originou (a subárea atual é resultado da divisão em quadrantes da área que a originou). Para isso é estabelecido um valor limite de comparação para a qualidade de índice de krigagem. Esse valor limite é estabelecido como uma porcentagem do índice da área original. Caso o valor de índice obtido na subárea atinja uma porcentagem específica do valor obtido na área de origem, então a qualidade da amostragem é considerada satisfatória, caso contrário uma amostragem com mais dados deve ser realizada.

Por exemplo, se a área original apresentou o valor 10 para o indicador "AIC/quantidade", e se for estabelecido um limite de $100 \%$ para qualidade, a subárea a ser analisada precisa apresentar o valor igual ou menor que $100 \%$ do valor do indicador da área original. Ou seja, a subárea deve apresentar um valor menor ou igual a 10 do indicador "AIC/quantidade" para amostra ser considerada de qualidade aceitável. Lembrando que quanto menor o valor do indicador "AIC/quantidade", melhor a qualidade da amostra.

Caso o limite escolhido tenha sido 105\%, a subárea a ser analisada precisa apresentar o valor de índice igual ou menor que 10,5 para ser considerado com qualidade aceitável. Caso o limite escolhido tenha sido $110 \%$, a subárea a ser analisada precisa apresentar o valor de índice igual ou menor que 11 para ser considerado com qualidade aceitável. Caso o limite escolhido tenha sido $115 \%$, a subárea a ser analisada precisa apresentar o valor de índice igual ou menor que 11,5 para ser considerado com qualidade aceitável.

A Figura 22 ilustra alguns resultados de testes realizados para diferentes valores de porcentagem limite para qualidade. Os valores para as porcentagens analisadas como limite do parâmetro foram 100\%, 105\%, 110\% e 115\%. Para cada limite, a Figura 22 ilustra os esquemas de amostragem resultantes, a divisão de áreas final e a interpolação resultante para o este estudo.

Os esquemas de amostragem resultantes ao método de exploração aplicado estão representados nas Figura 22 (a), (b), (c) e (d) e são relativos ao limite de comparação de qualidade de $100 \%, 105 \%, 110 \%$ e $115 \%$, respectivamente. Uma análise visual destes esquemas de amostragem indica semelhanças entre os esquemas das Figura 22 (c) e (d) e um pouco mais de diferenças entre os esquemas das Figura 22 (a) e (b). Além disso, os esquemas das Figura 22 (c) e (d) parecem melhor amostrar o campo e suas áreas de variabilidade. Ou seja, os limites de $110 \%$ e $115 \%$ oferecem bons resultados ao método.

O mesmo ocorre com as imagens que indicam as divisões de áreas resultantes, representadas pelas Figura 22 (e), (f), (g) e (h), relativas aos limites de 100\%, 105\%, 110\% e 115\%, respectivamente. Existe uma semelhança maior entre as Figura $22(\mathrm{~g})$ e (h) se comparadas com as Figura 22 (e) e (f). Ou seja, existe uma semelhança maior entre os limites de $110 \%$ e 115\%, 
do que entre os limites de $100 \%$ e $105 \%$. Além disso, os limites de $110 \%$ e $115 \%$, também aparentam apresentar uma divisão final que melhor aborda a variabilidade da área.

Com base nos resultados apresentados, o valor de $110 \%$ foi escolhido como limite para o critério de qualidade do índice "AIC/quantidade".

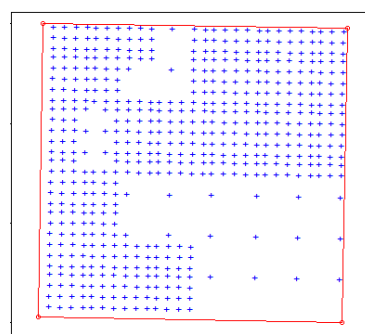

(a)

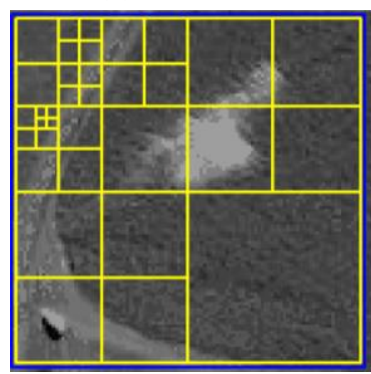

(e)

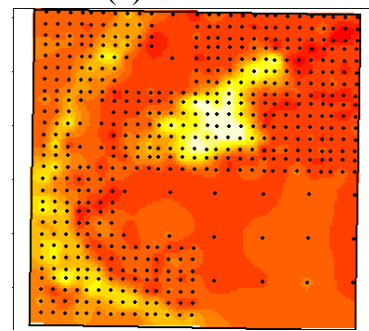

(i)

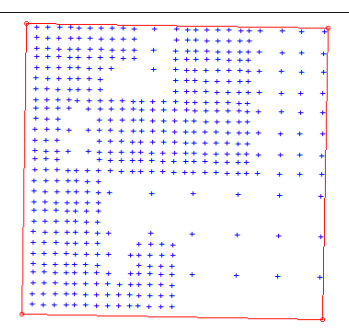

(b)

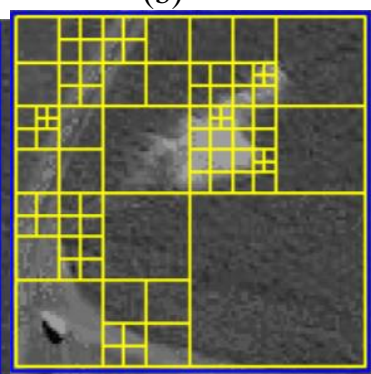

(f)

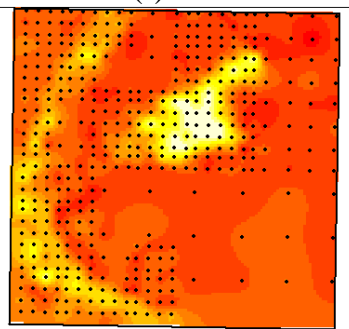

(j)

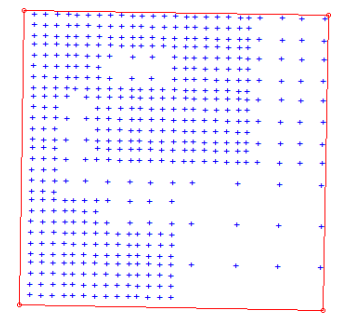

(c)

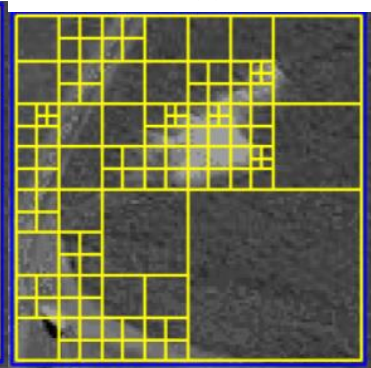

(g)

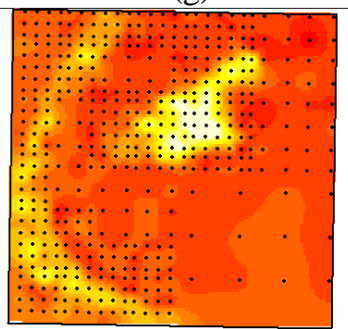

(k)

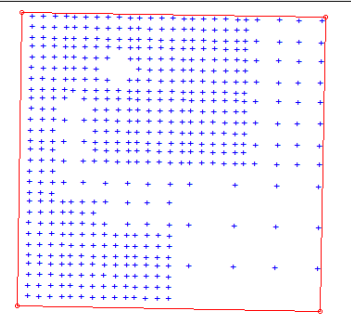

(d)

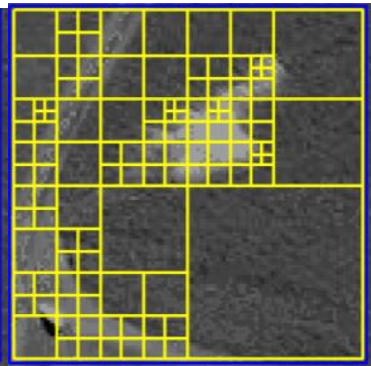

(h)

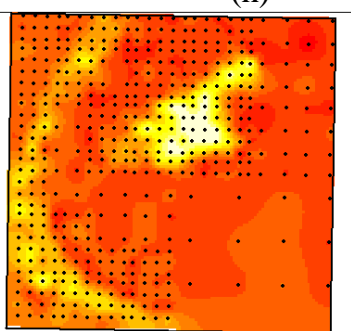

(1)

Figura 22. Resultados do estudo sobre critério de decisão de qualidade em relação à indicadores de krigagem, aplicado sobre o Conjunto Amostral I, em NC, para a Área I. Esquemas de amostragem para limites iguais a (a) $100 \%$, (b) $105 \%$, (c) $110 \%$ e (d) $115 \%$. Esquemas de divisões para limites iguais a (e) $100 \%$, (f) $105 \%$, (g) $110 \%$ e (h) $115 \%$. Imagens sobre krigagem para limites iguais a (i) $100 \%$, (j) $105 \%$, (k) $110 \%$ e (l) $115 \%$.

Por exemplo, a Tabela 3, apresenta os resultados do método de amostragem conforme parâmetros definidos anteriormente aplicados sobre a Área I e sobre as subáreas I-I, I-II, I-III e I-IV. Para estabelecer se as amostras das subáreas são de qualidade satisfatória é necessário comparar o valor do indicador "AIC/quantidade" dessas subáreas com o da Área I de origem. Como o valor limite escolhido foi $110 \%$ e como o valor do indicador "AIC/quantidade" da Área I é 8,52 , então o valor de comparação é $110 \%$ x 8,52, que resulta no valor 9,37. Assim, para que a amostra seja considerada de qualidade aceitável, o indicador "AIC/quantidade" das subáreas deve ser menor ou igual que 9,37. Conforme a Tabela 3, as subáreas I-I, I-II, I-III e IIV apresentam o valor do indicador "AIC/quantidade" igual a 9,06, 8,07, 7,83 e 6,57, respectivamente. Ou seja, todas as subáreas apresentam qualidade satisfatória da amostra. Caso 
alguma delas apresentasse um valor maior do que 9,37, então as amostras dessa subárea não apresentariam uma qualidade desejada, por consequência seria necessário realizar uma amostragem mais densa sobre ela.

Tabela 3. Análise sobre o Conjunto Amostral I, sobre dados em NC, na Área I, para escala de precisão de 3,5 m, escalas de exploração de $3,5 \mathrm{~m}$, densidade de variabilidade de desvio padrão de $1 / 2$ do levantamento exploratório e qualidade de quantidade de 4 pontos.

\begin{tabular}{l|rrrrr}
\hline \multicolumn{5}{c}{ subárea } \\
\hline & \multicolumn{7}{c}{ I } & II & I-II & I-III & I-IV \\
Área (m²) & 14163,54 & 3540,91 & 3540,88 & 3540,85 & 3540,88 \\
Área (ha) & 1,42 & 0,35 & 0,35 & 0,35 & 0,35 \\
Quantidade de amostras & 49 & 16 & 12 & 9 & 12 \\
Amostras por m 2 $^{2}$ & 0,0034 & 0,0045 & 0,0033 & 0,0025 & 0,0033 \\
Amostras por ha & 34,59 & 45,18 & 33,88 & 25,41 & 33,88 \\
\hline Média (NC) & 78,53 & 78,87 & 83,16 & 81,44 & 71,25 \\
Mediana (NC) & 72 & 69 & 80 & 84 & 69 \\
Moda (NC) & 65 & 69 & 80 & 68 & 65 \\
Maior valor (NC) & 129 & 129 & 113 & 113 & 85 \\
Menor valor (NC) & 51 & 51 & 65 & 68 & 64 \\
Banda (NC) & 78 & 78 & 48 & 45 & 21 \\
\hline Desvio padrão (dp) & 17,91 & 25,59 & 15,09 & 14,08 & 6,73 \\
CV & 0,22 & 0,32 & 0,18 & 0,17 & 0,09 \\
\hline Variabilidade (C) & 326,33 & 716,61 & 231,62 & 291,91 & 47,64 \\
Alcance (a) & 8,63 & 11,68 & 5,56 & 20,42 & 8,49 \\
\hline Predição de krig. Média (NC) & 79,23 & 80,74 & 82,81 & 84,16 & 71,63 \\
Predição de krig. Mediana (NC) & 77,90 & 74,44 & 82,63 & 83,99 & 70,84 \\
Predição de krig. Moda (NC) & 79,42 & 68,04 & 83,14 & 84,61 & 69,64 \\
Predição de krig. Dp & 9,40 & 16,64 & 4,9966 & 9,22 & 3,04 \\
\hline loglik & $-205,82$ & $-69,52$ & $-45,45$ & $-32,27$ & $-36,46$ \\
AIC & 417,64 & 145,05 & 96,90 & 70,54 & 78,93 \\
BIC & 423,32 & 147,37 & 98,36 & 71,13 & 80,38 \\
AIC/quantidade & 8,52 & 9,06 & 8,07 & 7,83 & 6,57 \\
\hline Variância de krig. média & 235,30 & 400,12 & 207,17 & 143,92 & 35,83 \\
Variância de krig. máx. & 335,33 & 603,98 & 252,12 & 307,19 & 51,54 \\
\hline & & & & &
\end{tabular}




\subsection{Densidade de variabilidade}

Nesta seção, é relatado o estudo realizado sobre o comportamento do método de amostragem em relação ao critério de densidade de variabilidade com uso de diferentes parâmetros e limites.

Os experimentos foram realizados com a aplicação do método de amostragem sobre o Conjunto Amostral I, analisando os dados de NC, referente a Área I. Para os critérios de decisão, foram estabelecidas escala de precisão e escalas de exploração com valores iguais a 3,5m. O critério de qualidade foi estabelecido com uma quantidade mínima de 4 amostras por área e limite $110 \%$ para índice de krigagem "AIC/quantidade". A escala espacial de variabilidade foi estabelecida a partir do levantamento exploratório inicial.

Numa análise prévia sobre os dados de escala de cor cinza da imagem, a Área I foi dividida em subáreas (I-I, I-II, I-III e I-IV) (Figura 23 (a)) para observar seu comportamento em relação à variabilidade, através de uma amostragem em grade regular quadrada com o espaçamento de $3,5 \mathrm{~m}$.

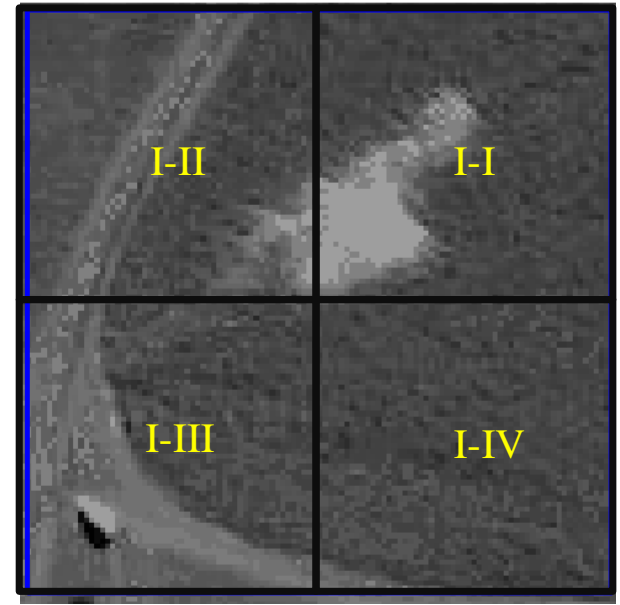

(a)

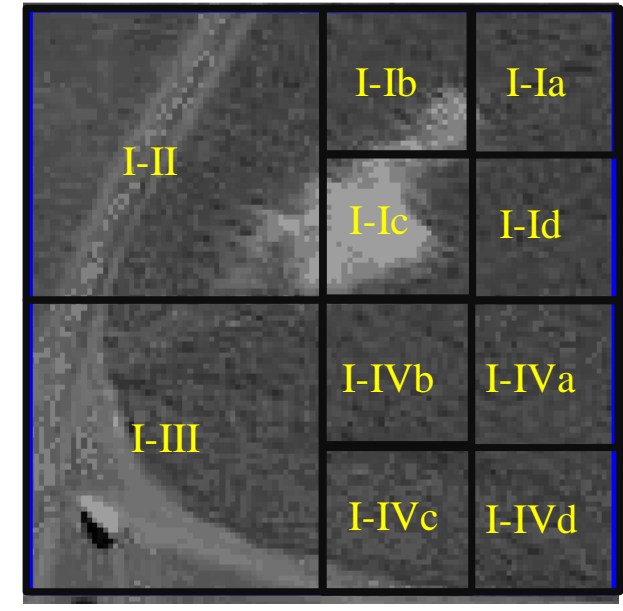

(b)

Figura 23. Área I e suas (a) subáreas I-I, I-II, I-III e I-IV e (b) subáreas I-Ia, I-Ib, I-Ic, I-Id, I-II, I-III, I-IVa, I$\mathrm{IVb}, \mathrm{I}-\mathrm{IVc}$ e I-IVd.

Na Tabela 4 estão apresentados os resultados das amostragens em grade regular quadrada com espaçamento 3,5m realizadas sobre a Área I total e sobre as subáreas I-I, I-II, I-III e I-IV. Observando os parâmetros variabilidade, desvio padrão e CV, a subárea I-I apresenta os maiores valores, 947,42, 29,50 e 0,35, respectivamente, em comparação com as outras subáreas; a subárea I-IV apresenta os menores valores, 126,14, 10,80 e 0.15, respectivamente; e as 
subáreas I-II (390,62, 18,58 e 0,22, respectivamente) e I-III (454,08, 21,89 e 0,24, respectivamente) apresentam valores intermediários.

O alcance do variograma, na subárea I-I tem o valor de 19,07m e na subárea I-IV ele é de apenas 3,20m. Esta diferença indica que, provavelmente, na subárea I-I as variações deixam de apresentar dependência espacial apenas após 19,70 m, e na subárea I-IV as amostras já apresentam independência espacial a partir dos 3,20 m. Ou seja, na subárea I-IV as amostras já passam a ser aleatórias a partir da distância de 3,20 m. Observando a imagem que representa essa a Área I (Figura 23), pode-se dizer que a subárea I-I apresenta heterogeneidade, que poderia ser uma falha ou uma área com característica bem destoante do restante, de variabilidade com um alcance de até 19,70 m; e que a subárea I-IV é uma área mais homogênea, com uma variabilidade mais granulada, com dependência espacial abaixo de 3,20m.

Ainda na Tabela 4 observa-se que, como esperado, a média sobre os dados de predição por krigagem para a Área I e as subáreas I-I, I-II, I-III e I-IV (80,28 NC, 82,53 NC, 83,48 NC, 87,69 NC e 70,89 NC, respectivamente) são muito parecidos com a média sobre os dados amostrados em grade (80,12 NC, 82,60 NC, 83,56 NC, 88,31 NC e 71,25 NC, respectivamente).

Tabela 4. Método aplicado sobre o Conjunto Amostral I, sobre dados em NC, para amostragem em grade com espaçamento de 3,5m para a Área I e suas subáreas (I-I, I-II, I-III e I-IV).

\begin{tabular}{|c|c|c|c|c|c|}
\hline & Área I & $\begin{array}{c}\text { Subárea } \\
\text { I-I }\end{array}$ & $\begin{array}{c}\text { Subárea } \\
\text { I-II }\end{array}$ & $\begin{array}{c}\text { Subárea } \\
\text { I-III }\end{array}$ & $\begin{array}{c}\text { Subárea } \\
\text { I-IV }\end{array}$ \\
\hline Área $\left(\mathbf{m}^{2}\right)$ & 14163,54 & 3283,48 & 3283,45 & 3283,42 & 3283,45 \\
\hline Área (ha) & 1,42 & 0,33 & 0,33 & 0,33 & 0,33 \\
\hline Quantidade de amostras & 1156 & 289 & 289 & 289 & 289 \\
\hline Amostras por $\mathbf{m}^{2}$ & 0,082 & 0,088 & 0,088 & 0,088 & 0,088 \\
\hline Amostras por ha & 816,18 & 880,17 & 880,17 & 880,17 & 880,17 \\
\hline Média (NC) & 80,12 & 82,60 & 83,56 & 88,31 & 71,25 \\
\hline Mediana (NC) & 73 & 70 & 78 & 85 & 69 \\
\hline Moda (NC) & 65 & 158 & 75 & 113 & 65 \\
\hline Maior valor (NC) & 158 & 158 & 158 & 158 & 128 \\
\hline Menor valor (NC) & 1 & 44 & 52 & 11 & 49 \\
\hline Banda (NC) & 157 & 114 & 106 & 147 & 79 \\
\hline Desvio padrão (dp) & 21,97 & 29,50 & 18,58 & 21,89 & 10,80 \\
\hline $\mathrm{CV}$ & 0,27 & 0,35 & 0,22 & 0,24 & 0,15 \\
\hline Variabilidade $(C)$ & 437,29 & 947,42 & 390,62 & 454,08 & 126,14 \\
\hline Alcance $(a)$ & 8,89 & 19,07 & 7,28 & 4,53 & 3,20 \\
\hline Predição de krig. média (NC) & 80,28 & 82,53 & 83,48 & 87,69 & 70,89 \\
\hline Predição de krig. mediana (NC) & 72,90 & 69,96 & 79,20 & 82,96 & 70,21 \\
\hline Predição de krig. moda (NC) & 68,07 & 67,09 & 75,62 & 73,51 & 67,99 \\
\hline Predição de krig. dp & 20,29 & 28,13 & 16,08 & 18,289 & 6,93 \\
\hline
\end{tabular}


Ou seja, os resultados para a aplicação do método de amostragem indicam que é possível relacionar a variabilidade da área com o alcance determinado pelo variograma.

Aplicando-se o método de amostragem sobre o Conjunto Amostral I, analisando os dados de NC, referente a Área I e depois isoladamente sobre suas subáreas I-I e I-IV, com o critério de qualidade sendo igual à quantidade mínima de dados com o limite mínimo de 4 amostras, a escala de precisão igual a 3,5 m e as escalas de exploração horizontal e vertical, ambas iguais a 3,5 m. Para as três situações (método aplicado à Área I e às subáreas I-I e I-IV) foi utilizado como critério de densidade de variabilidade o parâmetro desvio padrão com limite igual a metade do desvio padrão obtido no levantamento exploratório. Para a Área I, os resultados estão indicados na Tabela 5 e na Figura 24, para a subárea I-I, na Tabela 6 e na Figura 25, e para a subárea I-IV, na Tabela 7 e na Figura 26.

Tabela 5. Método de amostragem aplicado sobre o Conjunto Amostral I, sobre dados em NC, da Área I, para escala de precisão de 3,5 m, escalas de exploração de $3,5 \mathrm{~m}$, qualidade de quantidade de 4 pontos e densidade de variabilidade de desvio padrão de 1/2 do levantamento exploratório.

\begin{tabular}{|c|c|c|c|c|c|c|c|}
\hline & \multicolumn{2}{|c|}{ amostragem } & \multicolumn{5}{|c|}{ subárea } \\
\hline & exploratório & final & I & $\mathrm{I}-\mathrm{I}$ & I-II & I-III & I-IV \\
\hline Área $\left(\mathbf{m}^{2}\right)$ & 14163,54 & 14163,54 & 14163,54 & 3540,91 & 3540,88 & 3540,85 & 3540,88 \\
\hline Área (ha) & 1,42 & 1,42 & 1,42 & 0,35 & 0,35 & 0,35 & 0,35 \\
\hline Quantidade de amostras & 408 & 511 & 49 & 16 & 12 & 9 & 12 \\
\hline Amostras por $\mathbf{m}^{2}$ & 0,0288 & 0,0360 & 0,0034 & 0,0045 & 0,0033 & 0,0025 & 0,0033 \\
\hline Amostras por ha & 288,06 & 360,78 & 34,59 & 45,18 & 33,88 & 25,41 & 33,88 \\
\hline Média (NC) & 80,54 & 86,57 & 78,53 & 78,87 & 83,16 & 81,44 & 71,25 \\
\hline Mediana (NC) & 74 & 79 & 72 & 69 & 80 & 84 & 69 \\
\hline Moda (NC) & 65 & 78 & 65 & 69 & 80 & 68 & 65 \\
\hline Maior valor (NC) & 158 & 158 & 129 & 129 & 113 & 113 & 85 \\
\hline Menor valor (NC) & 1 & 44 & 51 & 51 & 65 & 68 & 64 \\
\hline Banda (NC) & 157 & 114 & 78 & 78 & 48 & 45 & 21 \\
\hline Desvio padrão (dp) & 22,75 & 23,89 & 17,91 & 25,59 & 15,09 & 14,08 & 6,73 \\
\hline $\mathbf{C V}$ & 0,28 & 0,27 & 0,22 & 0,32 & 0,18 & 0,17 & 0,09 \\
\hline Variabilidade $(C)$ & 493,86 & 504,70 & 326,33 & 716,61 & 231,62 & 291,91 & 47,64 \\
\hline Alcance $(a)$ & 8,23 & 9,57 & 8,63 & 11,68 & 5,56 & 20,42 & 8,49 \\
\hline Predição de krig. média (NC) & 80,83 & 82,26 & 79,23 & 80,74 & 82,81 & 84,16 & 71,63 \\
\hline Predição de krig. mediana (NC) & 75,87 & 76,00 & 77,90 & 74,44 & 82,63 & 83,99 & 70,84 \\
\hline Predição de krig. moda (NC) & 68,62 & 70,33 & 79,42 & 68,04 & 83,14 & 84,61 & 69,64 \\
\hline Predição de krig. dp & 17,60 & 18,98 & 9,40 & 16,64 & 4,99 & 9,22 & 3,04 \\
\hline
\end{tabular}

Os espaçamentos de grade iniciais do levantamento principal para a área I e das subáreas II e I-IV, foram determinados em 16,8 m, 14 m e 7 m, respectivamente, obtidos a partir da análise dos respectivos levantamentos exploratórios. 
No método de amostragem aplicado à Área I (Tabela 5), o desvio padrão do levantamento exploratório obtido foi 22,75. Portanto nas decisões para divisão de suas subáreas baseados na densidade de variabilidade, sendo o critério de decisão o parâmetro desvio padrão com limite igual a metade do desvio padrão obtido no levantamento exploratório, se suas subáreas (por exemplo, subáreas I-I, I-II, I-III e I-IV) tiverem um desvio padrão menor do que metade de 22,75, então ela não será mais dividida, caso contrário, será dividida. Por exemplo, a subárea IIV é a única que apresenta desvio padrão igual a 6,73 que é menor do que 11,375 , portanto não foi mais dividida. As subáreas restantes foram divididas até que o desvio padrão fosse menor que esse limite, ou até que fossem atingidos os limites das escalas de precisão ou de exploração (Figura 24).

Tabela 6. Método aplicado sobre o Conjunto Amostral I, sobre dados em NC, na subárea I-I, para escala de precisão de 3,5 m, escalas de exploração de 3,5 m, qualidade de quantidade de 4 pontos e densidade de variabilidade de desvio padrão de $1 / 2$ do levantamento exploratório.

\begin{tabular}{|c|c|c|c|c|c|c|c|}
\hline & \multicolumn{2}{|c|}{ amostragem } & \multicolumn{5}{|c|}{ subárea } \\
\hline & exploratório & final & $1-1$ & I-la & $\mathrm{I}-\mathrm{Ib}$ & I-IC & I-Id \\
\hline Área $\left(\mathrm{m}^{2}\right)$ & 3283,48 & 3283,48 & 3283,48 & 820,87 & 820,87 & 820,86 & 820,87 \\
\hline Área (ha) & 0,32 & 0,32 & 0,32 & 0,08 & 0,08 & 0,08 & 0,08 \\
\hline Quantidade de amostras & 204 & 137 & 25 & 9 & 9 & 9 & 9 \\
\hline Amostras por $\mathrm{m}^{2}$ & 0,06 & 0,0417 & 0,0076 & 0,0109 & 0,0109 & 0,0109 & 0,0109 \\
\hline Amostras por ha & 621,29 & 417,24 & 76,13 & 109,63 & 109,63 & 109,64 & 109,63 \\
\hline Média (NC) & 83,17 & 99,09 & 83,64 & 71,33 & 82,22 & 102,2 & 69 \\
\hline Mediana (NC) & 70 & 83 & 74 & 74 & 76 & 78 & 67 \\
\hline Moda (NC) & 158 & 158 & 78 & 61 & 62 & 158 & 61 \\
\hline Maior valor (NC) & 158 & 158 & 158 & 80 & 158 & 158 & 88 \\
\hline Menor valor (NC) & 44 & 51 & 61 & 61 & 62 & 62 & 61 \\
\hline Banda (NC) & 114 & 107 & 97 & 19 & 96 & 96 & 27 \\
\hline Desvio padrão (dp) & 29,94 & 35,61 & 29,42 & 7,28 & 29,16 & 43,31 & 9,02 \\
\hline CV & 0,36 & 0,35 & 0,35 & 0,10 & 0,35 & 0,42 & 0,13 \\
\hline Variabilidade (C) & 1039,45 & 1065,16 & 912,22 & 4103,60 & 850,45 & 1985,14 & 90,84 \\
\hline Alcance $(a)$ & 23,05 & 12,17 & 12,69 & 1948,58 & 1,35 & 6,98 & 9,32 \\
\hline Predição de krig. média (NC) & 82,98 & 84,36 & 85,20 & 72,84 & 82,23 & 111,47 & 69,40 \\
\hline Predição de krig. mediana (NC) & 70,49 & 73,54 & 75,90 & 73,98 & 82,14 & 111,81 & 68,79 \\
\hline Predição de krig. moda (NC) & 67,90 & 73,23 & 74,93 & 77,51 & 82,15 & 132,64 & 64,44 \\
\hline Predição de krig. dp & 27,95 & 27,18 & 23,18 & 4,83 & 3,05 & 20,82 & 5,05 \\
\hline
\end{tabular}

Observa-se pela Figura 24, Figura 25 e Figura 26, que no caso do método aplicado à Área I e à subárea I-I, que apresentam maiores variabilidades, o limite da metade do desvio padrão como critério foi utilizado satisfatoriamente. Mas já no caso da subárea I-IV, que apresenta baixa variabilidade, esse mesmo limite causa uma amostragem aparentemente maior do que a necessária, visto que é uma área de baixa variabilidade e poderia ser menos amostrada. Isto 
ocorre porque mais dificilmente uma subárea sua (por exemplo, subárea I-IVa) terá metade da variabilidade de área original (subárea I-IV), causando subdivisões excessivas, ou seja, nesse caso o método não alcança seu objetivo de amostragem reduzida em áreas de pouca variabilidade. Portanto, para abranger os casos de diferentes variabilidades na área inicial, seria interessante utilizar algum mecanismo que estipule de forma mais satisfatória os limites para o critério de densidade de variabilidade levando em consideração a variabilidade inicial da área total.

Tabela 7. Método de amostragem aplicado sobre o Conjunto Amostral I, sobre dados em NC, na subárea I-IV, para escala de precisão de $3,5 \mathrm{~m}$, escalas de exploração de $3,5 \mathrm{~m}$, qualidade de quantidade de 4 pontos e densidade de variabilidade de desvio padrão de $1 \frac{1}{2}$ do levantamento exploratório.

\begin{tabular}{lrr|rrrrr}
\hline & \multicolumn{2}{c}{ amostragem } & \multicolumn{5}{c}{ subárea } \\
\hline & exploratório & final & I-IV & I-IVa & I-IVb & I-IVc & I-IVd \\
Área (m') & 3283,45 & 3283,45 & 3283,45 & 820,86 & 820,86 & 820,86 & 820,86 \\
Área (ha) & 0,32 & 0,32 & 0,32 & 0,08 & 0,08 & 0,08 & 0,08 \\
Quantidade de amostras & 204 & 241 & 81 & 25 & 25 & 25 & 25 \\
Amostras por m ${ }^{2}$ & 0,0621 & 0,0733 & 0,0246 & 0,0304 & 0,0304 & 0,0304 & 0,0304 \\
Amostras por ha & 621,29 & 733,9 & 246,69 & 304,55 & 304,55 & 304,55 & 304,55 \\
\hline Média (NC) & 71,77 & 71,32 & 71,6 & 68,6 & 69,2 & 78,12 & 67,72 \\
Mediana (NC) & 69 & 69 & 69 & 69 & 69 & 78 & 68 \\
Moda (NC) & 65 & 65 & 69 & 69 & 69 & 65 & 65 \\
Maior valor (NC) & 128 & 128 & 128 & 88 & 88 & 128 & 81 \\
Menor valor (NC) & 49 & 49 & 52 & 52 & 54 & 56 & 56 \\
Banda (NC) & 79 & 79 & 76 & 36 & 34 & 72 & 25 \\
\hline Desvio padrão (dp) & 11,31 & 11,30 & 12,25 & 7,48 & 8,26 & 17,91 & 7,32 \\
CV & 0,15 & 0,15 & 0,17 & 0,10 & 0,11 & 0,22 & 0,10 \\
\hline Variabilidade (C) & 136,90 & 136,96 & 249,68 & 57,76 & 69,67 & 42194,51 & 53,71 \\
Alcance (a) & 3,22 & 3,44 & 16,52 & 3,44 & 3,13 & 2026,51 & 0,17 \\
\hline Predição de krig. média (NC) & 71,41 & 70,58 & 70,83 & 68,61 & 69,78 & 76,58 & 67,72 \\
Predição de krig. mediana (NC) & 70,57 & 69,52 & 69,26 & 68,74 & 69,89 & 75,59 & 67,72 \\
Predição de krig. moda (NC) & 68,46 & 68,77 & 68,26 & 68,38 & 69,53 & 78,06 & 67,72 \\
Predição de krig. dp & 6,54 & 6,82 & 8,44 & 3,64 & 3,87 & 12,18 & 0,17 \\
\hline & & & & & & & \\
\hline
\end{tabular}

Na Tabela 5, na Tabela 6 e na Tabela 7 os valores do CV acompanham o comportamento da variabilidade, sendo maior para áreas de maior variabilidade e menor para áreas de menor variabilidade. Além disso o CV é um índice que indica um valor relativo, permite a comparação de valores que apresentam unidades de medidas distintas. Dessa forma, o CV tem potencial para ser usado como uma referência na determinação para o valor limite do desvio padrão no critério de decisão de densidade de variabilidade. Por exemplo, no caso da subárea I-IV, que tem um CV inicial menor do que 0,20, o método de amostragem foi aplicado novamente, mas 
agora com o limite igual ao desvio padrão do levantamento exploratório. O resultado indicado na Figura 27, mostram a área menos amostrada, como era o esperado para uma área de baixa variabilidade.

Portanto, os resultados demostram grande potencial no uso conjunto dos parâmetros desvio padrão e CV para a determinação do critério de densidade de variabilidade. Sendo que uma determinada faixa de valores do CV determinaria os limites para o critério. 

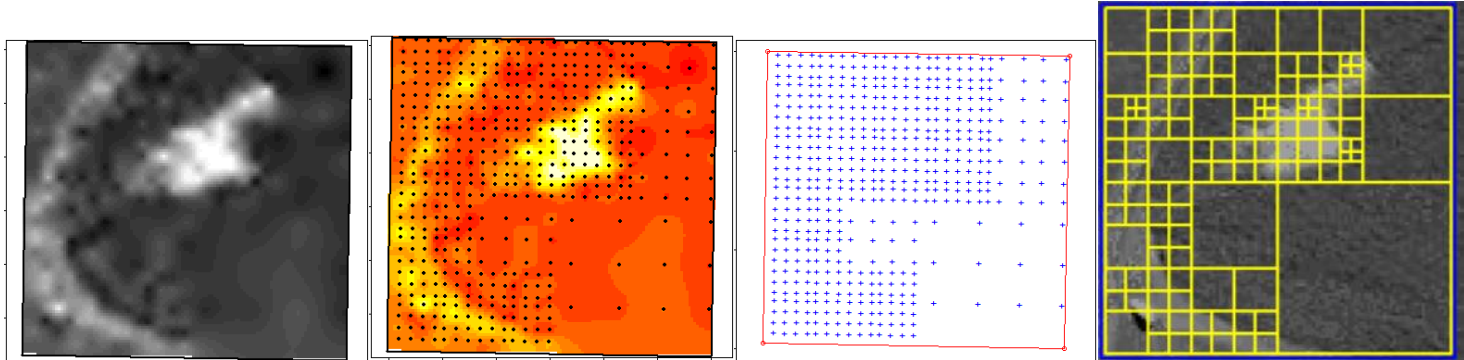

Figura 24. Método de amostragem aplicado sobre o Conjunto Amostral I, sobre dados em NC, na Área I.
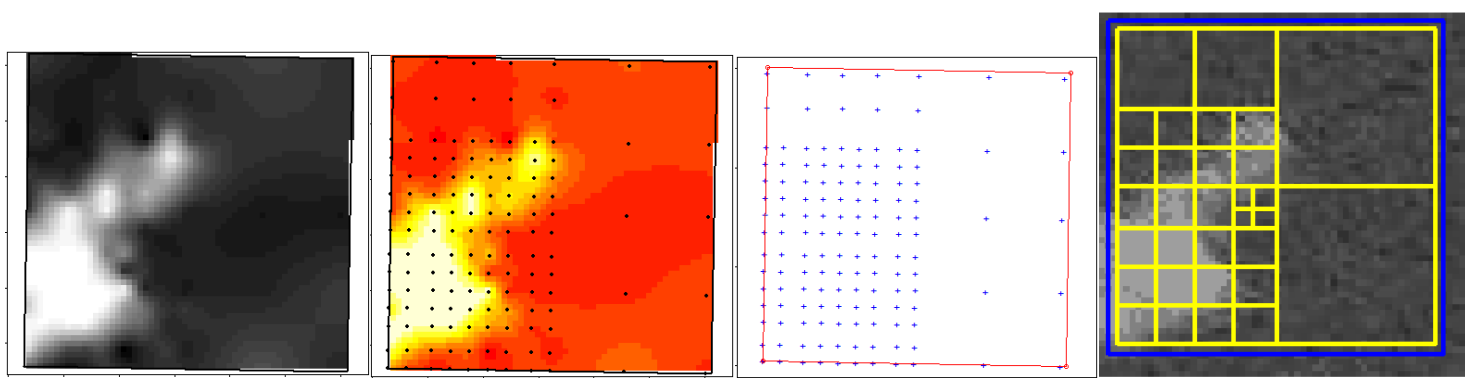

Figura 25. Método de amostragem aplicado sobre o Conjunto Amostral I, sobre dados em NC, na subárea I-I.
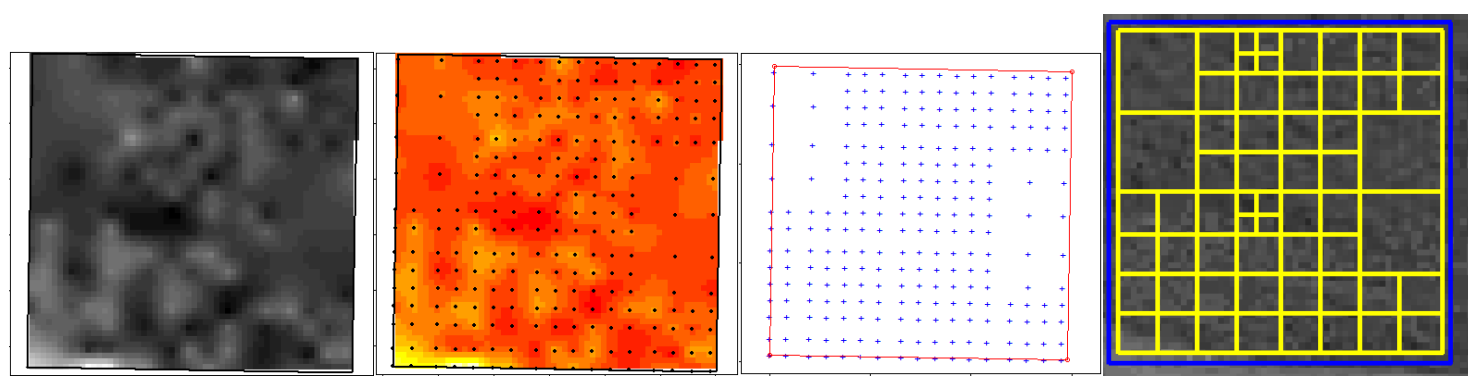

Figura 26. Método de amostragem aplicado sobre o Conjunto Amostral I, sobre dados em NC, na subárea I-IV.
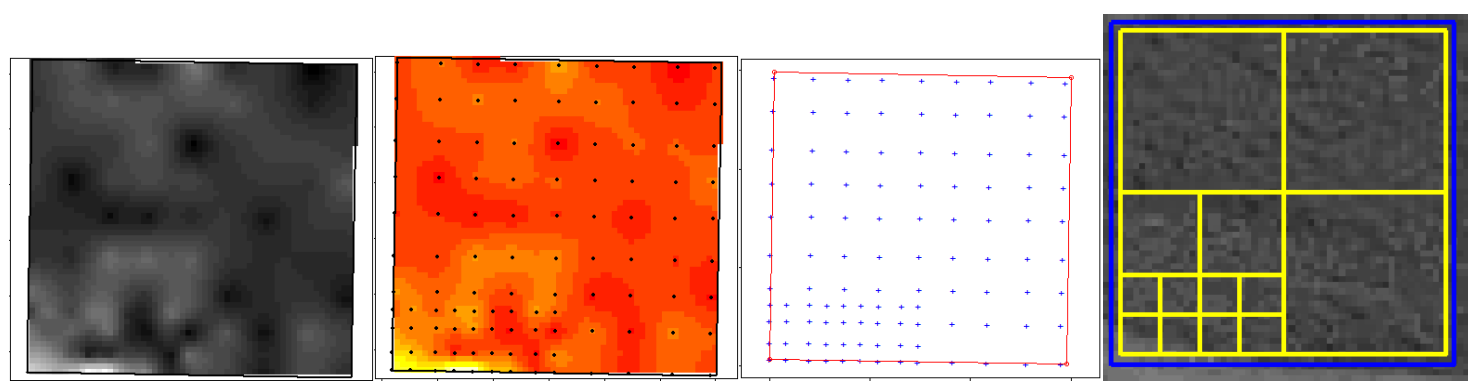

Figura 27. Método de amostragem aplicado sobre o Conjunto Amostral I, sobre dados em NC, na subárea I-IV, com limite igual ao desvio padrão. 


\subsection{Amostragem e planejamento de trajetórias}

Nessa seção, os resultados de alguns dos estudos anteriores são detalhados em relação às vantagens que o método propõe sobre o método tradicional, no que diz respeito à economia de custos sobre quantidade amostras e sobre a distância percorrida.

Supondo que o veículo autônomo tivesse que percorrer o campo da Área I por completo, ou seja, passar por todos os seus 169 corredores (estruturação em linhas de referência). Ou seja, ele deveria percorrer uma distância de 20491,86 m considerando apenas os comprimentos dos corredores e 20609,46 m considerando também as manobras de cabeceira (manobra simples). Nessa exploração completa seriam coletados 28561 pontos, segundo o esquema de estruturação do ambiente com a intersecção de linhas de referência.

Tomando como exemplo uma exploração com escala de precisão e escalas de exploração de 1,4 m e comparando seus resultados com uma exploração completa. Observa-se pelos resultados da Tabela 8 que, com a utilização do método de amostragem proposto, a quantidade de linhas percorridas teve uma redução de 49,1\%. A distância percorrida nos corredores teve redução de $49,1 \%$. A distância percorrida total (considerando também as manobras de cabeceira) teve uma redução 43,6\%. E a quantidade de pontos amostrados teve uma significativa redução de $91,5 \%$. Para escalas menos precisas, essa redução fica ainda mais evidente, tal como redução de $98 \%$ dos pontos amostrados para a escala valendo $3,5 \mathrm{~m}$.

Portanto, os resultados da Tabela 8 indicam que a quantidade de pontos na amostra final e as distâncias percorridas utilizando o método de amostragem seriam bem menores do que em comparação com uma exploração completa.

Tabela 8. Resultados de experimentos para amostragem e planejamento de trajetórias sobre o Conjunto Amostral I na Área I.

\begin{tabular}{ccccccc}
\hline $\begin{array}{c}\text { Escala } \\
\text { de } \\
\text { precisão } \\
(\mathbf{m})\end{array}$ & $\begin{array}{c}\text { Escalas de } \\
\text { exploração } \\
(\mathbf{m})\end{array}$ & $\begin{array}{c}\text { Quantidade } \\
\text { de linhas } \\
\text { referência } \\
\text { horizontais }\end{array}$ & $\begin{array}{c}\text { Distância } \\
\text { percorrida } \\
\text { (somente } \\
\text { corredores) } \\
(\mathbf{m})\end{array}$ & $\begin{array}{c}\text { Distância } \\
\text { percorrida } \\
\text { (somente } \\
\text { manobras) } \\
(\mathbf{m})\end{array}$ & $\begin{array}{c}\text { Distância } \\
\text { percorrida } \\
\text { (corredores + } \\
\text { manobras) } \\
(\mathbf{m})\end{array}$ & $\begin{array}{c}\text { Quantidade } \\
\text { de pontos } \\
\text { amostrados }\end{array}$ \\
\hline completa & completa & 169 & 20491,86 & 117,54 & 20609,46 & 28561 \\
1,4 & 1,4 & 86 & 10427,81 & 1188,60 & 11616,41 & 2408 \\
2,1 & 2,1 & 65 & 7881,48 & 904,40 & 8785,88 & 994 \\
2,8 & 2,8 & 30 & 3637,60 & 480,20 & 4117,80 & 511 \\
3,5 & 3,5 & 33 & 4001,37 & 641,20 & 4642,57 & 511 \\
4,2 & 4,2 & 26 & 3152,59 & 658,00 & 3810,59 & 271 \\
7 & 7 & 17 & 2061,31 & 399,00 & 2460,31 & 179 \\
14 & 14 & 9 & 1091,28 & 294,00 & 1385,28 & 67 \\
21 & 21 & 8 & 970,02 & 210,00 & 1180,02 & 9 \\
\hline
\end{tabular}


Em relação às manobras de cabeceira, analisando a distância percorrida nas manobras observa-se que para uma quantidade maior de linhas percorridas através do método há um acréscimo considerável na distância percorrida, e para todos os casos a distância percorrida em cabeceira pelo método é maior que a distância percorrida em modo completo. Isto ocorre porque, na exploração completa, linhas vizinhas são abordadas em sequência, assim a distância percorrida em manobra é sempre mínima, e pelo método, a coleta de dados não é realizada em corredores vizinhos e a intercalação entre eles exige uma distância maior percorrida. Tal fato poderia ser minimizado através da utilização de técnicas de minimização de trajetória em conjunto com manobras mais complexas. 


\subsection{Metodologia completa aplicada sobre o Conjunto Amostral II}

O método de amostragem foi aplicado sobre o Conjunto Amostral II, referente à Área II para três casos: utilizando a informação de CE rasa do solo, de CE profunda do solo e a informação do índice NDVI sobre plantação de cana-de-açúcar.

Para todos os casos, a escala de precisão e as escalas de exploração horizontal e vertical, foram fixadas em 4,2 m. A quantidade de dados no critério de qualidade foi estabelecida com o limite mínimo de 4 amostras. Ainda no critério de qualidade, para o indicador "AIC/quantidade" foi estabelecido o limite de 1/10 do "AIC/quantidade" da área de origem, tal valor foi determinado a partir de observações de resultados em testes de aplicação do método sobre o Conjunto Amostral II.

Os limites para o critério de densidade de variabilidade foram determinados avaliando-se cada caso. Se o CV do levantamento exploratório fosse menor do que 0,2, então o limite de densidade de variabilidade deveria ser igual ao desvio padrão de referência (também obtido no levantamento exploratório). Se o CV fosse menor do que 0,3 , então o limite deveria ser igual a 3/4 do desvio padrão. Se o CV fosse maior do que 0,3 , então o limite deveria ser igual a metade do desvio padrão.

A Tabela 9 fornece os resultados do levantamento exploratório e da amostragem final para os três casos. A leitura dos coeficientes de variabilidade para CE rasa, CE profunda e NDVI durante o levantamento exploratório foi $0,29 \mathrm{mS} / \mathrm{m}^{2}, 0,52 \mathrm{mS} / \mathrm{m}^{2}$ e 0,27 , respectivamente. Dessa forma, os limites para o critério de densidade de variabilidade foram estipulados em 3/4 para CE rasa e NDVI e 1/2 para CE profunda.

Observa-se pela Tabela 9 que os dados de CE rasa são os que apresentam maior desvio padrão e variabilidade, 3,84 e 21,29, respectivamente, em comparação com 3,22 e 11,80 para CE profunda e 0,06 e 0,00 para NDVI.

Observando os resultados de amostragem em comparação entre os casos, verifica-se que apesar de CE rasa apresentar uma maior variabilidade, CE profunda resultou em maior quantidade de amostras para o campo todo (762 amostras de CE profunda em comparação com 395 amostras de CE rasa). Já a amostragem sobre NDVI, que tem menor variabilidade, resultou 
em uma quantidade maior de pontos (1377) em comparação com CE rasa e profunda (395 e 762, respectivamente), que têm maior variabilidade.

Tabela 9. Resultados do levantamento exploratório e da amostragem final para o método de amostragem aplicado sobre o Conjunto Amostral II (CE rasa, CE profunda e NDVI) da Área II.

\begin{tabular}{lrr|rr|rr}
\hline & \multicolumn{2}{c|}{ CE rasa $\left(\mathrm{mS} / \mathrm{m}^{2}\right)$} & \multicolumn{2}{c|}{ CE profunda $\left(\mathrm{mS} / \mathrm{m}^{2}\right)$} & \multicolumn{2}{c}{ NDVI } \\
\cline { 2 - 7 } Amostragem & exploratório & final & exploratório & final & exploratório & final \\
\hline Área (m²) & 34905 & 34905 & 34905 & 34905 & 34905 & 34905 \\
Área (ha) & 3,49 & 3,49 & 3,49 & 3,49 & 3,49 & 3,49 \\
Quantidade de amostras & 658 & 395 & 658 & 762 & 607 & 1377 \\
Amostras por ha & 188,51 & 113,16 & 188,51 & 218,30 & 173,90 & 394,49 \\
\hline Média & 13,44 & 14,26 & 6,21 & 6,69 & 0,20 & 0,20 \\
Mediana & 13,13 & 13,41 & 5,57 & 5,77 & 0,19 & 0,19 \\
Moda & 4,44 & 6,37 & $-1,64$ & $-0,63$ & 0,15 & 0,18 \\
\hline Desvio padrão (dp) & 3,84 & 4,95 & 3,22 & 3,54 & 0,05 & 0,06 \\
CV & 0,29 & 0,35 & 0,52 & 0,53 & 0,27 & 0,29 \\
\hline Variabilidade (C) & 21,29 & 23,32 & 11,80 & 12,72 & 0,00 & 0,00 \\
Alcance (a) & 22,77 & 4,25 & 23,04 & 25,12 & 8,61 & 0,19 \\
\hline Predição de krig. média & 13,36 & 13,79 & 6,24 & 6,32 & 0,20 & 0,20 \\
Predição de krig. mediana & 12,98 & 13,58 & 5,46 & 5,47 & 0,19 & 0,20 \\
Predição de krig. moda & 13,05 & 13,69 & 4,52 & 5,23 & 0,19 & 0,20 \\
Predição de krig. dp & 3,26 & 2,09 & 2,93 & 3,01 & 0,04 & 0,00 \\
\hline
\end{tabular}

Esses resultados contrariam o esperado pelo método, que é que dados de menor variabilidade resulte em uma quantidade menor de pontos e dados de maior variabilidade, em uma quantidade maior de pontos. Isto se dá, provavelmente, devido à escolha dos limites do critério de densidade de variabilidade que dá início às amostragens. Por exemplo, o limite inicial para $\mathrm{CE}$ rasa oferece uma margem mais ampla (3/4) do que o limite inicial determinado para CE profunda (1/2). Assim é mais fácil que se atinja uma densidade satisfatória para CE rasa do que para $\mathrm{CE}$ profunda, resultando em uma amostragem menos densa. A mesma conclusão pode ser estendida para o caso do NDVI, que mesmo tendo um limite mais amplo, por apresentar uma variabilidade muito baixa resultou em uma amostragem mais densa do que o necessário. Ou seja, uma escolha não adequada do critério determinou uma amostragem menos eficiente, o que evidencia a necessidade um estudo mais profundo sobre como determinar os limites iniciais para o critério de densidade de variabilidade, de forma que a quantidade final amostrada também reflita a variabilidade do campo como um todo, resultando em menor quantidade de amostras para dados com menos variabilidade.

Observando os resultados isoladamente para cada caso, os esquemas de amostragem da Figura 28 (d) em comparação com as imagens resultantes de krigagem da Figura 28 (b) mostram 
que as regiões mais amostradas foram aquelas em que ocorrem as mudanças de níveis de valores, ou seja, onde há uma maior variabilidade. O mesmo ocorre para o caso de CE profunda (Figura 29 (d) e Figura 29 (b)). Já para os dados de NDVI que apresentam variabilidade nula, a Figura 30 (c) e a Figura 30 (d) refletem a baixa variabilidade sobre a informação NDVI, resultando em um esquema de amostragem quase que homogêneo e com poucas divisões.

Observando os resultados para o método de amostragem aplicado sobre os três casos na Área II, conclui-se que o método atingiu seu objetivo de amostrar mais densamente locais com maior variabilidade e menos densamente locais com menos variabilidade.

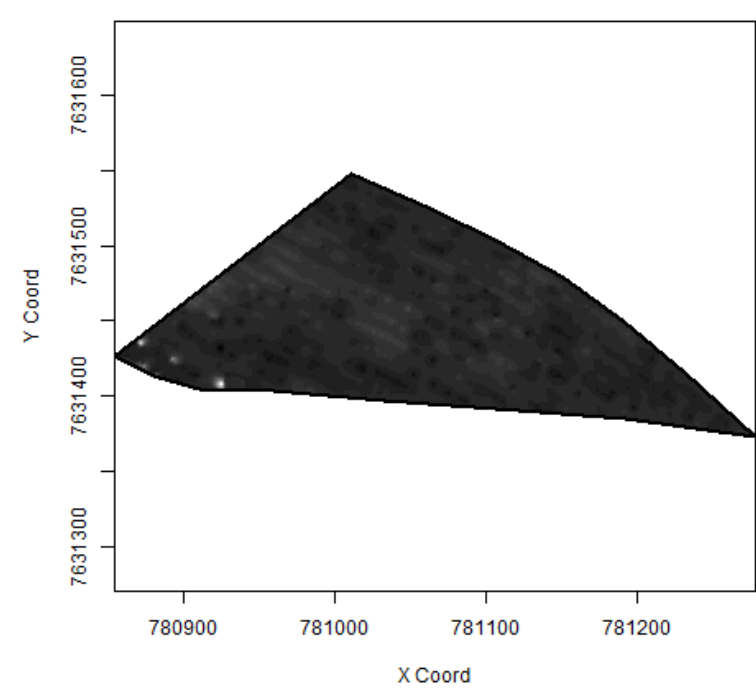

(a)

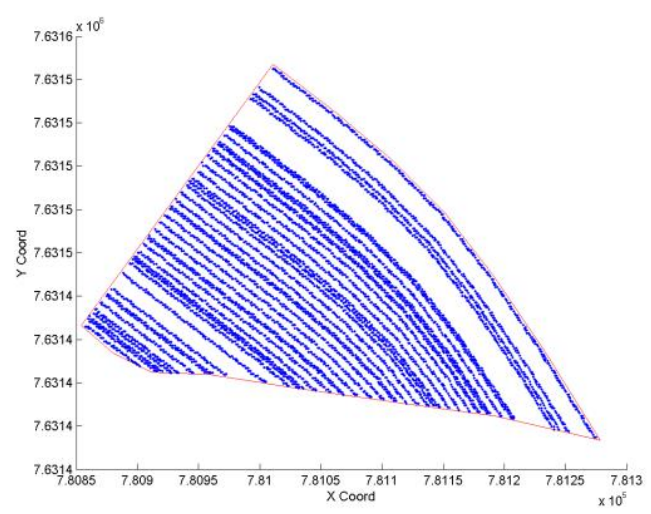

(c)

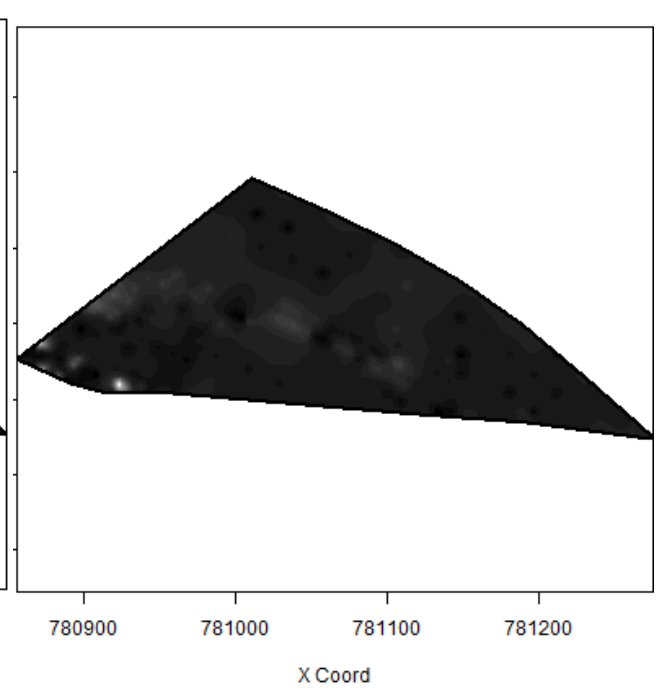

(b)

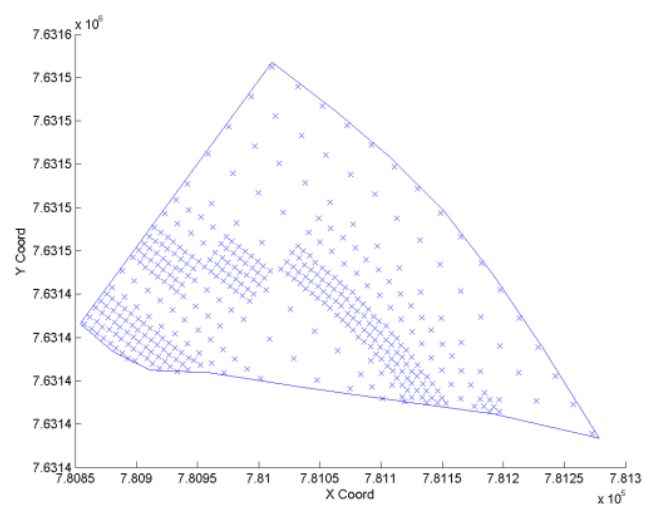

(d)

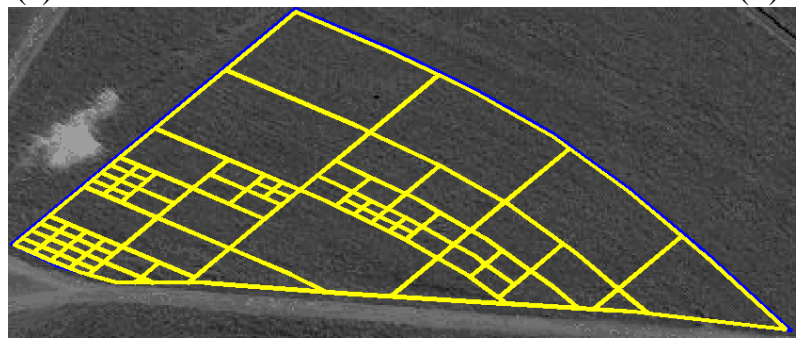

(e)

Figura 28. Resultados sobre CE rasa na Área II. (a) Dados originais krigados, (b) resultado de krigagem sobre amostra final, (c) linhas de referências percorridas, (d) esquema de amostragem final e (e) esquema de divisões final. 


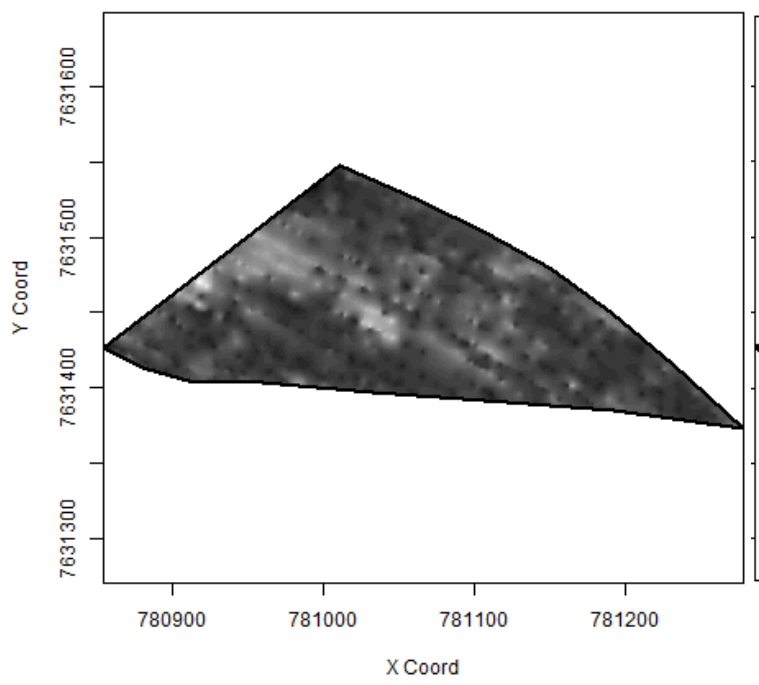

(a)

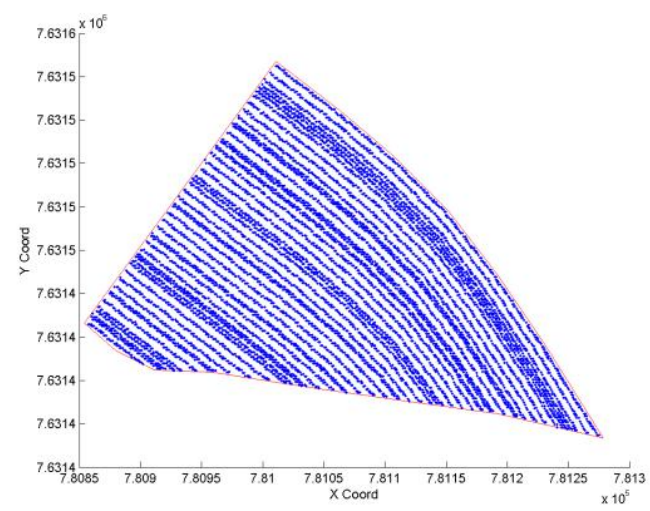

(c)

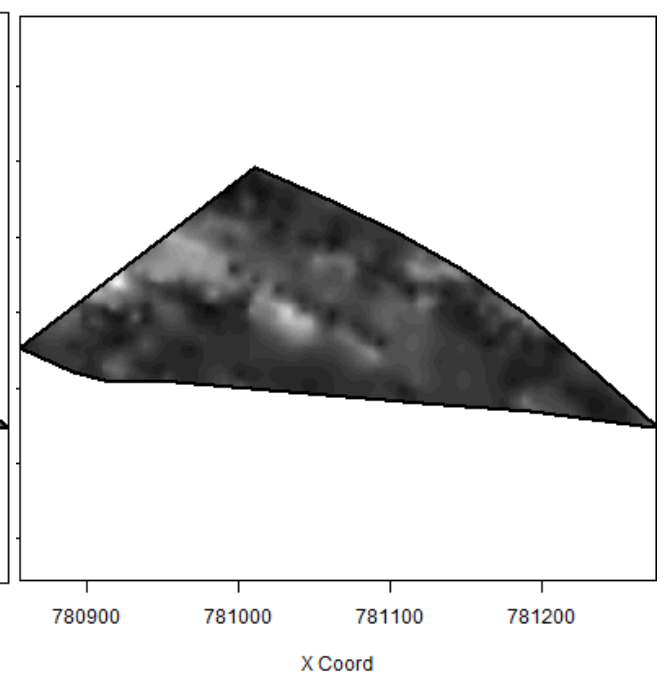

(b)

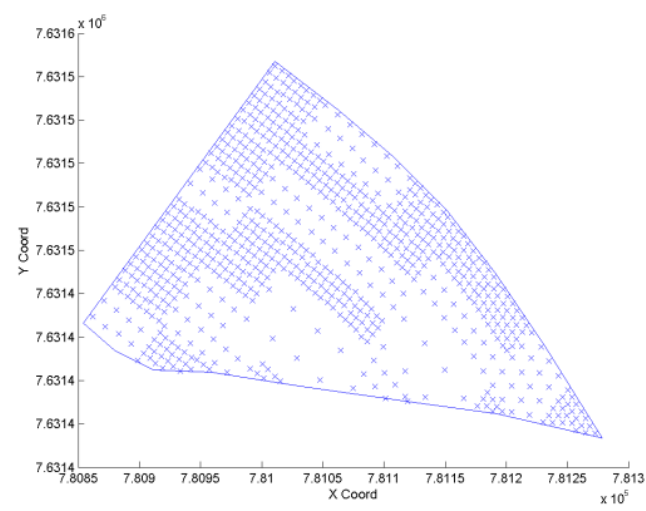

(d)

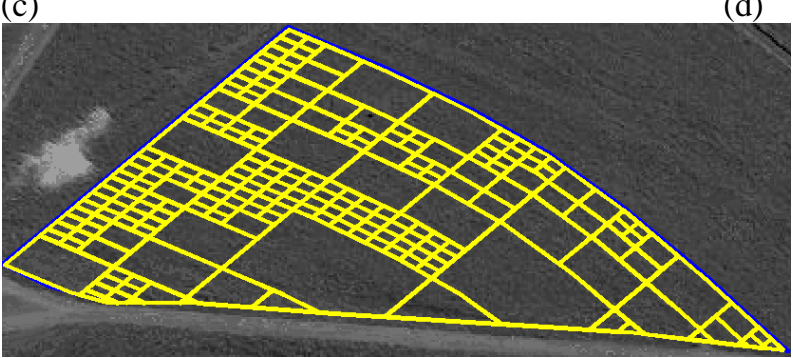

(e)

Figura 29. Resultados sobre CE profunda na Área II. (a) Dados originais krigados, (b) resultado de krigagem sobre amostra final, (c) linhas de referências percorridas, (d) esquema de amostragem final e (e) esquema de divisões final. 


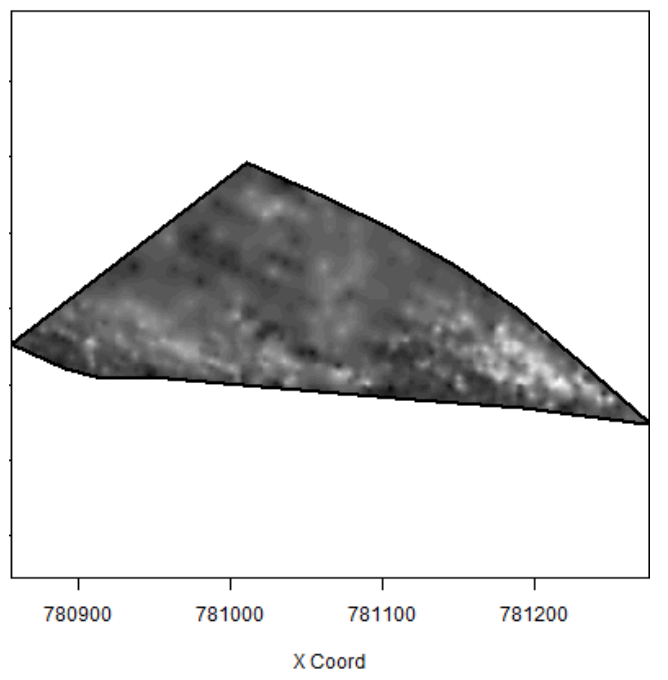

(a)
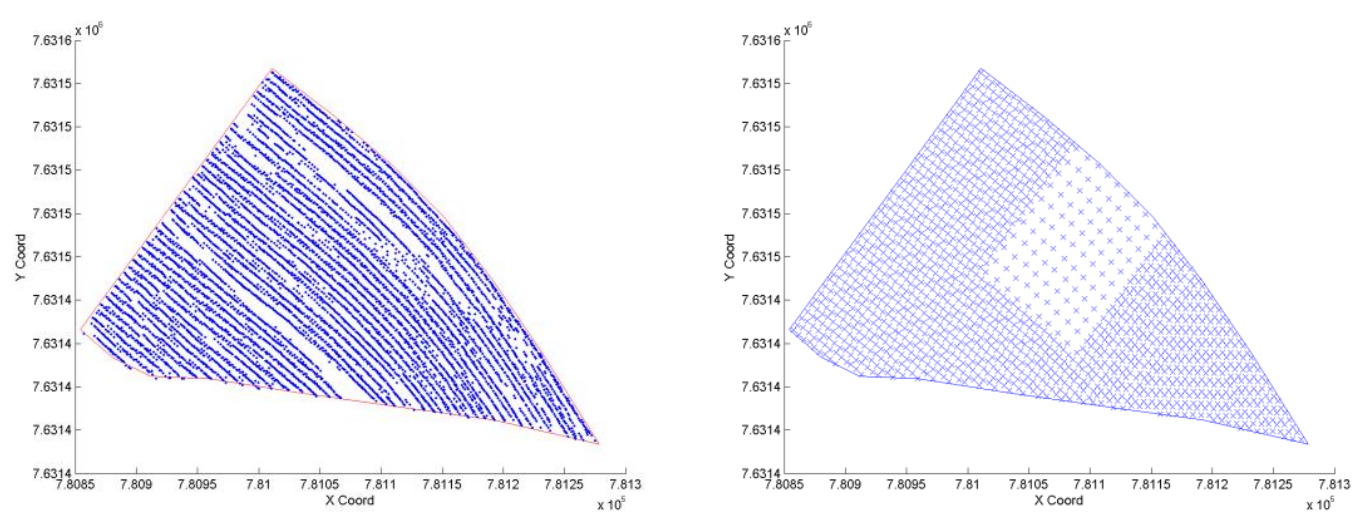

(b)

(c)

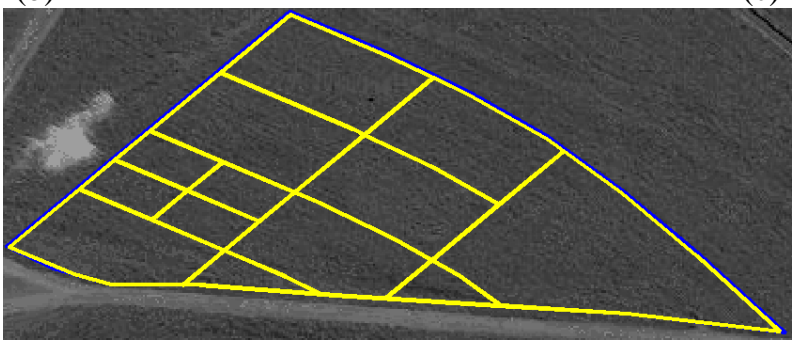

(d)

Figura 30. Resultados sobre NDVI na Área II. (a) resultado de krigagem sobre amostra final, (b) linhas de referências percorridas, (c) esquema de amostragem final e (d) esquema de divisões final. 
A Tabela 10 indica os resultados que mostram a quantidade de pontos amostrados e a distância percorrida. Para CE rasa, CE profunda e NDVI, a quantidade de pontos amostrados foi igual a 395, 762 e 1388, respectivamente, o que, comparado com os 105896 pontos que seriam obtidos em uma amostragem por sensoriamento completa (levando em consideração o esquema de estruturação do ambiente com a intersecção de linhas de referência), representa reduções de $99,6 \%, 99,2 \%$ e $98,7 \%$, respectivamente.

Para CE rasa, CE profunda e NDVI, a distância percorrida nos corredores foi de 7766,4 m, 9776,36 m e 8465,23 m, que em comparação com os 50697,71 m que seriam percorridos em uma exploração completa, representam reduções de $84,6 \%, 80,6 \%$ e $83,2 \%$.

Tabela 10. Resultados sobre quantidade de amostras e distância percorrida final para o método de amostragem aplicado sobre o Conjunto Amostral II (CE rasa, CE profunda e NDVI) da Área II.

\begin{tabular}{|c|c|c|c|c|}
\hline & $\begin{array}{l}\text { Percurso } \\
\text { completo }\end{array}$ & $\mathrm{CE}$ rasa $\left(\mathrm{mS} / \mathrm{m}^{2}\right)$ & $\begin{array}{c}\text { CE profunda } \\
\left(\mathrm{mS} / \mathrm{m}^{2}\right)\end{array}$ & NDVI \\
\hline Quantidade de pontos amostrados & 105896 & 395 & 762 & 1388 \\
\hline Qtdd. de linhas referência horizontais & 248 & 41 & 49 & 42 \\
\hline Distância percorrida nos corredores (m) & 50497,71 & 7766,40 & 9776,36 & 8465,23 \\
\hline Distância percorrida em manobras (m) & 172,90 & 1075,90 & 1418,90 & 1003,80 \\
\hline $\begin{array}{l}\text { Distância total percorrida } \\
\text { (corredor+manobra) }(\mathbf{m})\end{array}$ & 50670,61 & 8842,30 & 11195,26 & 9469,03 \\
\hline
\end{tabular}

Neste caso, tal como nos resultados apresentados anteriormente, observa-se que há um aumento da distância percorrida nas manobras de cabeceira, ocasionado pela entrada e saída nos corredores de forma intercalada e não em sequência como numa exploração completa. Levando em consideração as distâncias percorridas na cabeceira, as reduções sobre a distância percorrida passam a ser $82,5 \%, 77,9 \%$ e $81,3 \%$, para CE rasa, CE profunda e NDVI, respectivamente.

Desta forma, os resultados apresentados evidenciam a vantagem da utilização do método de amostragem proposto em comparação com uma exploração completa. 


\subsection{Considerações finais}

A percepção sobre a variabilidade é essencial para a utilidade do método. No caso de uma área homogênea, com muito pouca variabilidade, o método resultará em um esquema em grade simples. Um esquema em grade simples também ocorrerá no caso em que existe variabilidade constante. O método apresentará todo seu potencial quando utilizado em campos com a existência de fronteiras de variabilidade, amostrando mais densamente as áreas de transições de valores.

A existência de variabilidade pode ser avaliada através do uso de índices de oportunidade sobre o conjunto de dados. Já a existência de áreas de diferentes variabilidades pode ser percebida com uma análise que permita ao avaliador ir selecionando e observando com mais detalhes subconjuntos de dados referentes às áreas que mostrem ter diferenças. O método de amostragem em fases e subáreas permite essa detecção durante sua execução, capacitado pela possibilidade de deslocamento oferecida através do uso do veículo autônomo agrícola com sensores embarcados e coletando as informações necessárias de acordo com as indicações das análises em fases.

A fase de levantamento exploratório, através do uso do esquema aninhado adaptado, permitiu uma primeira avaliação do campo e também a identificação dos fatores utilizados para guiar a amostragem na fase principal, tal como a escala espacial de variabilidade utilizada para determinar os espaçamentos iniciais de amostragem.

As análises evidenciam que a precisão alcançada depende da capacidade da máquina agrícola na aplicação de insumos a taxa variada, relacionada ao método através dos critérios de escalas de exploração horizontal e vertical. Além disso, a precisão alcançada também pode ser limitada a critério do usuário através da especificação da escala de precisão. O método oferece a possibilidade de sondagem da variabilidade em pequena escala, mas a utilidade de um alto detalhamento, ou seja, alta precisão, é limitada por capacidades das pessoas e dos equipamentos que farão uso dessa informação.

Sobre a questão da qualidade dos dados amostrados, para as situações abordadas, os resultados refletem o compromisso que há entre a qualidade e os fatores envolvidos (a precisão desejada, as restrições práticas, o padrão de dependência e a alocação dos pontos amostrais). Para a aplicação do método de forma generalizada, se faz necessária uma análise mais profunda da relação dos fatores envolvidos com cada caso específico. 
Mesmo tendo apresentando resultados satisfatórios para atingir os objetivos propostos, algumas possíveis melhorias devem ser realizadas para tornar o método mais robusto a aplicações mais amplas, tais como a aplicação de índices que auxiliem na caracterização inicial da variabilidade espacial do solo utilizando técnicas quantitativas, por exemplo, o índice de oportunidade. Trabalhos futuros também podem levar em consideração a covariância entre diferentes variáveis, partindo do pressuposto de que existe indicadores indiretos de variabilidade. Como refinamento, sugere-se também que sejam incorporadas considerações sobre anisotropia e tendência que, quando existentes, devem ser retirados antes da elaboração do variograma.

Os resultados apresentados abrem espaço para discussões de possíveis estudos para desenvolvimento de trabalhos futuros. Por exemplo, existe a possibilidade de uso de métodos, tais como lógica fuzzy, para a determinação dos critérios de decisão sobre a densidade de variabilidade utilizando mais de um parâmetro como referência. Outra possibilidade é o uso da metodologia SSA (Spatial Simulated Annealing), para avaliar e escolher a melhor localização das amostras dentro do esquema proposto.

Apesar de o trabalho exposto ter sido elaborado com o intuito de agregar inteligência ao planejamento de trajetórias de um veículo autônomo agrícola de sensoriamento, o algoritmo gerado para amostragem inteligente abre campos de aplicação além daquele proposto inicialmente, podendo auxiliar na realização de amostragem mesmo sem o uso de veículos autônomos. Ao propor um modo mais eficiente e racional de coletar amostras, pode ser utilizado pela comunidade que trabalha com amostragem e que encontra dificuldades em relação a custo e na mão de obra. Nesse sentido, o método se mostra útil ao agregar o conceito da densidade da variabilidade e contemplar a zona de transição da variabilidade, diferente do que se faz na forma tradicional de realizar a amostragem. 



\section{Conclusões}

Os resultados apresentados nesta tese evidenciam a potencial capacidade do método de amostragem a ser utilizado como uma ferramenta de apoio à novas práticas agrícolas, oferecendo uma alternativa mais inteligente aos métodos tradicionais de sensoriamento embarcado. A utilização do método de amostragem proposto pode fomentar práticas mais eficientes de gerenciamento da plantação através da união prática de teorias geoestatísticas, de tecnologias robóticas e de sensoriamento.

O método se mostrou eficaz no quesito planejamento de trajetórias para veículos em ambientes agrícolas. Ao oferecer uma abordagem que leva em consideração características estruturais do campo, tais como a presença de linhas de plantio, e um modo mais racional de abordá-las, contribui para o desenvolvimento de tecnologias frente à complexidade de elementos presentes em áreas agrícolas. O planejamento de trajetória como suporte às ações de sensoriamento embarcado também apresentou resultados positivos ao oferecer uma redução de mais de $49 \%$ na distância final percorrida pelo veículo, o que pode acarretar em reduções de gastos relacionados ao veículo no processo de sensoriamento, tais como reduções de consumo de combustível, de manutenções mecânicas por desgaste e tempo de mão de obra.

A união entre teoria geoestatística e teorias de planejamento de trajetórias em um método de sensoriamento embarcado agregou o conhecimento necessário para realizar a proposta de gerar um processo mais ágil e econômico de amostragem de campos agrícolas, agregando eficiência ao processo. Os resultados comparativos entre os dados gerados pelo método de 
amostragem proposto em comparação com métodos tradicionais de obtenção de dados por sensoriamento mostram que o método oferece reduções que chegam a $98 \%$ na quantidade de pontos amostrados, o que facilita processos de análise, mas ao mesmo tempo garante a qualidade da informação coletada.

Os resultados também mostram que o método oferece a possibilidade de melhora na qualidade dos dados coletados, ao fornecer mais informações sobre regiões em que as variáveis são mais dinâmicas, de maior variabilidade, e fornecer somente a informação suficiente sobre regiões de pouca mobilidade, de menor variabilidade. Tal abordagem possibilita análises mais confiáveis ao considerar regiões que apresentam transições abruptas no valor de suas amostras e que são aquelas que precisam de mais dados do que regiões que apresentam certa constância entre valores.

Conclui-se que é viável a amostragem utilizando sensoriamento embarcado e baseada na variabilidade do campo, racionalizando a quantidade, garantindo a qualidade da informação e agregando inteligência ao uso de tecnologias na exploração de sistemas agrícolas em toda sua complexidade. 


\section{Referências Bibliográficas}

AGRA (2014). IEEE Robotics \& Automation Society - Technical Committee on Agricultural Robotics and Automation. Disponível em: < http://www.fieldrobot.com/ieeeras/>. Acesso em: jan. 2014.

AMORIM, D.; TOMAZELLI, I.; SALLOWICZ, M.; NEDER, V. (2014). PIB cresce 0,2\% no $1^{\circ}$ trimestre com queda da indústria e de investimento. Estadão, São Paulo, 30 maio 2014. Economia, Negócios. Disponível em: < http://economia.estadao.com.br/noticias/negocios,pibcresce-0-2-no-1-trimestre-com-queda-da-industria-e-de-investimento,186509e >. Acesso em: 29 julho 2014.

ARCHILA， J.F.; GUERRERO， H.B.; TIBERT, A.J.; TANGERINO, G.T.; TABILE, R.A.; TORRES, C.J.; BECKER, M.; PORTO, A.J.V.; INAMASU, R.Y.; SOUSA, R.V. (2013) AGRIBOT - Mobile robot to support of agricultural precision activities. In: XXII COBEM, 2013, Ribeirao Preto - SP. Anais..., 2013.

AUERNHAMMER, H.; SPECKMANN, H. (2006). Communication Issues and Internet Use: Dedicated Communication Systems and Standards for Agricultural Applications. In: KITANI, O. Handbook of Agricultural Engineering: Information Technology. CIGR ASABE, 2006. V. 6, p. 435-452.

BARRIENTOS, A.; COLORADO, J.; CERRO, J.; MARTINEZ, A.; ROSSI, C.; SANZ, D.; VALENTE, J. (2011). Aerial remote sensing in agriculture: a practical approach to area coverage and path planning for fleets of mini aerial robots. Journal of Field Robotics 28 (5), 667-689.

BERNARDI, A.C.; NAIME, J.M.; RESENDE, A.V.; BASSOI, L.H.; INAMASU, R.Y. (Ed.). (2014). Agricultura de precisão: resultados de um novo olhar. São Carlos, SP: Embrapa Instrumentação, 2014. 596p.

BLACKMORE, B.S.; STOUT, W.; WANG, M.; RUNOV, B. (2005). Robotic agriculture - the future of agricultural mechanisation?. In: Stafford, J.V. (Ed.), Proceedings of the 5th European Conference on Precision Agriculture. Wageningen Academic Publishers, The Netherlands, pp. 621-628.

BLACKMORE, B. S.; GRIEPENTROG, H. W. (2006). Autonomous Vehicles and Robotics. In: MUNACK, A. (Ed.). CIGR Handbook of Agricultural Engineering. St. Joseph, Michigan, USA: CIGR -- The International Commission of Agricultural Engineering, 2006. p. 204-215. 
BLACKMORE, S. (2009). New concepts in agricultural automation. HGCA Conference: Precision in arable farming current practice and future potential. Anais...2009. Disponível em: <http://www.unibots.com/Papers/Simon Blackmore 21 Sept 09.pdf>. Acesso em: 6 fev. 2013.

BOCHTIS, D.D.; VOUGIOUKAS, S.G. (2008). Minimising the non-working distance travelled by machines operating in a headland field pattern. Biosystems Engineering, 101 (1), $1-12$.

BOCHTIS, D. D.; SORENSEN, C. G. (2009). The vehicle routing problem in field logistics part I. Biosystems Engineering, v. 104, n. 4, p. 447-457, dez. 2009.

BOCHTIS, D.D.; SORENSEN, C.G.; VOUGIOUKAS, S.G. (2010). Path planning for in-field navigation-aiding of service units. Computers and Electronics in Agriculture, 74 (1), 80-90.

BOCHTIS, D.D.; SORENSEN, C.G. (2014). Special Issue: Operations management. Biosystems Engineering, 120 (2014) I.

BONHAM-CARTER, G.F. (1994). Geographic information systems for geoscientists: modelling with GIS. Ottawa: Pergamon, 1994. 397 p. (Computer methods in the geosciences, n.13).

BURGESS, T. M.; WEBSTER, R. (1980a). Optimal interpolation and isarithmic mapping of soil properties, I. The semi-variogram and punctual kriging. Journal of Soil Science, 31, 315331.

BURGESS, T. M.; WEBSTER, R. (1980b). Optimal interpolation and isarithmic mapping of soil properties, II. Block kriging. Journal of Soil Science, 31, 333-341.

BURGESS, T. M.; WEBSTER, R. (1984a). Optimal sampling strategies for mapping soil types I - Distribution of boundary spacings. Journal of Soil Science, v. 35, p. 641-654, 1984.

BURGESS, T. M.; WEBSTER, R. (1984b). Optimal sampling strategies for mapping soil types II - Risk functions and sampling intervals. Journal of Soil Science, v. 35, p. 655-665, 1984.

COMMITTEE on assessing crop yield: Site-Specific Farming, Information Systems,and Research Opportunities, N.R.C. (1997). Precision Agriculture in the 21st Century: Geoespatial and Information Technologies in Crop Management - Summary. Washington, DC: National Research Concil. 
COSTA, C.C.; GUILHOTO, J.J.M. (2011). Impactos da agricultura de precisão na economia brasileira. In: Agricultura de precisão: um novo olhar. São Carlos, SP: Embrapa Instrumentação, 2011. p. 307-313.

CONESA, J.; RIBEIRO, A.; ANDUJAR, D.; FERNANDEZ-QUINTANILLA, C.; DORADO, J. (2012). Multi-path planning based on a NSGA-II for a fleet of robots to work on agricultural tasks. In: IEEE World Congress on Computational Intelligence (IEEE WCCI 2012), Brisbane, Australia.

COULTER, R. (1992). Implementation of the Pure Pursuit Path Tracking Algorithm. Technical Report CMU-RI-TR-92-01. The Robotics Institute, Carnegie Mellon University, Pittsburgh, PA, USA.

DIGGLE, P.J.; RIBEIRO Jr, P.J. (2007). Model-based geostatistics. New York: Springer. 228p. FERNANDES, V.O.; NOGUEIRA, R.E. (2010). Consequências da mudança de datum na representação cartográfica direcionada para ambiente SIG. Portal de Cartografia. Londrina, v.3, n.1, 2010.

GARCIA-ALEGRE, M.C.; GUINEA, D. (1997). Building an architecture for a farming robot. In: International Workshop on Robotics \& Automated Machinery for Bio-Robotics (pp. 225260).

GARCIA-ALEGRE, M.C., RECIO, F. (1998). Basic visual and motor agents for increasingly complex behaviour generation on a mobile robot. Autonomous Robots, 5(1), 19-28.

GARCIA-ALEGRE, M.C.; RIBEIRO, A.; GARCIA-PEREZ, L. MARTINEZ, R.; GUINEA, D.; POZO-RUZ, A. (2001). An autonomous robot in agriculture tasks. On Precision Agriculture, 25-30. Disponível em: <http://citeseerx.ist.psu.edu/viewdoc/download?doi=10.1.1.27.3626\&rep=rep1\&type=pdf $>$. Acesso em: julho 2014.

GARCIA-PEREZ, L.; GARCIA-ALEGRE, M.C.; RIBEIRO, A.; GUINEA, D. (2008). An agent of behaviour architecture for unmanned controlo $f$ a farming vehicle. Computers and Electronics in Agriculture, 60 (2008) 39-48.

GASCUEL-ODOUX, C.; BOIVIN, P. (1994). Variability of variograms and spatial estimates due to soil sampling : a case study. Geoderma, v. 62, p. 165-182, 1994. 
GASSO, V.; SORENSEN, C.A.G.; OUDSHOORN, F.W.; GREEN, O. (2013). Controlled traffic farming: a review of the environmental impacts. European Journal of Agronomy, 48 (2013) 66-73.

GITELSON, A.A.; GRITZ, Y.; MERZLYAK, M.N. (2003). Relationships between leaf chlorophyll content and spectral reflectance and algorithms for non-destructive chlorophyll assessment in higher plant leaves. Journal of Plant Physiology, v. 160, p. 271-282.

GODOY, E.P.; TABILE, R. A.; PEREIRA, R.R.D. ; TANGERINO, G.T.; PORTO, A.J.V.; INAMASU, R.Y. (2009). Design and Implementation of a Mobile Agricultural Robot for Remote Sensing Applications. In: CIGR Section V International Symposium Technology and Management to Increase the Efficiency in Sustainable Agricultural Systems, 2009, Rosario. Proceedings...CIGR Section V International Symposium 2009. Rosario : CIGR, 2009.

GODOY, E.P.; TABILE, R. A.; PEREIRA, R.R.D. ; TANGERINO, G.T.; PORTO, A.J.V.; INAMASU, R.Y. (2010). Design and Implementation of an Electronic Architecture for an Agricultural Mobile Robot. Revista Brasileira de Engenharia Agrícola e Ambiental, v.14, n.11, p. 1240-1247, Nov. 2010.

GODOY, E.P.; TANGERINO, G.T.; TABILE, R.A.; INAMASU, R.Y.; PORTO, A.J.V. (2012). Networked Control System for the Guidance of a Four-Wheel Steering Agricultural Robotic Platform. Journal of Control Science and Engineering, v. 2012, p. 1-10, 2012.

GOOGLE Maps Image APIs. (2014). Static Maps API V2 Developer Guide. Disponível em: <https://developers.google.com/maps/documentation/staticmaps>. Acesso em: 14 jan 2014

GOOVAERTS, P. (1999). Geostatistics in soil science: state-of-the-art and perspectives. Geoderma, 89(1-2), 1-45, 1999.

GRIFT, T.; ZHANG, Q.; KONDO, N.; TING, K. C. (2008). A review of automation and robotics for the bioindustry. Journal of Biomechatronics Engineering, v.1, n.1, p.37-54, 2008.

HAMEED, I.A. (2014). Intelligent coverage path planning for agricultural robots and autonomous machines on three-dimensional terrain. Journal of Intelligent \& Robotic Systems, jun. 2014, v. 74, n. 3-4, p. 965-983.

HATFIELD, J.L.; GITELSON, A.A.; SCHEPERS, J.S.; WALTHALL, C.L. (2008). Application of spectral remote sensing for agronomic decisions. Agronomy Journal, 100:117131. 
HOLLAND Scientific (2011). Disponível em <http://hollandscientific.com/ACS-430.html>. Acesso em: 16 mai. 2011.

INAMASU, R.Y.; SIMÕES, M.S.; LUCHIARI JR, A.; RABELLO, L.M.; MOLIN, J.P. (2007). Sistema de medida de condutividade elétrica do solo adaptado à um implemento agrícola (subsolador). São Carlos: Embrapa Instrumentação Agropecuária, 2007. 5p. (Embrapa Instrumentação Agropecuária, Circular Técnica, n. 40.)

INAMASU, R.Y.; NAIME, J.M.; RESENDE, A.V.; BASSOI, L.H.; BERNARDI,A.C. (Ed.). (2011). Agricultura de precisão: um novo olhar. São Carlos, SP: Embrapa Instrumentação, 2011. 334p.

JENSEN, J.R. (2009). Sensoriamento remoto do ambiente: uma perspectiva em recursos terrestres. Tradução da segunda edição. São José dos Campos, SP: Parêntese. 598 p.

JIN, J.; TANG, L. (2006). Optimal path planning for arable farming. Paper number 061158, 2006 ASAE Annual Meeting.

JIN, J.; TANG, L. (2010). Optimal path planning for arable farming on 2D surfaces. Transactions of the ASABE, 53 (1), 283-295.

KEICHER, R.; SEUFERT, H. (2000). Automatic guidance for agricultural vehicles in Europe. Computers and Electronics in Agriculture, 25 (1-2), 169-194.

KERRY, R.; OLIVER, M.A. (2004). Average variorams to guide soil sampling. International Journal of Applied Earth Observation and Geoinformation 5. p. 307-325.

KERRY, R.; OLIVER, M.A. (2007). Comparing sampling needs for variograms of soil properties computed by the method of moments and residual maximum likelihood. Geoderma, 140(4), 383-396.

KERRY, R.; OLIVER, M.A.; FROGBROOK, Z.L. (2010). Sampling in Precision Agriculture. In: OLIVER, M. Geostatistics Applications for Precision Agriculture. Springer. cap. 2. p. 35-63.

GEOLIG - Laboratório de Informática Geológica, Instituto de - USP. Disponível em < http://geolig.igc.usp.br/geoestat >. Acesso em: 01 jun. 2013. 
LARK, R. M. (2000). Estimating variograms of soil properties by the method-of- moments and maximum likelihood. European Journal of Soil Science, v. 51, n. December, p. 717-728, 2000.

LARK, R. (2002). Optimized spatial sampling of soil for estimation of the variogram by maximum likelihood. Geoderma, v. 105, n. 1-2, p. 49-80, jan. 2002.

LARK, R. M. (2011). Spatially nested sampling schemes for spatial variance components: Scope for their optimization. Computers \& Geosciences, v. 37, n. 10, p. 1633-1641, out. 2011.

LENAIN, R.; THUILOT, B.; CARIOU, C. (2006). High accuracy path tracking for vehicles in presence of sliding: application to farm vehicle automatic guidance for agricultural tasks. Autonomous Robots, 21 (1), 79-97.

LINKER, R.; BLASS, T. (2008). Path-planning algorithm for vehicles operating in orchards. Biosystems Engineering, 101 (2), 152-160.

LUCHIARI Jr, A.; BORGHI, E.; AVANZI, J.C.; FREITAS, A.A.; BORTOLON, L; BORTOLON, E.S.O.; UMMUS, M.E.; INAMASU, R. (2010). Zonas de manejo: teoria e prática. In: Agricultura de precisão: um novo olhar. São Carlos, SP: Embrapa Instrumentação, 2011. p. 60-64.

MAPA. (2013a). Análise de conjuntura econômica do setor agrícola, do mercado de insumos e do crédito rural. Informativo de Economia Agrícola, 1(06), 1-7. Disponível em < http://www.agricultura.gov.br/politica-agricola/publicacoes/informativo-de-economiaagricola>. Acesso em 11 jan. 2014.

MAPA. (2013b). Agricultura de Precisão. Boletim Técnico, 1-36. Disponível em < http://www.agricultura.gov.br/arq_editor/Boletim\%20tecnico.pdf $>$. Acesso em 11 jan. 2014.

MARCHANT, B.P.; LARK, R.M. (2006). Adaptive sampling and reconnaissance surveys for geostatistical mapping of the soil. European Journal of Soil Science, 57(6), 831-845.

MARCHANT, B.P.; LARK, R.M. (2010). Sampling in Precision Agriculture, Optimal Designs from Uncertain Models. In: OLIVER, M. Geostatistics Applications for Precision Agriculture. Springer. cap. 3. p. 65-88.

MATHERON, G. (1963). Principles of geostatistics. Economic Geology, 58, 1246-1266. 
MCBRATNEY, A. B.; WEBSTER, R.; BURGESS, T. M. (1981). The design of optimal sampling schemes for local estimation and mapping of regionalized variables I. Computers \& Geosciences, v. 7, n. 4, p. 331-334, 1981.

MCBRATNEY, A. B.; WEBSTER, R. (1981). The design of optimal sampling schemes for local estimation and mapping of regionalized variables II. Computers \& Geosciences, v. 7, n. 4, p. 335-365, 1981.

MCBRATNEY, A.B.; PRINGLE, M.J. (1999). Estimating average and proportional variograms of soil properties and their potential use in Precision Agriculture. Precision Agriculture, v. 1, n. 2, p. 125-152, 1999.

MIESCH, A.T. (1975). Variograms and variance components in geochemistry and ore evaluation. Geological Society of America Memoir, 142, 333-340.

MMA - MINISTÉRIO DO MEIO AMBIENTE. Segurança química, Agrotóxicos. (2014). Disponível em: < http://www.mma.gov.br/seguranca-quimica/agrotoxicos>. Acesso em: 29 julho 2014.

MOLIN, J.P (2003). Agriculutra de Precisão: o gerenciamento da variabilidade. Piracicaba: o autor, 2001, reimpressão, 2003. 83 p.

MULLA, D. J. (2013). Twenty five years of remote sensing in precision agriculture: Key advances and remaining knowledge gaps. Biosystems Engineering, v. 114, n. 4, p. 358-371. 2013.

OKSANEN, T. (2007). Path Planning algorithms for agricultural field machines. Ph.D. dissertation, Dept. Automation and Systems Technology, Autom. Tech. Lab., Helsinki Univ. of Technology, Espoo, Finland, 2007.

OKSANEN, T.; VISALA, A. (2009). Coverage path planning algorithms for field machines. Journal of Field Robotics, 26 (8), 651-668, 2009.

OLIVER, M.A.; WEBSTER, R. (1986). Combining nested and linear sampling for determining the scale form of spatial variation of regionalized variables. Geographical Analysis, 18(3), $227-242$.

OLIVER, M.A. (2010a). Geostatistics Applications for Precision Agriculture. Springer. $331 \mathrm{p}$. 
OLIVER, M.A. (2010b). An Overview of Geostatistics and Precision Agriculture. In: OLIVER, M.A. Geostatistics Applications for Precision Agriculture. Springer. cap. 1. p. 1-32.

OLIVEIRA, R.P. (2009). Contributions towards decision support for sit-specific crop management. Thesis (Doctor of Philosophy) - Australian Centre for Precision Agriculture, Faculty of Agriculture, Food and Natural Resources, University of Sydney, Australia.

OLIVEIRA, R. P.; BERNARDI, A.C.C.; RABELLO, L. M. (2011). A oportunidade de manejo por sítio-específico indicada na variação espacial da condutividade elétrica aparente do solo. In: Agricultura de precisão: um novo olhar. São Carlos, SP: Embrapa Instrumentação, 2011. P. 55-59.

OLIVEIRA, R. P.; BENITES, V. M. (2011). Variabilidade do solo como indicador da oportunidade da agricultura de precisao em sistema de plantio direto. In: Agricultura de precisão: um novo olhar. São Carlos, SP: Embrapa Instrumentação. p. 194-200. 2011.

OLIVEIRA, R. P.; BERNARDI, A.C.C.; RABELLO, L. M.; INAMASU, R.Y. (2012) Spatial variability index based on soil proprieties for no-till and pasture site specific management in Brazil. In: INTERNATIONAL CONFERENCE FOR PRECISION FOR PRECISION AGRICULTURE, 2012, Indianápolis. Proceedings... Indianápolis, 2012.

OLIVEIRA, R. P.; WHELAN, B.M.; MCBRATNEY, A. (2013). A segmentation approach to delineate zones for differential nitrogen interventions. In: Precision agriculture' 13, p. 411418, 2013.

PARDO-IGÚZQUIZA, E.; DOWD, P.A. (1998). Maximum likelihood inference of spatial covariance parameters of soil properties. Soil Science, 163, 212-219.

PATTERSON, H.D.; THOMPSON, R. (1971). Recovery of inter-block information when block sizes are unequal. Biometrika, 58, 545-554.

PEDERSEN, S. M.; FOUNTAS, S.; HAVE, H.; BLACKMORE, B.S. (2005). Agricultural robots - an economic feasibility study. Precision Agriculture, p. 589-596, 2005.

PEDERSEN, S. M.; FOUNTAS, S.; HAVE, H.; BLACKMORE, B.S. (2006). Agricultural robots - system analysis and economic feasibility. Precision Agriculture, v. 7, n. 4, p. 295308, 27 jul. 2006. 
PEETS, S.; MOUAZEN, A.M.; BLACKBURN, K.; KUANG, B.; WIEBENSOHN, J. (2012). Methods and procedures for automatic collection and management of data acquired from onth-go sensors with application to on-th-go soil sensors. Computers and electronics in Agriculture, 81 (2012) 104-112.

PHILLIPS, A.J.; NEWLANDS, N.K.; LIANG, S.H.L.; ELLERT, B.H. (2014). Integrated sensing of soil moisture at the field-scale: measuring, modeling and sharing for improved agricultural decision support. Computers and Eletronics in Agriculture, 107 (2014) 73-88.

PRICE, O.R.; OLIVER, M.A.; WALKER, A.; WOOD, M. (2009). Estimating the spatial scale of herbicide and soil interactions by nested sampling, hierarchical analysis of variance and residual maximum likelihood. Environmental pollution, v. 157, n. 5, p. 1689-1696, maio 2009.

RABELLO, L.M.; INAMASU, R.Y.; TORRE NETO, A.; MOLIN, J.P; LUCHIARI JR, A.; SIMÕES, M.S. (2008a). Sistema de medida de condutividade elétrica do solo adaptado a um implemento agrícola (subsolador). In: Congresso Brasileiro de Agricultura de Precisão, ConBap, 2008, Piracicaba. Anais... Piracicaba: ESALQ/USP, 2008. P.22-35. 1 CD-ROM.

RABELLO, L.M.; INAMASU, R.Y.; TORRE NETO, A.; LUCHIARI, A.; MOLIN, J.P.; SIMÕES,M.S. (2008b). Soilcondutivity electrical measurement system suited to anagricultural implement (subsoiler). In.: International Conference on Precision Agriculture, 9., 2008, Denver. Proceedings... Denver, 2008.

RABELLO, L.M.; INAMASU, R.Y.; BERNARDI, A.C.C.; NAIME, J.M.; MOLIN,J.P. (2011). Mapeamento da condutividade elétrica do solo - Sistema protótipo. In: Agricultura de precisão: um novo olhar. São Carlos, SP: Embrapa Instrumentação, 2011. p. 41-45.

RIBEIRO, A., FERNANDEZ-QUINTANILLA, C., BARROSO, J., GARCIA-ALEGRE, M.C. (2005). Development of an image analysis system for estimation of weed cover and weed pressure. In: Stanford, V. (Ed.), Proceedings of the Fifth European Conference on Precision Agriculture. Wageningen Academic Publishers, Netherland, pp. 169-174.

RIBEIRO Jr, P.J. \& DIGGLE, P.J. (2012). Package GeoR. Disponível em: < http://www.leg.ufpr.br/geoR/ >. Acesso em: jan. 2014.

SCHUELLER, J.K. (2010). Geostatistics and Precision Agriculture: A way forward. In: OLIVER, M.A. Geostatistics Applications for Precision Agriculture. Springer. cap. 12. p. 305-312. 
SHIRATSUCHI, L.S.; BRANDÃO, Z.N.; VICENTE, L.E.; VICTORIA, D.C.; DUCATI, J.R.; OLIVEIRA, R.P.; VILELA, M.F. (2014). Sensoriamento remoto: conceitos básicos e aplicações na agricultura de precisão. In: Agricultura de precisão: um novo olhar. São Carlos, SP: Embrapa Instrumentação, 2011. p. 307-313.

SORENSEN, C.G.; FOUNTAS, S.; NASH, E.; PESONEN, L.; BOCHTIS, D.D.; PEDERSEN, S.M.; BLACKMORE, S.B. (2010). Conceptual model of a future farm management information system. Computers and Electronics in Agriculture, 72(1), 37-47, 2010.

SORENSEN, C.G.; PESONEN, L.; BOCHTIS, D.D.; VOUGIOUKAS, S.G.; SUOMI, P. (2011). Functional requirements for a future farm management information system. Computers and Electronics in Agriculture, 76(2), 266-276. , 2011.

SOUSA, R.V.; INAMASU, R.Y.; PORTO, A.J.V. (2006). Desenvolvimento e simulação de uma arquitetura robótica híbrida para robô agrícola móvel. In: Workshop em Tecnologias de Robótica em Agricultura, 2006, São Carlos - SP. Anais do Workshop em Tecnologias de Robótica em Agricultura, 2006.

SOUSA, R.V. (2007). Robô Agrícola Móvel (RAM): uma arquitetura baseada em comportamentos hierárquicos e difusos para sistemas autônomos de guiagem e navegação. Tese (Doutorado) - Escola de Engenharia de São Carlos, Universidade de São Paulo, São Carlos.

STONE, M. L.; BENNEWEIS, R. K.; VAN BERGEIJK, J. (2008). Evolution of electronics for mobile agricultural equipment. Transactions of the ASABE, v.51, n.2, p.385-390, 2008.

STENTZ, A. DIMA, C.; WELlingTON, C.; HERMAN, H.; STAGER, D. (2002). A system for semi-autonomous tractor operations. Autonomous Robots, 13, 87-104.

TABILE, R.A.; GODOY, E.P.; PEREIRA, R.R.D.; TANGERINO, G.T.; PORTO, A.J.V.; INAMASU, R.Y. (2010). Design of the Mechatronic Architecture of an Agricultural Mobile Robot. In: 3rd Annual Dynamic Systems and Control Conference and 5th IFAC Symposium on Mechatronic Systems, 2010, Boston. Proceedings of the IFAC MECH2010. Boston : IFAC, 2010.

TABILE, R.A.; GODOY, E.P.; PEREIRA, R.R.D.; TANGERINO, G.T.; PORTO, A.J.V.; INAMASU, R.Y. (2011a). Design and development of the architecture of an agricultural mobile robot. Engenharia Agrícola, Jaboticabal, v.31, n.1, p.130-142, jan./fev., 2011.

TABILE, R.A.; INAMASU, R.Y.; PORTO, A.J.V. (2011b). Robótica na agricultura de precisão. In: Agricultura de precisão: um novo olhar. São Carlos, SP: Embrapa Instrumentação, 2011. p. 120-125. 
TABILE, R.A; GODOY, E.P.; TANGERINO, G.T.; PORTO, A.J.V.; INAMASU, R.Y.; SOUSA, R.V. (2013). Application of systematic methods in the electromechanical design of an agricultural mobile robot. In: Agricontrol, 2013, Aalto University - Espoo. Anais..., 2013. v. 1. p. 276-281.

TANGERINO, G.T.; GODOY， E.P.; TABILE， R.A.; SANCHES， R.M.; INAMASU, R.Y.; PORTO, A.J.V. (2011a). Controle de esterçamento de robô agrícola móvel de quatro rodas guiáveis. In: X Simpósio Brasileiro de Automação Inteligente, 2011, São João Del-Rei MG. Proceedings of Simpósio Brasileiro de Automação Inteligente, 2011.

TANGERINO, G. T.; GODOY, E. P.; TABILE, R.A.; INAMASU, R. Y. ; PORTO, A. J.V. (2011b). Hydraulic networked control of four Wheel steering agricultural robot. In: IX EEE International Conference on Control \& Automation, 2011, Santiago - Chile. Proceedings of IX EEE International Conference on Control \& Automation, 2011.

TERRALIB (2014). A GIS classes and functions library, Physical Data Models. Disponível em: <http://www.terralib.org/php/docs.php?body=TechnicalDocs>. Acesso em: jul. 2014.

THUILOT, B.; CARIOU, C.; MARTINET, P.; BERDUCAT, M. (2002). Automatic guidance of a farm tractor relying on a single CP-DGPS. Auton.Robot. 13, 53-71.

VAN-GROENIGEN, J.W. (2000). The influence of variogram parameters on optimal sampling schemes for mapping by kriging. Geoderma 97 (2000) 223-236.

VOUGIOUKAS, S.; BLACKMORES, S.; NIELSEN, J.; FOUNTAS, S. (2006). A two-stage optimal motion planner for autonomous agricultural vehicles. Precision Agriculture, 7, 361377.

VOUGIOUKAS, S.G. (2009). A framework for motion coordination of small teams of agricultural robots. In: van Henten, E.J., Goense, D., Lokhorst, C. (Eds.) Precision agriculture 09. Wageningen Academic Publishers, The Netherlands, pp. 585-593.

WEBSTER, R.; OLIVER, M. A. (1992). Sample adequately to estimate variograms of soil properties. Journal of Soil Science, v. 43, p. 177-192, 1992.

WEBSTER, R.; WELHAM, S.J.; POTTS, J.M.; OLIVER, M.A. (2006). Estimating the spatial scales of regionalized variables by nested sampling, hierarchical analysis of variance and 
residual maximum likelihood. Computers \& Geosciences, v. 32, n. 9, p. 1320-1333, nov. 2006.

WEBSTER, R.; OLIVER, M. (2007). Geostatistics for Environmental Scientists. 2 ed. John Wiley \& Sons, Ltd. 102 p.

WHELAN, B.; MCTRATNEY, A. (2000). The "null hypothesis" of precision agriculture management. Precision Agriculture, 2000.

WILSON, J.N. (2000). Guidance of agricultural vehicles - a historical perspective. Computers and Electronics in Agriculture, 25 (1-2), 3-9.

YOUDEN, W.J.; MEHLICH, A. (1937). Selection of efficient methods for soil sampling. Contributions of the Boyce Thompson Institute for Plant Research, 9, 59-70.

ZHU, Z.; CHEN, J.; YOSHIDA, T.; TORISU, R.; SONG, Z.; MAO, E. (2007). Path tracking control of autonomous agricultural mobile robots. Journal of Zhejiang University Science A, 8 (10), 1596-1603. 